\title{
A review of measurement-based assessments of the aerosol direct radiative effect and forcing
}

\author{
H. Yu ${ }^{1,2}$, Y. J. Kaufman ${ }^{2}$, M. Chin ${ }^{2}$, G. Feingold ${ }^{3}$, L. A. Remer ${ }^{2}$, T. L. Anderson ${ }^{4}$, Y. Balkanski ${ }^{5}$, N. Bellouin ${ }^{6}$, \\ O. Boucher ${ }^{7,6}$, S. Christopher ${ }^{8}$, P. DeCola ${ }^{9}$, R. Kahn ${ }^{10}$, D. Koch ${ }^{11}$, N. Loeb ${ }^{12}$, M. S. Reddy ${ }^{7,13}$, M. Schulz ${ }^{5}$, \\ T. Takemura ${ }^{14}$, and M. Zhou ${ }^{15}$ \\ ${ }^{1}$ Goddard Earth Science and Technology Center, University of Maryland at Baltimore County, Baltimore, Maryland, USA \\ ${ }^{2}$ Laboratory for Atmospheres, NASA Goddard Space Flight Center (GSFC), Greenbelt, Maryland, USA \\ ${ }^{3}$ NOAA Environmental Technology Laboratory (ETL), Boulder, Colorado, USA \\ ${ }^{4}$ University of Washington, Seattle, Washington, USA \\ ${ }^{5}$ Laboratoire des Sciences du Climat et de l'Environnement, CEA/CNRS - LSCE, L'Orme des Merisiers, France \\ ${ }^{6}$ Met Office, Exeter, UK \\ ${ }^{7}$ Laboratoire d' Optique Atmosphérique (LOA), Villeneuve d'Ascq, France \\ ${ }^{8}$ University of Alabama, Huntsville, Alabama, USA \\ ${ }^{9}$ NASA Headquarters, Washington, D.C., USA \\ ${ }^{10}$ NASA Jet Propulsion Laboratory (JPL), Pasadena, California, USA \\ ${ }^{11}$ NASA Goddard Institute for Space Studies (GISS), New York, New York, USA \\ ${ }^{12}$ NASA Langley Atmospheric Research Center (LaRC), Hampton, Virginia, USA \\ ${ }^{13}$ NOAA Geophysical Fluid Dynamics Laboratory (GFDL), Princeton, New Jersey, USA \\ ${ }^{14}$ Kyushu University, Fukuoka, Japan \\ ${ }^{15}$ Georgia Institute of Technology, Atlanta, Georgia, USA
}

Received: 27 May 2005 - Published in Atmos. Chem. Phys. Discuss.: 30 August 2005

Revised: 17 November 2005 - Accepted: 17 January 2006 - Published: 27 February 2006

\begin{abstract}
Aerosols affect the Earth's energy budget directly by scattering and absorbing radiation and indirectly by acting as cloud condensation nuclei and, thereby, affecting cloud properties. However, large uncertainties exist in current estimates of aerosol forcing because of incomplete knowledge concerning the distribution and the physical and chemical properties of aerosols as well as aerosol-cloud interactions. In recent years, a great deal of effort has gone into improving measurements and datasets. It is thus feasible to shift the estimates of aerosol forcing from largely model-based to increasingly measurement-based. Our goal is to assess current observational capabilities and identify uncertainties in the aerosol direct forcing through comparisons of different methods with independent sources of uncertainties. Here we assess the aerosol optical depth $(\tau)$, direct radiative effect (DRE) by natural and anthropogenic aerosols, and direct climate forcing (DCF) by anthropogenic aerosols, focusing on satellite and ground-based measurements supplemented by global chemical transport model
\end{abstract}

Correspondence to: $\mathrm{H}$. $\mathrm{Yu}$

(hyu@climate.gsfc.nasa.gov)
(CTM) simulations. The multi-spectral MODIS measures global distributions of aerosol optical depth $(\tau)$ on a daily scale, with a high accuracy of $\pm 0.03 \pm 0.05 \tau$ over ocean. The annual average $\tau$ is about 0.14 over global ocean, of which about $21 \% \pm 7 \%$ is contributed by human activities, as estimated by MODIS fine-mode fraction. The multiangle MISR derives an annual average AOD of 0.23 over global land with an uncertainty of $\sim 20 \%$ or \pm 0.05 . These high-accuracy aerosol products and broadband flux measurements from CERES make it feasible to obtain observational constraints for the aerosol direct effect, especially over global the ocean. A number of measurement-based approaches estimate the clear-sky DRE (on solar radiation) at the top-of-atmosphere (TOA) to be about $-5.5 \pm 0.2 \mathrm{Wm}^{-2}$ (median \pm standard error from various methods) over the global ocean. Accounting for thin cirrus contamination of the satellite derived aerosol field will reduce the TOA DRE to $-5.0 \mathrm{Wm}^{-2}$. Because of a lack of measurements of aerosol absorption and difficulty in characterizing land surface reflection, estimates of DRE over land and at the ocean surface are currently realized through a combination of satellite

Published by Copernicus GmbH on behalf of the European Geosciences Union. 
retrievals, surface measurements, and model simulations, and are less constrained. Over the oceans the surface DRE is estimated to be $-8.8 \pm 0.7 \mathrm{Wm}^{-2}$. Over land, an integration of satellite retrievals and model simulations derives a DRE of $-4.9 \pm 0.7 \mathrm{Wm}^{-2}$ and $-11.8 \pm 1.9 \mathrm{Wm}^{-2}$ at the TOA and surface, respectively. CTM simulations derive a wide range of DRE estimates that on average are smaller than the measurement-based DRE by about 30-40\%, even after accounting for thin cirrus and cloud contamination.

A number of issues remain. Current estimates of the aerosol direct effect over land are poorly constrained. Uncertainties of DRE estimates are also larger on regional scales than on a global scale and large discrepancies exist between different approaches. The characterization of aerosol absorption and vertical distribution remains challenging. The aerosol direct effect in the thermal infrared range and in cloudy conditions remains relatively unexplored and quite uncertain, because of a lack of global systematic aerosol vertical profile measurements. A coordinated research strategy needs to be developed for integration and assimilation of satellite measurements into models to constrain model simulations. Enhanced measurement capabilities in the next few years and high-level scientific cooperation will further advance our knowledge.

\section{Table of Contents}

1 Introduction

2 Assessments of current capabilities in characterizing tropospheric aerosols and estimating the aerosol direct effect

2.1 Optical properties determining the aerosol direct effect

2.2 Measurement of tropospheric aerosols

2.2.1 Ground-based networks

2.2.2 Satellite remote sensing

2.2.3 Intensive field experiments

2.3 Characterization of surface albedo and clouds

2.3.1 Surface reflection and albedo

2.3.2 Clouds

2.4 Modeling of atmospheric radiative transfer

3 Assessments of global and regional aerosols and their direct radiative effect and climate forcing

3.1 Description of assessments

3.1.1 Scope of assessments

3.1.2 Datasets of aerosol optical depth

3.1.3 Datasets of aerosol direct radiative effect

3.1.4 Uncertainties in estimating the aerosol direct effect

3.2 Assessments of the global aerosol

direct radiative effect

3.2.1 Global patterns of aerosol optical depth and direct radiative effect

3.2.2 Intercomparisons of global average aerosol optical depth
3.2.3 Intercomparisons of global average aerosol direct radiative effect

Over ocean

Over land

3.3 Assessments of the regional aerosol direct radiative effect

3.3.1 Intercomparisons over ocean

3.3.2 Comparisons with AERONET derived direct radiative effect over land

3.3.3 Comparisons of the radiative efficiency with results from the literature

3.4 Estimate of anthropogenic aerosol direct

climate forcing

4 Discussion: outstanding issues

4.1 Direct effect in the thermal infrared range and in cloudy conditions

4.2 Deriving aerosol direct effect over land from satellite

4.3 Aerosol single-scattering albedo and absorption

4.4 Diurnal cycle

4.5 Spatial and temporal scaling

4.6 Long-term trends of aerosols and their radiative effects

5 Concluding remarks

5.1 Summary of findings from this review

5.2 Future research

Acronyms and symbols

Acknowledgement

References

\section{Introduction}

Aerosols participate in the Earth's energy budget directly by scattering and absorbing radiation (McCormick and Ludwig, 1967; Charlson and Pilat, 1969; Atwater, 1970; Mitchell Jr., 1971; Coakley et al., 1983) and indirectly by acting as cloud condensation nuclei and, thereby, affecting cloud properties (Twomey, 1977; Albrecht, 1989; Rosenfeld and Lensky, 1998). Moreover, the direct absorption of radiant energy by aerosols can influence the atmospheric temperature structure and, thereby, cloud formation - a phenomenon that has been labeled the semi-direct effect (Hansen et al., 1997; Ackerman et al., 2000; Koren et al., 2004). The addition of anthropogenic aerosols to the atmosphere may change the radiative fluxes at the top-of-atmosphere (TOA), at the surface, and within the atmospheric column. A positive radiative effect at the TOA indicates addition of energy to the earth-atmosphere system (i.e., a warming effect) whereas a negative effect indicates a net loss of energy (i.e., a cooling effect). Herein, we designate a perturbation of net (downward minus upward) irradiance (summed over solar and thermal infrared spectrum) by anthropogenic aerosols (both directly and indirectly) as aerosol climate forcing $(A C F)$ and distinguish this from the aerosol radiative effect (ARE) of the total aerosol (natural plus anthropogenic). This review will focus on aerosol direct 
radiative effect (DRE) by the total aerosol and aerosol direct climate forcing $(D C F)$ by the anthropogenic aerosol.

Recent reports summarize that on a global average the sum of direct and indirect forcing by anthropogenic aerosols $(\mathrm{ACF})$ at the TOA is likely to be negative and may be comparable in magnitude to the positive forcing of about $2.4 \mathrm{Wm}^{-2}$ by anthropogenic greenhouse gases (IPCC, 2001). Aerosol forcing assessments to date have been based largely on model calculations, although these models have been initialized and evaluated to some degree with satellite and surface measurements. Large uncertainties exist in current estimates of aerosol forcing because of incomplete knowledge concerning the distribution and the physical and chemical properties of aerosols as well as aerosol-cloud interactions. The uncertainty for the aerosol direct climate forcing (DCF) is about a factor of 2 to 3 whereas that for the indirect forcing is much larger and difficult to quantify (IPCC, 2001; Haywood and Boucher, 2000). These uncertainties raise questions about the interpretation of the 20th century temperature record (Anderson et al., 2003a) and complicate the assessment of aerosol impacts on surface-atmosphere interactions, the atmospheric boundary layer (Yu et al., 2002), global surface air temperatures (Charlson et al., 1992; Penner et al., 1992; Kiehl and Briegleb, 1993; Hansen et al., 1997), the hydrological cycle (Ramanathan et al., 2001a), photochemistry (Dickerson et al., 1997), and ecosystems (Chameides et al., 1999). Accordingly, the US Climate Change Research Initiative (CCRI) has specifically identified research on atmospheric concentrations and effects of aerosols as a top priority (NRC, 2001).

Reduction in these uncertainties requires a coordinated research strategy that will successfully integrate data from multiple platforms (e.g., ground-based networks, satellite, ship, and aircraft) and techniques (e.g., in-situ measurement, remote sensing, numerical modeling, and data assimilation) (Penner et al., 1994; Heintzenberg et al., 1996; Kaufman et al., 2002a; Diner et al., 2004; Anderson et al., 2005a). In recent years, a great deal of effort has gone into improving measurements and data sets, including the establishment of ground-based networks, the development and implementation of new and enhanced satellite sensors, and the execution of intensive field experiments in various aerosol regimes around the globe (e.g., Kahn et al., 2004a). As a result of these efforts it is now feasible to shift the estimates of DRE and DCF from largely model-based to increasingly measurement-based. In this new approach, satellite measurements provide the basis for the regional- to global-scale assessments and chemical transport models are used to interpolate and supplement the data in regions/conditions where observational data are not available. Measurements from ground-based networks and intensive field experiments are required for evaluating both the satellite retrievals and the model simulations. Model simulation is an indispensable tool for estimating past aerosol forcing and projecting future climate due to changes in atmospheric aerosols, while observations can be used to improve and constrain model simulations of aerosol impacts through synthesis and integration (e.g., Collins et al., 2001; Yu et al., 2003, 2004). AEROCOM, an international initiative of scientists interested in aerosols and climate (http://nansen.ipsl.jussieu.fr/ AEROCOM/), is documenting and intercomparing more than a dozen models and a large number of observations to identify and reduce the uncertainty in current global aerosol assessments (Kinne et al., 2005; Textor et al., 2005; Schulz et al., $2005^{1}$ ).

The US Climate Change Science Program (CCSP) was established in 2002 to coordinate and integrate scientific research on global change and climate change. The CCSP, sponsored by 13 U.S. federal agencies, is currently developing and extending its research activities to support policymaking and adaptive management (http://www.climatescience.gov/Library/stratplan2003/ final/ccspstratplan2003-all.pdf). The present review is one of three aerosol-related reports being prepared for CCSP. The purposes of this review are (1) to assess measurementbased understanding of tropospheric aerosols and their direct effects; (2) to estimate uncertainty associated with them through examining the differences among various estimates; and (3) to explore the use of recent measurements to improve the performance of model simulations. Specifically, we will:

- Assess the global aerosol distribution and direct radiative effect using satellites supplemented by chemical transport models.

- Assess the anthropogenic component, using satellite data and models.

- Evaluate these assessments against surface network data and field experiments and compare them to model estimates.

Section 2 is an overview of factors determining DRE and DCF and of current capabilities in characterizing these factors. Global and regional comparisons among different measurements/simulations are presented in Sect. 3 for aerosol optical depth, DRE and DCF (solar and clear-sky). We discuss outstanding issues in Sect. 4. Our findings are summarized in Sect. 5.

\section{Assessments of current capabilities in characterizing tropospheric aerosols and estimating the aerosol di- rect effect}

The aerosol direct radiative effect and its potential influences on climate were proposed and debated during the late

\footnotetext{
${ }^{1}$ Schulz, M., Textor, C., Kinne, S., et al.: Radiative forcing by aerosols as derived from the AeroCom present-day and preindustrial simulations, Atmos. Chem. Phys. Discuss., submitted, 2005.
} 
1960s and early 1970s (e.g., McCormick and Ludwig, 1967; Charlson and Pilat, 1969; Atwater, 1970; Mitchell Jr., 1971). The interactions between aerosols and solar radiation are determined by a combination of aerosol properties (loading, chemical composition, size distribution, shape), surface properties (e.g., spectral and angular variations of surface albedo), clouds (cloud fraction, optical thickness, and vertical distribution), and geographical parameters (latitude, season). Assumptions associated with radiative transfer (RT) modeling also influence the assessment of the aerosol direct effect. Due to a lack of data and computational resources, evidence of the aerosol effect on global radiation (warming or cooling) was uncertain. Nevertheless, these pioneering studies highlighted the importance of acquiring better information concerning aerosols, and thereby inspired substantial research efforts in the intervening decades. Below is an overview of how a variety of factors determine the aerosol direct effect and how recent observations have advanced our knowledge.

\subsection{Optical properties determining the aerosol direct effect}

The complex interaction of aerosols with radiation is usually understood using three optical parameters: aerosol optical depth (AOD, $\tau$ ), the single-scattering albedo (SSA, $\left.\omega_{0}\right)$, and the phase function. Aerosol optical depth measures the magnitude of aerosol extinction (due to scattering and absorption) integrated in the vertical column. It is an e-folding length of the decrease of a direct beam when traveling through the aerosol layer. Single-scattering albedo (SSA or $\left.\omega_{0}\right)$ is the ratio of the scattering coefficient to the extinction coefficient, measuring the relative importance of scattering and absorption. The aerosol effect on the TOA radiative budget switches from net cooling to net warming at a certain value of SSA, depending on surface albedo (e.g., Charlson and Pilat, 1969; Atwater, 1970; Mitchell Jr., 1971; Hansen et al., 1997). The angular distribution of scattering radiation is described by the phase function, i.e., a ratio of the scattered intensity at a specific direction to the integral of the scattered intensity at all directions. In principle, given the size distribution of an assumed spherical aerosol, the phase function can be calculated from the Mie theory (van de Hulst, 1981; Bohren and Huffman, 1983). In practice, approximations such as the Henyey-Greenstein (HG) phase function (Henyey and Greenstein, 1941) have been used in most radiative transfer models (e.g., Fu and Liou, 1993). The HG phase function is defined in terms of a single parameter - the asymmetry factor $(g)$ - with $g=1$ for completely forward scattering and $g=0$ for symmetric (e.g. Rayleigh) scattering. Typical values of $g$ range from 0.5 to 0.8 .

These aerosol optical properties vary with the wavelength of radiation. The wavelength-dependence of optical depth is usually represented by the Ångström exponent (Ångström, 1929, 1930), with high values of Ångström exponent indicative of small particles and low values representative of large particles. Generally, at visible wavelengths, the singlescattering albedo decreases with wavelength for non-dust aerosols and increases for dust aerosols (Dubovik et al., 2002). The asymmetry factor $g$ decreases with wavelength because of the decrease in the scattering-effective particle size (e.g., Hansen and Travis, 1974).

Aerosol optical properties also depend strongly on the size distribution. Therefore any factors affecting the size distribution will impact the optical properties. One critical factor is the relative humidity (RH). Some aerosol types are hygroscopic, meaning that they grow as they take up water vapor. As a result, their size increases and their refractive indices change, in turn leading to changes in their optical properties. This effect is non-linear and varies with aerosol composition. For example, as RH increases from $40 \%$ to $80 \%$, the scattering cross section of sulfate-dominated aerosol doubles, whereas it increases by only $10-40 \%$ for smoke over the same RH range (Hobbs et al., 1997; Kaufman et al., 1998). Observations also indicate that the hygroscopicity of smoke aerosols varies with the aging of smoke (Kotchenruther and Hobbs, 1998; Magi and Hobbs, 1998). The response of the absorption coefficient to increasing RH is uncertain, although theoretical studies indicate it should be much smaller than that for the scattering coefficient (Redemann et al., 2001). Consequently, for hygroscopic aerosol, SSA increases with RH. In addition, $g$ increases with increasing RH and particle size.

In contrast to greenhouse gases, aerosol loading and optical properties exhibit large spatial and temporal variability. Due to variability in sources and sinks, different aerosol components are associated with different geographical areas, and the residence time in the troposphere is relatively short (about 1 week). The vertical distribution of aerosol varies substantially, which is determined by the injection height and a variety of atmospheric processes. Such variations complicate the estimate of aerosol direct effect in cloudy skies and in the thermal infrared region. The method by which different species mix in aerosols can have a significant effect on aerosol optical properties. In reality, different chemical species can be in the same particles (internal mixing) or different particles (external mixing). While the mixing state has little effect on scattering (e.g., Chylek et al., 1995; Pilinis et al., 1995; McMurry et al., 1996; Malm and Kreidenweis, 1997), it can have a great effect on the absorption efficiency, defined as absorption cross section per unit aerosol mass (unit: $\mathrm{m}^{2} / \mathrm{g}$ ). Light absorption of a mixture of black carbon and transparent particles is significantly higher for an internal mixture than for an external mixture, resulting in a smaller SSA (Horvath, 1993; Chylek et al., 1995; Jacobson, 2000; 2001) and higher absorption efficiency (Martins et al., 1998). 


\subsection{Measurement of tropospheric aerosols}

Errors in the estimation of aerosol optical properties can have a tremendous impact on the estimate of aerosol direct radiative effect. In recent years, the characterization of aerosols has been significantly improved through intensive field experiments, ground-based network measurements, and satellite remote sensing and its integration with model simulations, as summarized in the following.

\subsubsection{Ground-based networks}

The AEROsol Robotic Network (AERONET) program is a federated remote sensing network of well-calibrated sun photometers and radiometers. AERONET includes about 200 sites around the world, covering all major tropospheric aerosol regimes (Holben et al., 1998; 2001). Spectral measurements of sun and sky radiance are calibrated and screened for cloud-free conditions (Smirnov et al., 2000). AERONET stations provide direct, calibrated measurements of spectral AOD (normally at wavelengths of 440, 670, 870, and $1020 \mathrm{~nm}$ ) and provide inversion-based retrievals of a variety of effective, column-mean properties such as singlescattering albedo, and size distributions, phase function and asymmetry factor (Holben et al., 1998, 2001; Dubovik et al., 2000; Dubovik and King, 2001; Dubovik et al., 2002). Because of uniform calibration, cloud-screening, and retrieval methods, uniform data are available for all stations, some of which have operated for over 10 years. These data constitute a high-quality, ground-based aerosol climatology and, as such, have been widely used for aerosol process studies, as well as for evaluation and validation of model simulation and satellite remote sensing applications (e.g., Chin et al., 2002; Yu et al., 2003; Remer et al., 2005; Kahn et al., 2005a). It should be noted, however, that the inversion-based retrieval products have yet to be systematically validated by comparison to in-situ measurements.

AERONET measurements have been supplemented by other ground-based aerosol networks with less geographical or temporal coverage. The Interagency Monitoring of Protected Visual Environments (IMPROVE) network tracks spatial and temporal trends of visibility, and composition and extinction of near-surface aerosols in rural areas and National Parks of the US (Malm et al., 1994, 2004). Several multifilter rotating shadowband radiometer (MFRSR) networks measure the direct solar beam extinction and horizontal diffuse flux at multiple wavelengths (Harrison et al., 1994). These networks use an automated and objective cloud screening algorithm (Alexandrov et al., 2004a) and retrieve aerosol optical depth and particle size over a large geographical area of the United States (Alexandrov et al., 2002a, b). The NOAA Climate Modeling and Diagnostic Laboratory (CMDL) network, consisting of baseline observatories and regional stations, directly measures light absorption, total scattering and backscattering (e.g., Sheridan and Ogren, 1999), particle number concentration and chemical composition (Quinn et al., 2000).

In recent years, Raman Lidar and micro-pulse lidar (MPL) have been increasingly used to automatically and routinely retrieve profiles of aerosol backscattering and extinction during both day and night (e.g., Turner et al., 2001, 2002; Ferrare et al., 2001). The NASA Micro Pulse Lidar Network (MPLNET) acquires long-term observations of aerosol and cloud vertical structures continuously and in an autonomous fashion, in conjunction with AERONET sunphotometer measurements (Welton et al., 2001; 2002). The European Aerosol Research Lidar Network (EARLINET) was established in 2000 to characterize the horizontal, vertical, and temporal distribution of aerosols on a continental scale (Matthias et al., 2004). The Asian Dust Network (AD-Net) has been monitoring the transport of Asian dust through distributed lidar systems in East Asia (e.g., Murayama et al., 2001). The aerosol extinction profiles so derived are pivotal to a better assessment of aerosol direct solar forcing in cloudy sky conditions, aerosol thermal infrared forcing and aerosol-cloud interactions (Feingold et al., 2003).

These ground-based networks have been widely used to validate and help interpret results from satellite sensors and model simulations. In this study, however, we will only use AERONET measurements and retrievals with a global coverage.

\subsubsection{Satellite remote sensing}

A measurement-based characterization of aerosols on a global scale can only be realized through satellite remote sensing, due to aerosols' short lifetime, complex chemical composition and interaction in the atmosphere that result in large spatial and temporal heterogeneities. Monitoring aerosols from space has been performed for over two decades (King et al., 1999). Early aerosol monitoring from space used data from sensors that were designed for other purposes, e.g., Advanced Very High Resolution Radiometer (AVHRR) and Total Ozone Mapping Spectrometer (TOMS), among others. However, they have provided multi-decadal climatology of aerosol optical depth that has significantly advanced the understanding of aerosol distributions (e.g., Husar et al., 1997; Mishchenko et al., 1999, 2003; Geogdzhayev et al., 2002; Herman et al., 1997; Torres et al., 1998, 2002). The AVHRR, intended as a weather satellite, provides radiance observations in the visible and near infrared wavelengths that are sensitive to aerosol properties over the ocean. Originally intended for ozone monitoring, the UV channels used for TOMS are sensitive to aerosol absorption and not too sensitive to surface interferences, even over land (Torres et al., 1998). TOMS has proved to be extremely successful in monitoring biomass burning smoke and dust (Herman et al., 1997) and retrieving aerosol single-scattering albedo from space (Torres et al., 2005). A new sensor, OMI aboard Aura, has improved on such advantages. In recent years, 
satellite aerosol retrievals have become increasingly sophisticated. Now, satellites measure the angular dependence of polarization and radiance in multiple wavelengths in the UV through the IR at fine temporal and spatial resolution. From these observations, retrieved aerosol products now include not only optical depth at one wavelength, but spectral optical depth and particle size over both ocean and land, as well as more direct measurements of polarization and phase function. In addition, cloud screening is much more robust than before. Examples of such new and enhanced sensors include Polarization and Directionality of the Earth's Reflectance (POLDER), MODerate resolution Imaging Spectroradiometer (MODIS), andMulti-angle Imaging SpectroRadiometer (MISR), among others. Aerosol profiling from space is also making promising progress. In the following, a brief description of these new sensors is given. Readers are encouraged to refer to King et al. (1999) for details.

Polarization and Directionality of the Earth's Reflectance: POLDER is a unique aerosol sensor that consists of a wide field-of-view imaging spectro-radiometer capable of measuring multi-spectral, multi-directional, and polarized radiances. The observed multi-angle polarized radiances can be exploited to better separate the atmospheric contribution from the surface contribution over both land and ocean (Deuzé et al., 2001). The POLDER onboard the Japanese Advanced Earth Observation Satellite (ADEOS-1 and -2) has collected aerosol data over both land and ocean (e.g., Boucher and Tanré, 2000). A similar POLDER instrument flies on the PARASOL satellite launched in December 2004. A limitation of POLDER is its rather coarse spatial resolution of about $6 \mathrm{~km}$, which affects the ability to account for scene heterogeneities. In addition, larger aerosol particles, such as desert dust, do not polarize sunlight and therefore cannot be retrieved quantitatively.

MODerate resolution Imaging Spectroradiometer: MODIS, aboard NASA's twin satellites Terra and Aqua (crossing the equator in opposite directions at about 10:30 and 13:30 local time, respectively), performs near global daily observations of atmospheric aerosols. MODIS has 36 channels ranging from 0.44 to $15 \mu \mathrm{m}$. Seven of these channels between 0.47 and $2.13 \mu \mathrm{m}$ are used to retrieve aerosol properties over cloud and surface-screened areas (identified by using other channels and examining spatial variability (Martins et al., 2002; Li et al., 2004). The MODIS retrieval uses separate algorithms over land and ocean (Kaufman et al., 1997; Tanré et al., 1997; Remer et al., 2005). Over vegetated land, MODIS retrieves aerosol optical depth at three visible channels with high accuracy, i.e., $\pm 0.05 \pm 0.2 \tau$ (Chu et al., 2002; Remer et al., 2005). It also derives a fraction of small particles in terms of aerosol extinction (the so-called fine-mode fraction). This parameter over land should be treated as a qualitative measure only. Because of its wide spectral range over ocean and the greater simplicity of the ocean surface, MODIS has the unique capability of retrieving not only aerosol optical depth with greater accuracy, i.e., $\pm 0.03 \pm 0.05 \tau$ (Remer et al., 2002, 2005), but also quantitative aerosol size parameters (e.g., effective radius, fine-mode fraction of aerosol optical thickness) (Kaufman et al., 2002a; Remer et al., 2005). In comparison to AERONET retrievals for moderate AOD, the standard deviation of MODIS effective radius is $\pm 0.11 \mu \mathrm{m}$. On a monthly basis, the MODIS fine-mode fraction agrees with AERONET retrievals over ocean to within $20 \%$. At low AOD the uncertainties associated with MODIS size parameters are greater (Remer et al., 2005; Kleidman et al., 2005). Recent comparisons show that MODIS ocean retrievals of fine-mode fraction are systematically higher than suborbital estimates of the submicrometer fraction by about 0.2 during the ACE_Asia compaign (Anderson et al., 2005b).

Multi-angle Imaging SpectroRadiometer: MISR, aboard the sun-synchronous polar orbiting satellite Terra, measures upwelling solar radiance in four spectral bands (centered at 446, 558, 672, and $866 \mathrm{~nm}$ ) and at nine view angles spread out in the forward and aft directions along the flight path (at nadir, $\pm 70.5^{\circ}, \pm 60.0^{\circ}, \pm 45.6^{\circ}$, and $\pm 26.1^{\circ}$ of nadir) (Diner et al., 2002). It acquires global coverage about once per week. A wide range of along-track view angles makes it feasible to more accurately evaluate the surface contribution to the TOA radiances and hence retrieve aerosols over both ocean and land surfaces, including bright desert aerosol source regions and regions that would have been contaminated by sunglint for a mono-directional instrument (Diner et al., 1998; Martonchik et al., 1998a; 2002; Kahn et al., 2005a). Evaluation studies show that for the early post-launch algorithm (Version 12) overall, about two thirds of MISR AODs are within $20 \%$ or \pm 0.05 of coincident AERONET measurements. Over dark ocean, the MISR early post-launch AODs overall have a high bias of 0.038 (Kahn et al., 2005a; Abdou et al., 2005). New low-light level calibration, applied to aerosol product Versions 16 and higher, removes about $40 \%$ of the high bias in MISR AOD retrievals over the dark water (Kahn et al., 2005b; Bruegge et al., 2004). (Re-runs of the multi-year MISR data records with the Version 16 algorithm were not available in time for this assessment, but should be complete by early 2006.)

The MISR multi-angle data also sample scattering angles ranging from about $60^{\circ}$ to $160^{\circ}$ in midlatitudes, yielding information about particle size (Kahn et al., 1998, 2001, 2005a) and shape (Kalashnikova et al., 2005a, $b^{2}$ ). These quantities are of interest in-and-of themselves for identifying aerosol airmass types, and should also help further refine the accuracy of space-based AOD retrievals and particle property determinations.

CERES: The Clouds and the Earth's Energy System (CERES) measures broadband solar and terrestrial radiances

\footnotetext{
${ }^{2}$ Kalashnikova, O. V., Kahn, R. A., and Li, W-H.: The ability of multi-angle remote sensing observations to identify and distinguish mineral dust types: Part 2. Sensitivity data analysis, J. Geophys. Res., submitted, 2005b.
} 
at three channels with a large footprint (e.g., $20 \mathrm{~km}$ for CERES/Terra) (Wielicki et al., 1996). It is collocated with MODIS and MISR aboard Terra and with MODIS on Aqua. The observed radiances are converted to the TOA irradiances or fluxes using the Angular Distribution Models (ADMs) as a function of viewing angle, sun angle, and scene type (Loeb and Kato, 2002; Zhang et al., 2005a). Such estimates of TOA solar flux in clear-sky conditions can be compared to the expected flux for an aerosol-free atmosphere, in conjunction with measurements of aerosol optical depth from other sensors (e.g., MODIS and MISR) to derive the aerosol direct effect (Christopher and Zhang, 2002a, 2004; Loeb and Kato, 2002; Loeb and Manalo-Smith, 2005; Zhang and Christopher, 2003; Zhang et al., 2005b). The derived instantaneous value is then scaled to obtain a daily average. Broadband flux measurements from the Earth Radiation Budget Experiment (ERBE) have also been used in a similar way (e.g., Hsu et al., 2000). Note that a direct use of the coarse spatial resolution CERES measurements would exclude aerosol distributions in partly cloudy CERES scenes. Several approaches that incorporate coincident, high spatial and spectral resolution measurements (e.g., MODIS) have been employed to overcome this limitation (Loeb and Manalo-Smith, 2005; Zhang et al., 2005b).

Aerosol profiling: Profiling global aerosols using satellite-borne lidar is another emerging capability. Following a demonstration aboard the U.S. Space Shuttle mission in 1994 (Winker et al., 1996), the Geoscience Laser Altimeter System (GLAS) was launched in early 2003 to become the first polar orbiting satellite lidar (Schutz, 1998; Zwally et al., 2002). It provides global aerosol extinction (at $532 \mathrm{~nm}$ ) profiling for a one-month period out of every three-to-six months. Initial results demonstrate the capability of GLAS in detecting and discriminating multiple layer clouds, atmospheric boundary layer aerosols, and elevated aerosol layers (e.g., Spinhirne et al., 2005; Hart et al., 2005; Hlavka, et al., 2005). The Cloud-Aerosol Lidar and Infrared Pathfinder Satellite Observations (CALIPSO), scheduled to launch in 2006, will carry a lidar instrument (CALIOP) that will collect profiles of the attenuated backscatter at visible and nearinfrared wavelengths along with polarized backscatter in the visible channel (Winker et al., 2003). Flying in formation with the Aqua, AURA, POLDER, and CloudSat satellites, this vertically resolved information is expected to greatly improve passive aerosol and cloud retrievals as well as allow the development of new retrieval products (see Kaufman et al., 2003; Léon et al., 2003).

The high accuracy of aerosol products (mainly aerosol optical depth) from these new-generation sensors, together with improvements in characterizing the surface and clouds (see Sect. 2.2), can help reduce the uncertainties associated with the aerosol direct radiative effect, as discussed in several recent studies (Boucher and Tanré, 2000; Christopher and Zhang, 2002, 2004; Loeb and Kato, 2002; Bellouin et al., 2003; Yu et al., 2004; Remer and Kaufman, 2006; Loeb and Manalo-Smith, 2005; Zhang et al., 2005a, b). The retrieved aerosol size parameters can help distinguish anthropogenic aerosols from natural aerosols and hence help assess the anthropogenic aerosol radiative forcing (Kaufman et al., 2002a; Kaufman et al., 2005a; Christopher and Zhang, 2004). Current retrieval algorithms generally assume that aerosols are spherical in shape and have mono-modal or bi-modal size distribution. These assumptions may not be adequate and could introduce uncertainties in aerosol retrievals (Mishchenko et al., 1995; Zhao et al., 2003). As discussed earlier, individual sensors have their own strengths and weaknesses. No single sensor is adequate for characterizing the complex aerosol system; instead, they are usually complementary to each other. Therefore, the best strategy for characterizing global aerosols is to integrate measurements from different sensors. Furthermore, some sensors will fly in formation with other aerosol and cloud sensors (including OMI on Aura, CALIOP on CALIPSO) in the coming years. The constellation of these new-generation sensors, also called the A-Train (Stephens et al., 2002) provides an unprecedented opportunity to improve the characterization of global aerosols, clouds, and surface properties and hence the quantification of aerosol radiative forcing (Anderson et al., 2005a). These global measurements of aerosols can also be used to improve the performance of aerosol model simulations and hence the assessment of the aerosol direct radiative effect through an assimilation or integration process (e.g., Collins et al., 2001; Yu et al., 2003, 2004; Matsui et al., 2004; Liu et al., 2005). Finally, algorithms are being developed to retrieve aerosol absorption or single-scattering albedo from satellite observations (e.g., Kaufman et al., 2001; Torres et al., 2005). The NASA Glory mission, scheduled to launch in 2008, will deploy a multi-angle, multi-spectral polarimeter to determine the global distribution, microphysical properties, and chemical composition of natural and anthropogenic aerosols and clouds with accuracy and coverage sufficient for a reliable quantification of the aerosol direct and indirect effects on climate (Mishchenko et al., 2004).

\subsubsection{Intensive field campaigns}

Over the past decade, more than a dozen intensive field experiments have been conducted to study physical, chemical, and optical properties and radiative effects of aerosols in a variety of aerosol regimes around the world, as depicted in Fig. 1. These experiments have either been designed mainly for aerosol research or have included aerosol characterization as one of their major themes as part of interdisciplinary research efforts. A brief description of them is given in Table 1 . 


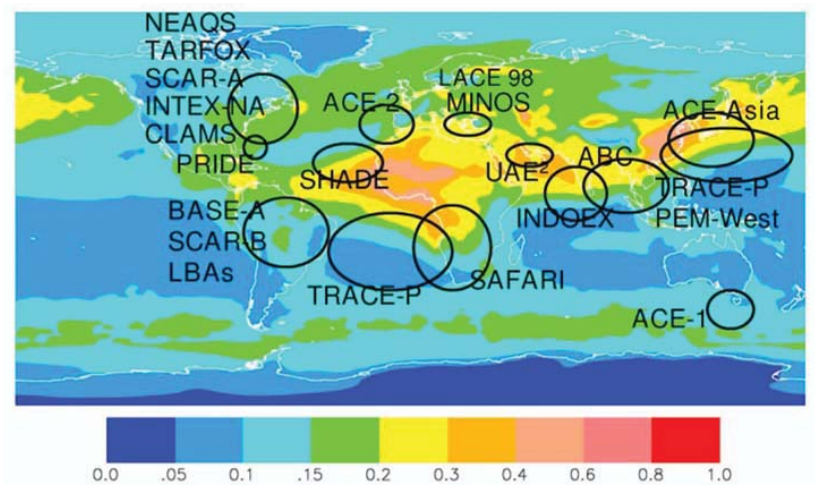

Fig. 1. Schematic of major intensive field experiments designed either mainly for aerosol research or by including aerosol characterization as part of an interdisciplinary research effort. The background represents the MODIS-MISR-GOCART integrated aerosol optical depth for 2001 (described in Sect. 3.1).

One of the main scientific goals of both TARFOX and ACE-2 was to examine how the North Atlantic is influenced by pollution outflows from North America and West Europe during the summer season (Russell et al., 1999; Raes et al., 2000). Aerosol processes and properties have also been a major theme in air quality and atmospheric chemistry experiments, such as NEAQS in New England (Quinn and Bates, 2003), MINOS in the Mediterranean region (Lelieveld et al., 2002), INTEX-NA (2004), and ICARTT (2004).

South and East Asia have been of great interest to the atmospheric chemistry community because of the rapid and persistent increase in emissions in that region in recent decades and the complexity of aerosol composition and properties in the region. As observed by INDOEX, brown hazes blanketing large areas of the northern Indian Ocean in the pre-monsoon season can significantly influence the atmospheric radiative budget, climate, and hydrological cycles (Ramanathan et al., 2001b). Such research is being extended to the broader Asia regions under the framework of Atmospheric Brown Cloud (ABC) (Ramanathan and Crutzen, 2003). In East Asia, a mixture of industrial pollution and mineral dust influences large areas of the North Pacific and may even reach the North American continent, especially during the spring season. In the 1990s, several missions, under the framework of NASA's global tropospheric experiment (GTE), have been conducted, including PEM-West A and B (Hoell et al., 1996, 1997). A decade of data describing Pacific aerosols is summarized in Clarke and Kapustin (2002). More recently, TRACE-P and ACE-Asia were conducted in the spring of 2001 to document and characterize such intercontinental transport and its regional and hemispheric impacts. In particular, ACE-Asia was designed specifically for comprehensive aerosol research (Huebert et al., 2003; Seinfeld et al., 2004).

In the tropics, biomass burning comprises a major source of atmospheric aerosols and several international missions have been conducted to investigate how the emissions of gases and particles from biomass burning influence atmospheric chemistry, radiative budget, and climate, including BASE-A (Kaufman et al., 1992), SCAR-B (Kaufman et al., 1998) and LBA-SMOCC (Andreae et al., 2004) over South America, SAFARI2000 (King et al., 2003a), SAFARI92 (Lindesay et al., 1996), and TRACE-A (Fishman et al., 1996) over South Africa and the South Atlantic Ocean.

The largest sources of mineral dust come from North Africa and the Arabian Peninsula. They impose pronounced impacts over the tropical and subtropical Atlantic Ocean, Arabian Sea and as far as Southeastern US, as documented by observations during SHADE (Tanré et al., 2003), PRIDE (Reid et al., 2003), and $\mathrm{UAE}^{2}$ (http://uae2.gsfc.nasa.gov/). The ACE-1 experiment was conducted over remote southern oceans to characterize the aerosols over the remote region least influenced by human activities (Quinn and Coffman, 1998).

During each of these comprehensive missions, aerosols were studied in great detail, using combinations of in-situ and remote sensing observations of physical and chemical properties from various platforms (e.g., aircraft, ship, satellite, ground-network) and numerical modeling (e.g., Seinfeld et al., 2004). In spite of their relatively short duration, these missions have acquired comprehensive data sets of regional aerosol properties that can be compared and compiled to understand the complex interactions of aerosols within the earth and atmosphere system. For such data comparison and compilation, it is required that different observations are sampling the same air mass and problems associated with individual measurements are well understood. Where aerosol properties are "over-determined" by coordinated deployment of multiple platforms and instruments, they can be used to identify inconsistencies and quantify uncertainties. Column closure studies are an example of using this approach to improve knowledge of aerosol radiative forcing (e.g., Russell et al., 1997).

\subsection{Characterization of surface albedo and clouds}

\subsubsection{Surface reflection and albedo}

Accurate portrayal of the surface reflection is important for determining how aerosols perturb the solar energy budget (Atwater, 1970; Mitchell Jr., 1971; Coakley et al., 1983). Multiple reflections between the surface and aerosols cause a non-linear surface influence in addition to the aerosol radiative effect. In general, the larger the surface reflection, the smaller the aerosol radiative effects are (for the same nonabsorbing aerosol). However, even weak aerosol absorption above a highly reflective surface (deserts or snow) would cause warming at the TOA. As such, inadequate characterization of surface reflection will introduce additional uncertainties in the estimate of the aerosol direct radiative effect. 
Table 1. List of major intensive field experiments that are relevant to aerosol research in a variety of aerosol regimes around the globe conducted in the past decade.

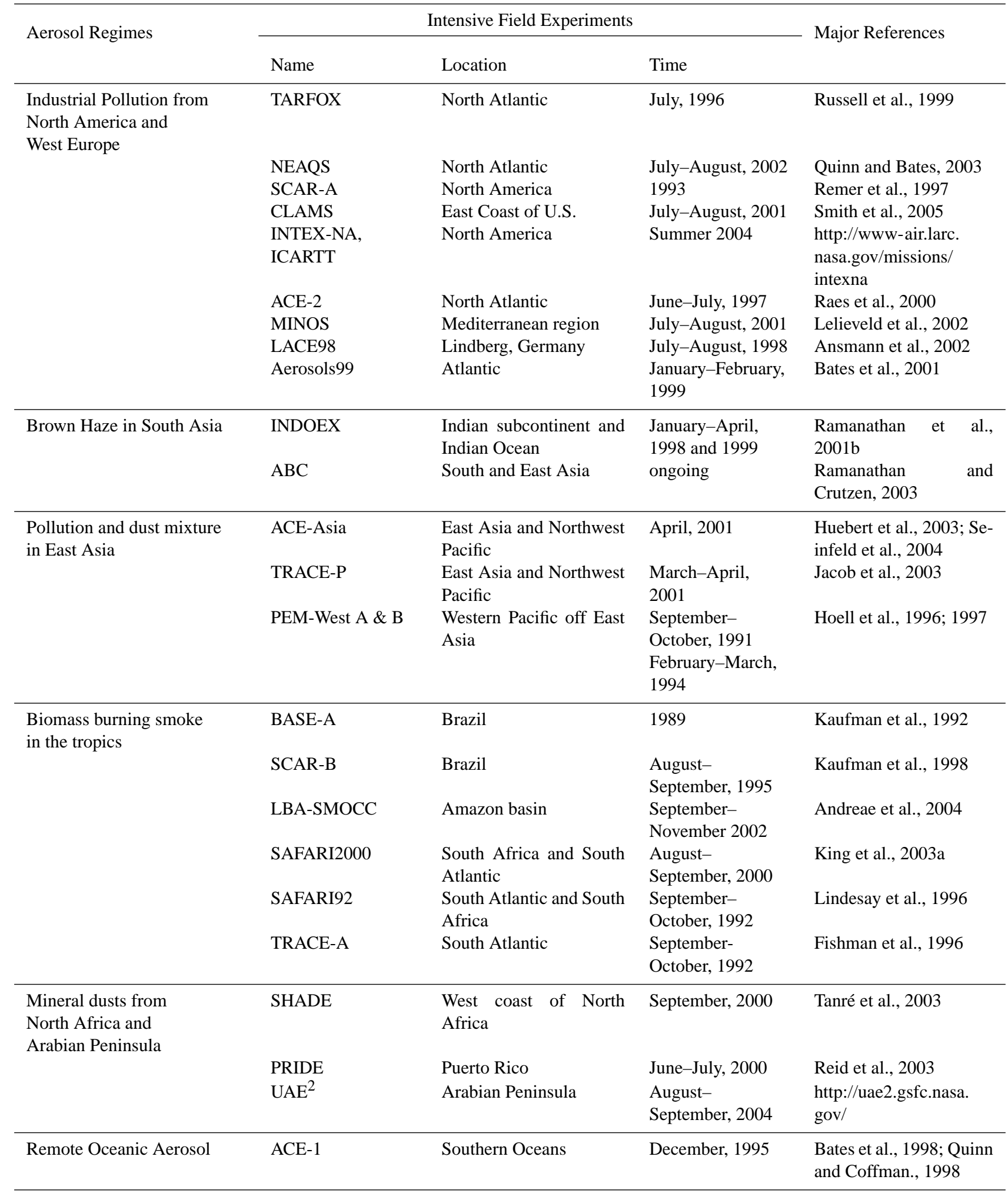



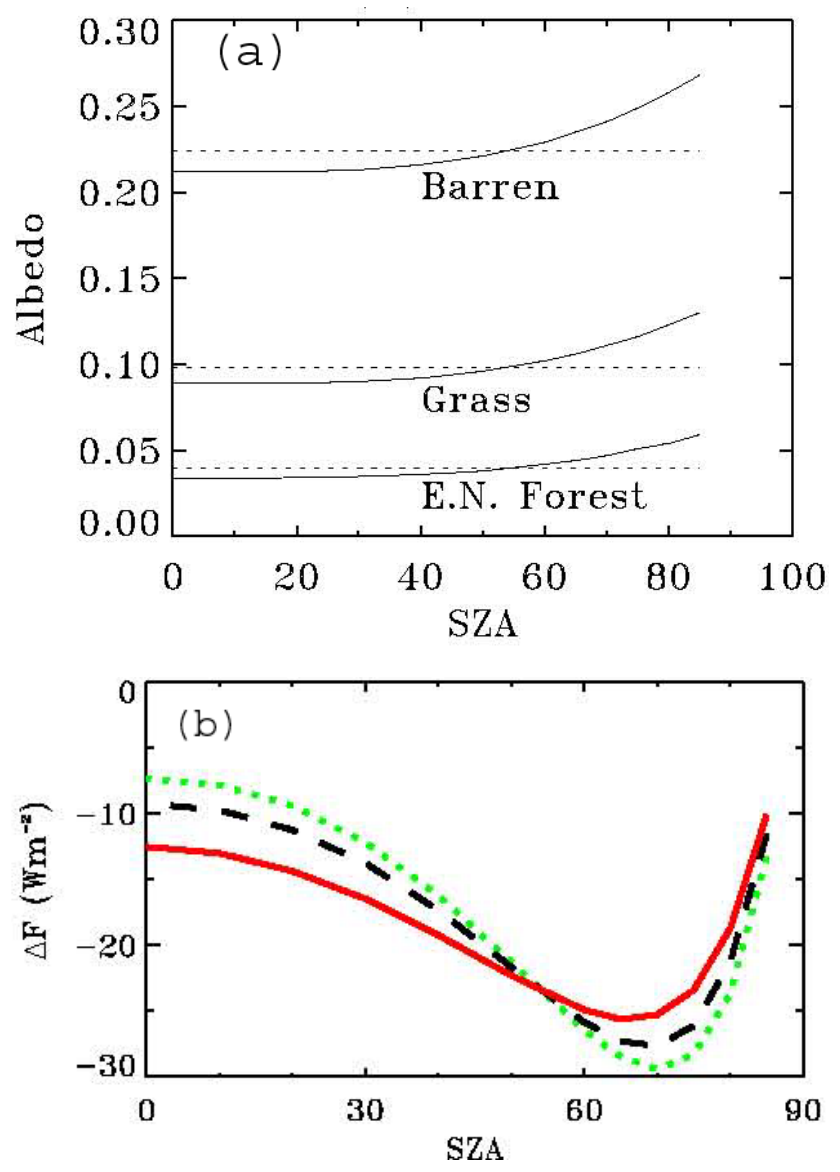

Fig. 2. (a) MODIS-derived black-sky (solid line) and white-sky albedo (dotted line) in the visible range for three land cover classifications, namely barren land, grass land, and evergreen needleleaf forest. The black-sky albedo increases with solar zenith angle (SZA) and equals the white-sky albedo at a SZA of about 55 degree. (b) Dependence of aerosol direct effect $(\Delta F)$ at the TOA on SZA over the grass land for prescribing white-sky albedo (green) and black-sky albedo (black), and calculating the surface reflectance based on model-calculated direct/diffuse ratio (red) (Yu et al., 2004). Aerosol optical depth is 0.4 at $550 \mathrm{~nm}$ and the Ångström exponent is 1 . A broadband single-scattering albedo is 0.95 .

The characterization of surface reflection is challenging. Reflection of solar radiation from natural surfaces is anisotropic and its angular distribution in the upper hemisphere is described by the bidirectional reflectance distribution function (BRDF). The BRDF is an intrinsic property of the surface, depending on the textures, structure, and compositions of the surface. In radiative transfer modeling, the reflection of radiation by the surface is generally simplified by using the concept of surface albedo, which is the ratio of reflected to incident solar radiation and should involve an integral of BRDF for all combinations of incident and reflection geometry in the upper hemisphere. In addition to its dependence on surface properties, the surface albedo is generally dependent on the wavelength and incident angle of incoming solar radiation. Because of this dependence, it is necessary to consider the modification of the incoming solar beam by the atmosphere and its impact on the surface albedo. For example, aerosol scattering changes the incident angle of solar radiation by increasing the diffuse radiation but decreasing the direct radiation. Because aerosol extinction is generally dependent on wavelength, the spectral composition of incident solar radiation is also different from that without aerosols (Yu et al., 2004; Bellouin et al., 2004). Due to large spectral variations of surface albedo and of aerosol extinction, a use of broadband albedo over the whole solar spectrum is inadequate. Giving that most surfaces have distinct reflectance and an albedo between the visible and near-infrared, it is a common practice to describe the surface albedo in two broad spectral ranges, one for UV-visible and the other for nearinfrared. A more detailed spectral surface albedo may be needed to better characterize the aerosol effect over vegetation and snow (Zhou et al., 2005).

Over ocean, the surface albedo depends primarily on wavelength and on solar and viewing angles, but also on wind-speed and chlorophyll concentration. A coupled atmosphere-ocean radiative transfer model (e.g., Jin et al., 2002,2004 ) is needed to adequately characterize such dependences (Yu et al., 2004). Often the land surface is highly heterogeneous, having highly anisotropic and wavelengthdependent optical properties (e.g., Dickinson, 1984). Therefore its characterization is even more difficult, leading to additional uncertainty in the aerosol direct effect. Until recently, aerosol radiative forcing calculations have assumed surface albedos that have been determined based on empirical parameterizations of vegetation and soils (Dickinson et al., 1993; Sellers et al., 1996). New satellite-borne instruments, such as MODIS and MISR, can much better characterize surface optical properties because they measure at multiple wavelengths and angles at spatial resolutions as fine as $1 \mathrm{~km}$ (Moody et al., 2005; Schaaf et al., 2002; Martonchik et al., 1998b). Their albedo products include both global black- and white-sky albedos, which represent respectively the directional hemispheric reflectance contributed by the direct beam and the bihemispherical reflectance contributed from reflection of diffuse light. These and other new datasets can provide better lower boundary conditions to the radiative transfer model and reduce the uncertainty in the estimate of aerosol direct effect (e.g., Yu et al., 2004).

The MODIS retrieved angular dependence of the surface reflection, i.e., a separation of direct beam and diffuse light contribution, also provides an unprecedented dataset for examining how the modifications of the directional and spectral composition of incident solar radiation by aerosols (as discussed earlier) could alter the surface reflection and the solar energy budget, adding to the aerosol direct effect ( $\mathrm{Yu}$ et al., 2004). Fig. 2a shows that the MODIS retrieved whitesky albedo is larger than the black-sky albedo at high solar zenith angles and smaller at low angles for different surface types. The surface reflection is calculated separately for the 
incident direct beam and diffuse light using the black-sky and white-sky albedo, respectively. A reduction of direct beam fraction (as would be caused by aerosols) increases the effective reflection at high Sun but decreases it at low Sun. Consequently, in comparison to those using a constant albedo (black-sky albedo or white-sky albedo), the TOA DRE shifts towards a negative value (more cooling or less warming) at high Sun, but towards a positive value (less cooling) at low Sun, as shown in Fig. $2 b$ for grassland. Clearly, the inclusion of land surface anisotropy is necessary for capturing diurnal aerosol effects. Magnitudes of such effects strongly depend on both the aerosol properties and land classifications (Yu et al., 2004). Bellouin et al. (2004) showed that the inclusion of anisotropy is also necessary over the ocean. With integration over solar zenith angles, the effects become much smaller, i.e., $5 \%$ for the monthly average TOA DRE over global land (Yu et al., 2004).

\subsubsection{Clouds}

Clouds can profoundly modify the aerosol radiative effects. The extent of their modification depends on both the aerosol and cloud properties, their relative positioning in the atmosphere, and on their diurnal variation with respect to the solar illumination (e.g., Liao and Seinfeld, 1998; Haywood and Shine, 1997; Zhou et al., 2005). Cloud properties that must be accounted for include cloud fraction, cloud optical depth and cloud droplet size. For absorbing aerosols, the vertical profile of clouds is also desired (Keil and Haywood, 2003). For a first-order approximation (as assumed in box models), the direct aerosol radiative effect is negligible in overcast skies, but is a cloud-fraction weighted product of clear and cloudy sky effects in partly cloudy skies (e.g., Charlson et al., 1992). Such an assumption only holds for optically thick clouds residing above the aerosol layer, where the solar radiation is sufficiently diffused by the cloud. For optically thin clouds, a significant amount of solar radiation is transmitted to, and will interact with, the underlying aerosol layer. Aerosols under clouds with reflectance of 0.2 (corresponding to optical depth of 2) will have $75 \%$ of the effect as aerosols in cloud free areas. If the absorbing aerosols lay above the cloud layer (in essence a very bright surface) then the aerosol absorption effect tends to be magnified. Thus, aerosols over clouds tend to induce a warming effect at the TOA.

MODIS uses multiple spectral bands to detect clouds, and retrieve cloud properties at moderate resolutions (Platnick et al., 2003). From the pressure dependence of thermal emission bands, MODIS infers the cloud top pressure and temperature. Using six visible and near-infrared bands, MODIS retrieves drop effective radius (weighted towards the cloud top), columnar optical thickness, and water path for different cloud thermodynamic phases (i.e., water, ice, and mixed) at $1 \mathrm{~km}$ resolution for overcast pixels. Figure 3 shows the annual cycle (2001) of cloud fraction and total (water plus ice) cloud optical depth averaged over the entire globe, land, and ocean. On a global annual average, the cloud fraction is about 0.63 and cloud optical depth is 10.8. Compared with clouds over ocean, clouds over land are optically thicker and have smaller cloud fraction. While the combination of MODIS/Terra and MODIS/Aqua allows for some indication of cloud evolution from late morning to early afternoon, the International Satellite Cloud Climatology Project (ISCCP) has been providing diurnal variations of clouds for two decades (Schiffer and Rossow, 1983; Rossow and Schiffer, 1991, 1999). Such information can be exploited to better constrain the estimate of the aerosol direct effect in cloudy sky conditions (in terms of diurnal variation of clouds) and to study interannual variations of the aerosol radiative effect.

However satellite cloud retrievals have significant uncertainties and biases, resulting from cloud heterogeneity, assumption on the size distribution, and inadequacy of accounting for surface and aerosol contributions to the reflectance, among others. These uncertainties/biases are sensor dependent and cross-platform comparisons generally show both consistence/correlation and discrepancies (Bréon and Doutriaux-Boucher, 2005; Mahesh et al., 2004). A plane-parallel approximation would result in a high bias in the effective radius for convective clouds with a great heterogeneity (e.g., Kaufman and Nakajima, 1993; Platnick and Valero, 1995; Reid et al., 1999). Exclusion of aerosols in the cloud retrieval algorithm could result in low biases in cloud optical depth (as large as -30\%) and effective radius (as large as $-3 \mu \mathrm{m}$ ) in cases of smoke overlaid low-level clouds (Haywood et al., 2004). The low bias of cloud droplet effective radius, hence the high bias in cloud reflectivity, could underestimate the TOA DRE by $\sim 4 \%$, while the low bias of cloud optical depth could overestimate the TOA DRE by $26 \%$ (Abel et al., 2004). Heavy aerosols may be misclassified as clouds (Brennan et al., 2005), which could introduce additional uncertainties in cloud retrievals. Profiling clouds from space is far from adequate. MODIS and AVHRR can detect cloud top but not cloud base. Spaceborne lidar such as GLAS and CALIOP has a capability of measuring the extinction profile of optically thin clouds (e.g., cloud optical depth $<3$ ). Such profiling is not possible for optically thick clouds, although the cloud top and base could be located through holes and edges of broken clouds (Spinhirne, et al., 2005). CloudSat, scheduled to be launched in 2006, will use radar to survey the vertical structure of cloud systems globally, including liquid and water content profile (Stephens et al., 2002).

\subsection{Modeling of atmospheric radiative transfer}

With a full set of aerosol optical properties available, a radiative transfer model can be employed to calculate the direct radiative effect of aerosol. While uncertainties associated with input parameters of aerosols, either from measurements or model simulations, will definitely propagate to the uncertainty of the direct radiative effect, additional uncertainties 

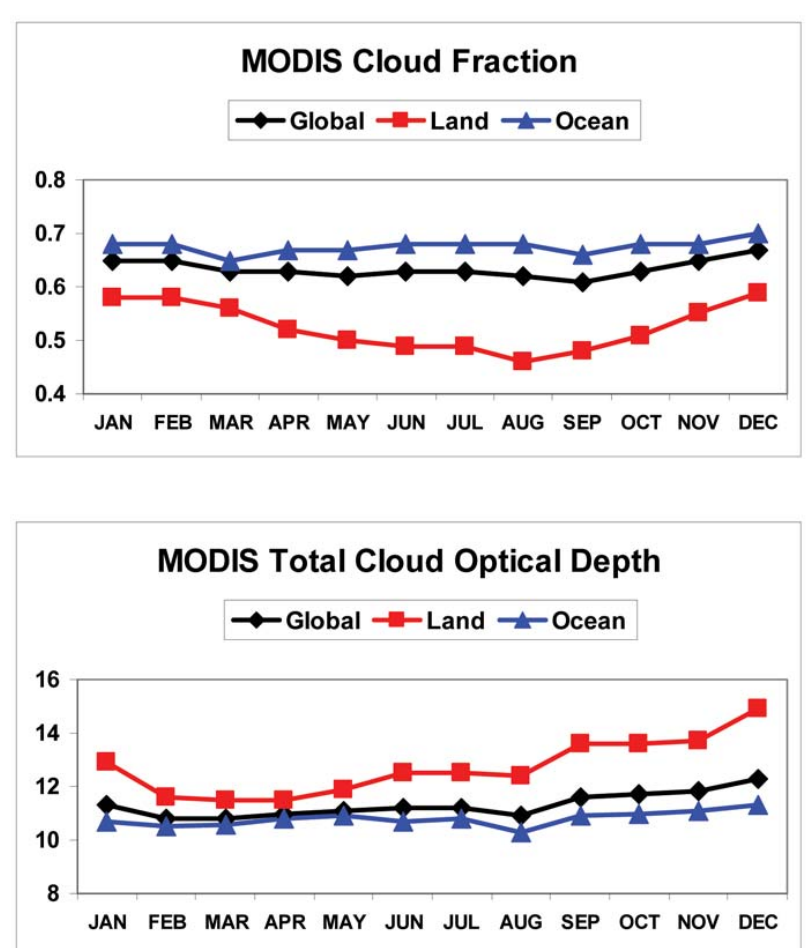

Fig. 3. Annual cycle (2001) of MODIS/Terra cloud fraction (top) and total cloud optical depth (bottom) averaged over globe, land, and ocean, respectively (derived from MODIS Level 3 monthly $1^{\circ} \times 1^{\circ}$ cloud products as described in King et al., 2003b; Platnick et al., 2003).

could be introduced by assumptions and parameterizations in modeling the radiative transfer in the atmosphere.

The early box model or one-line formula (e.g., Charlson et al., 1991; Chylek and Wong, 1995) represents aerosol-radiation interactions with a number of simplifications. While the calculations are straightforward, the simplifications cause large uncertainties in estimates of aerosol radiative forcing (e.g., Wendisch et al., 2001). In such box models, the aerosol properties are always assumed for a single wavelength (e.g., $550 \mathrm{~nm}$ ). However, the optical properties at $700 \mathrm{~nm}$ may be more representative for the whole solar spectrum than those at $550 \mathrm{~nm}$ (Blanchet, 1982). Box models do not adequately account for the spectral dependence of aerosol/Rayleigh scattering interactions, especially at short wavelengths and at low Sun where Rayleigh scattering is strong. In addition, multiple scattering effects become stronger at high aerosol loadings. Therefore, such simple box models should only be applied to optically thin atmospheres.

With the substantially enhanced computational capability of modern computers, it is now feasible to carry out sophisticated radiative transfer modeling. Most recent studies have used plane-parallel radiative transfer (RT) models numerically solved with a discrete-ordinate method, with varying levels of complexity depending on spectral resolution and

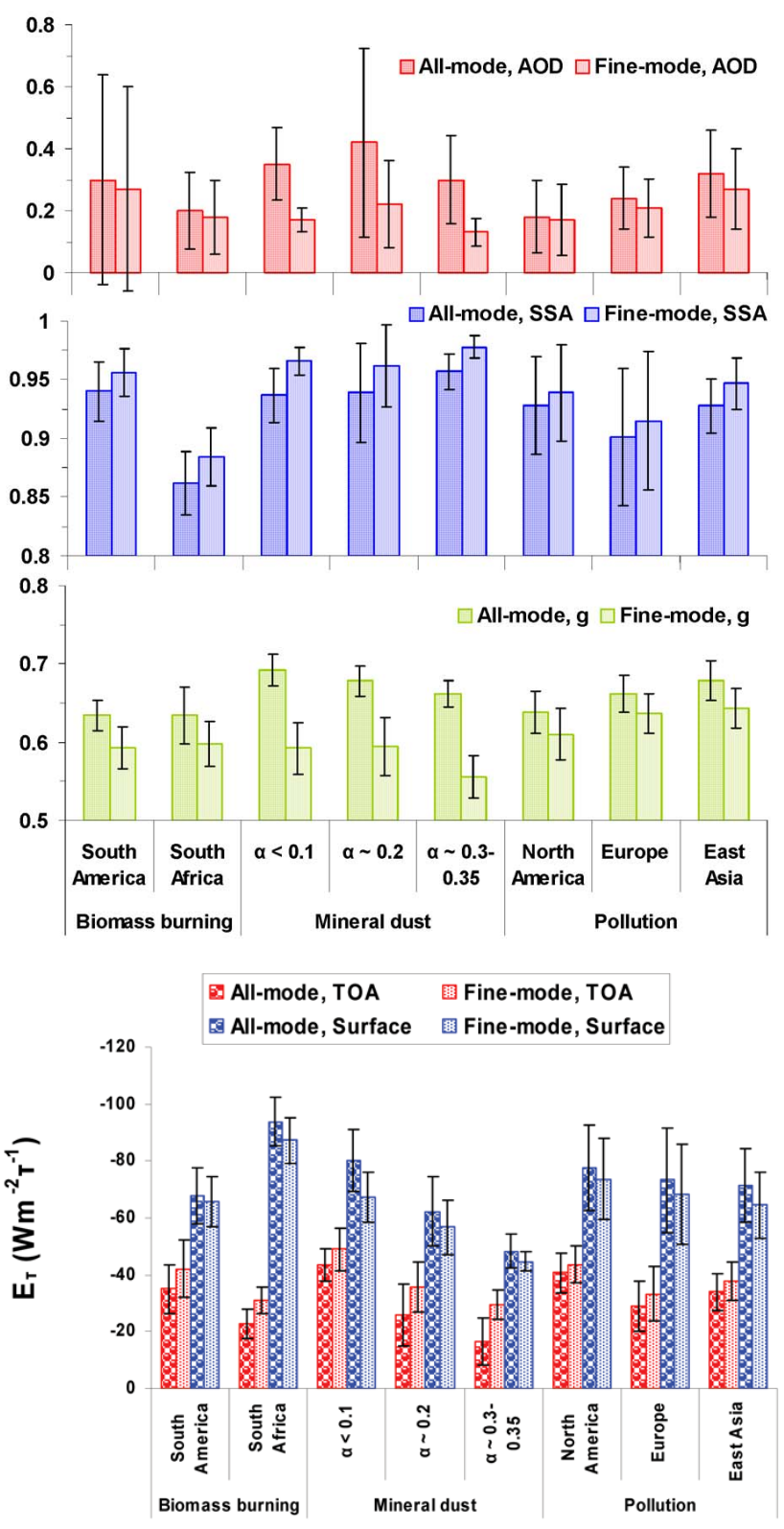

Fig. 4. Mean values and standard deviations of AERONET aerosol optical depth (AOD), single-scattering albedo (SSA), asymmetry factor $(g)$ at $550 \mathrm{~nm}$, and the calculated clear-sky radiative efficiency $\left(E_{\tau}\right)$ for typical aerosol types and over different geographical regions, where $\alpha$ is surface broadband albedo. Standard deviation is shown as the error bar (Zhou et al., 2005).

streams (e.g., Fu and Liou, 1993; Chou et al., 1993). Boucher et al. (1998) compared sulfate radiative effects calculated from a dozen such radiative transfer models. Recently, a few studies have used more sophisticated Monte-Carlo RT models (e.g., Podgorny et al., 2000; Podgorny and Ramanathan, 2001). Such modeling is capable of better characterizing the complex particle-radiation interactions in heterogeneous media, including aerosols in the vicinity of broken clouds. 
Simplified phase function parameterizations such as $\mathrm{HG}$ functions employed by most RT models cannot adequately represent backward scattering (van de Hulst, 1980), thereby introducing errors in the estimate of aerosol radiative forcing. Errors vary in magnitude, depending on the solar zenith angle, aerosol size distribution and refractive index (Boucher, 1998; Marshall et al., 1995). Aerosol direct solar effects change appreciably with the solar zenith angle (SZA). For purely scattering sulfate aerosol, the largest cooling occurs around a SZA of $\sim 70^{\circ}$ because of the angular dependence of both aerosol upscattering fraction and Rayleigh scattering (Nemesure et al., 1995; Boucher et al., 1998; Russell et al., 1999). Aerosol absorption decreases with increasing SZA, nearly compensating for the SZA-dependence of aerosol backscattering (Yu et al., 2002). The SZA-dependence of the aerosol direct effect is relatively weak for absorbing aerosols. Accurately modeling the SZA-dependence of aerosol radiative effect requires that the time step for radiative calculations be adequately small, e.g., less than $30 \mathrm{~min}$, in order to sample a range of solar zenith angles and calculate the unbiased daily average aerosol direct effect (Yu et al., 2004).

\subsection{Summary}

In summary, we present here an example that demonstrates how the aerosol direct solar effect is determined by a combination of aerosol and surface properties by using AERONET monthly measurements. AERONET sites with good accuracy and a full annual cycle were chosen to represent different aerosol types, geographical locations, and surface properties (Table 1 in Zhou et al., 2005). Figure 4 shows the AERONET measured aerosol optical properties of various aerosol types (biomass burning smoke, mineral dust, and industrial/urban pollution) for different geographical regions, with vertical bars representing one standard deviation and reflecting the variability of measurements. Both all-mode (total) and fine-mode aerosols are considered. It appears that the variability for AOD is generally much larger than the accuracy of AERONET measurements $( \pm 0.01$, Holben et al., 1998), while the variability for SSA and $g$ is comparable to the theoretical accuracy of their retrievals (i.e., \pm 0.03 for SSA and \pm 0.02 for $g$; Dubovik et al., 2000).

Figure 4 also shows the diurnally averaged, normalized aerosol direct effect based on the AERONET data. The normalized aerosol direct effect is referred to as radiative efficiency $\left(E_{\tau}\right)$, defined as $\mathrm{DRE} / \tau(550 \mathrm{~nm})$ (Anderson et al., 2005a). Here the DRE is calculated with a radiative transfer model (Fu and Liou, 1993) using the spectraldependent aerosol properties from AERONET, land albedos from MODIS, and ocean albedos from Jin et al. (2002, 2004), and $\tau(550 \mathrm{~nm})$ is the monthly averaged optical depth from AERONET measurements. The quantity of $E_{\tau}$ is mainly governed by aerosol size distribution and chemical composition (determining aerosol single-scattering albedo and phase function), surface reflectivity, and solar irradiance, and also to some degree depends on the optical depth because of multiple scattering. Again the vertical bars represent one standard deviation of $E_{\tau}$ for individual aerosol regimes.

Due to stronger absorption of smoke in South Africa (SSA $\sim 0.86 \pm 0.03)$ as compared to South America (SSA 0.94 \pm 0.03 ) (Dubovik et al., 2002; Eck et al., 2003), biomass burning aerosols in South Africa are found to have an average $E_{\tau}$ that is smaller by $\sim 35 \%$ at the TOA but larger by $\sim 38 \%$ at the surface. For industrial pollution, the aerosol absorption and hence the radiative efficiency are inbetween South Africa biomass burning smoke and South America smoke. On average, the TOA and surface $E_{\tau}$ are relatively large in North America.

Mineral dust dominates over North Africa and the Arabian Peninsula. Here the surface reflectivity is high and has considerable spatial variability, ranging from about 0.2 to 0.4 for albedo in the solar spectrum (Tsvetsinskaya et al., 2002). Dust outflow also influences nearby oceans substantially where the surface albedo is less than 0.1. Such large variations of surface albedo could be the major reason for the large differences of aerosol solar effect shown in the plots. The radiative efficiency ranges from -44 to $-17 \mathrm{Wm}^{-2} \tau^{-1}$ at the TOA and from -80 to $-48 \mathrm{Wm}^{-2} \tau^{-1}$ at the surface when the surface albedo changes from less than 0.1 to $0.3 \sim 0.35$. It also shows that the radiative efficiency of finemode aerosol is larger at the TOA but smaller at the surface than that of all-mode aerosol, due to a larger single-scattering albedo and smaller asymmetry factor of fine-mode aerosol retrieved from AERONET measurements.

\section{Assessments of global and regional aerosols and their direct effect}

\subsection{Description of assessments}

\subsubsection{Scope of assessments}

In this review, we concentrate on measurement-based assessments (e.g., from ground-based networks, satellite remote sensing, and intensive field experiments) of tropospheric aerosols and their direct radiative effect, supplemented by five global aerosol model simulations. We assess the aerosol properties and resulting estimates of the DRE derived from these different approaches, both globally (in Sect. 3.2) and regionally (in Sect. 3.3). DCF by anthropogenic aerosols is assessed in Sect. 3.4. In this section, the assessments concentrate on aerosol optical depth and influences on solar radiation in clear sky conditions. In Sect. 4, we will briefly discuss DRE in the thermal infrared range and in cloudy conditions. Because satellite sensors generally do not retrieve aerosols with good accuracy at high latitudes (due to weak sunlight and high surface reflectance of snow and ice), the global assessments are actually confined to areas between $60^{\circ} \mathrm{N}$ and 


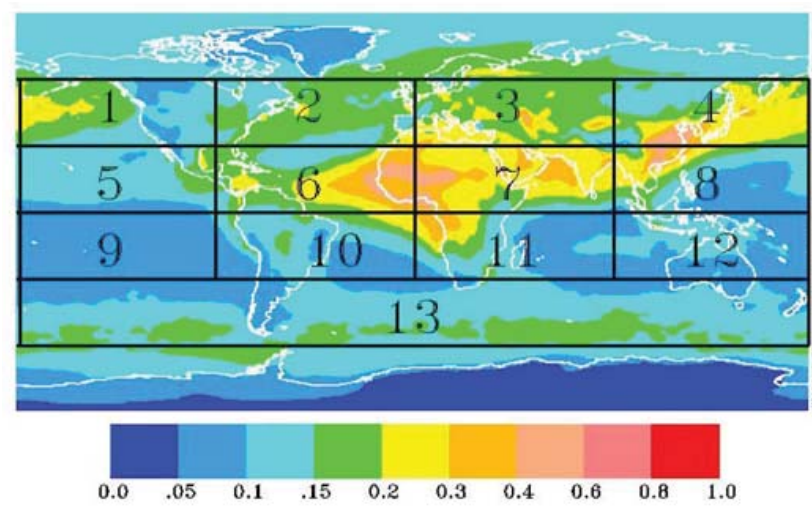

Fig. 5. Divisions of 13 zones defined for regional comparisons of aerosol and its direct effect. The background depicts the MODISMISR-GOCART integrated annual average aerosol optical depth at $550 \mathrm{~nm}$ for $2001 \mathrm{using}$ the data assimilation approach as described in Yu et al. (2003).

$60^{\circ} \mathrm{S}$. The regional assessments are conducted over the 13 zones shown in Fig. 5.

\subsubsection{Datasets of aerosol optical depth}

We have compared retrievals of aerosol optical depth from a number of datasets. These include derivations from different satellite sensors (e.g., Terra-MODIS, MISR), model simulations (e.g., GOCART, SPRINTARS, GISS, LMDZINCA, LOA, MPI-HAM), and satellite-model integrations (MO_GO, MI_GO, and MO_MI_GO), and are listed in Table 2. Aerosol retrievals from MODIS and MISR have previously been described in Sect. 2.1. All MODIS values of AOD or DRE shown in this paper are from Terra Collection 4 retrievals.

Five global aerosol models are included in our comparisons, namely GISS (Koch and Hansen, 2005; Koch et al., 20053 ; Miller et al., 2005 ${ }^{4}$ ), GOCART (Chin et al., 2000a, b, 2002, 2003, 2004; Ginoux et al., 2001, 2004), LMDZ-INCA (Schulz et al., 2006 ; Textor et al., 2005), LMDZ-LOA (Boucher and Pham, 2002; Reddy et al., 2004, 2005a, b), and SPRINTARS (Takemura et al., 2000, 2002, 2005). All models simulate major components of tropospheric aerosols,

\footnotetext{
${ }^{3}$ Koch, D., Schmidt, G., and Field, C.: Sulfur, sea salt and radionuclide aerosols in GISS ModelE, J. Geophys. Res., submitted, 2005.

${ }^{4}$ Miller, R. L., Cakmur, R. V., Perlwitz, J. A., Koch, D., Schmidt, G. A., Geogdzhayev, I. V., Ginoux, P., Prigent, C., and Tegen, I.: Mineral dust aerosols in the NASA Goddard Institute for Space Sciences ModelE atmospheric general circulation model, J. Geophys. Res., submitted, 2005.

${ }^{5}$ Schulz, M., Balkanski, Y., Textor, C., Guibert, S., Generoso, S., Boucher, O., Bréon, F.-M., Hauglustaine, D., and Hourdin, F.: The LMDzT-INCA global aerosol model and its evaluation with surface, lidar and satellite aerosol observations, in preparation, 2006.
}

including sulfate (natural and anthropogenic separately), organic carbon (natural and anthropogenic separately), black carbon, and size-resolvable dust and sea-salt. On the other hand, individual models differ in emissions inventories, parameterizations of physical and chemical processes of aerosols, radiative transfer schemes, and spatial resolution. Some models are driven by assimilated/nudged climatology, whereas others are coupled with an atmospheric general circulation model. All models provide the total aerosol optical depth under whole sky conditions. In addition, SPRINTARS and GISS provide the clear-sky AOD (denoted as SPRINTARS_clr and GISS_clr, respectively). For deriving SPRINTARS_clr AOT, clear sky is defined as a condition where the grid-average cloud fraction (maximum-random overlapping) is less than 0.2 at each time step of the model integration (e.g., $8 \mathrm{~min}$ ). GISS_clr is derived by weighting the simulated AOD with clear-sky fraction.

Both satellite retrievals and model simulations have uncertainties. The goal of data assimilation or objective analysis is to minimize the misfit between them and to form an optimal estimate of aerosol distributions, by combining them with weights inversely proportional to the square of the errors of individual descriptions. Statistical parameters characterizing the magnitude and propagation of errors are needed for the integration, including fractional error coefficients, minimum root-mean-square errors, and correlation lengths. An optimum interpolation approach is used in this study (Yu et al., 2003; Matsui et al., 2004). It can fill gaps in satellite retrievals and generate global distributions of aerosols in better agreement with ground-based measurements than either the satellite retrievals or model simulations are capable of alone (Yu et al., 2003). In this study, the error parameters are determined from comparisons with AERONET measurements (e.g., Remer et al., 2005; Chin et al., 2002; Kahn et al., 2005a) and spatial-correlation analysis of LITE data (Anderson et al., 2003b). MO_GO and MI_GO denote, respectively, an integration of GOCART simulations with MODIS (land and ocean) and MISR (land and ocean) retrievals. We also integrate GOCART simulations with MODIS retrievals over ocean and MISR retrievals over land, denoted as MO_MI_GO. By doing so, we take advantage of the high accuracy of MODIS over-ocean retrievals and the high accuracy of MISR retrievals over bright as well as darker land surfaces.

\subsubsection{Datasets of aerosol direct radiative effect}

Table 3 lists the estimates of aerosol direct solar effect included in the comparison. A brief description of each is presented in the table and readers are encouraged to refer to the relevant literature for more details. Although data years are not completely consistent among datasets, they would not significantly affect intercomparisons in this study. On global average, interannaul variations of AOD and DRE are fairly small (e.g., Remer and Kaufman, 2006; Loeb and Manalo- 
Table 2. List of products participated in the intercomparison of aerosol optical depth.

\begin{tabular}{|c|c|c|}
\hline Products & Brief Descriptions & Major References \\
\hline MODIS & Terra-MODIS monthly $1^{\circ} \times 1^{\circ}$ data (MOD08_M3) & $\begin{array}{l}\text { Kaufman et al., 1997; Tanré et al., 1997; } \\
\text { Remer et al., } 2005\end{array}$ \\
\hline MISR & MISR monthly $0.5^{\circ} \times 0.5^{\circ}$ data (MIL3MAE) & Diner et al., 1997 ; Kahn et al., 2005 \\
\hline MO_GO & $\begin{array}{l}\text { Integration of GOCART simulations with MODIS retrievals } \\
\text { (land and ocean) }\end{array}$ & Yu et al., 2003 \\
\hline MI_GO & $\begin{array}{l}\text { Integration of GOCART simulations with MISR retrievals } \\
\text { (land and ocean) }\end{array}$ & \\
\hline MO_MI_GO & $\begin{array}{l}\text { Integration of GOCART simulations with retrievals from } \\
\text { MODIS over ocean and from MISR over land. }\end{array}$ & \\
\hline GOCART & $\begin{array}{l}2001 \text { whole-sky monthly average; resolution: } 2.5^{\circ} \times 2^{\circ} \text {, } \\
30 \text { vertical layers; driven by assimilated meteorology } \\
\text { NASA/GEOS-DAS }\end{array}$ & $\begin{array}{l}\text { Chin et al., 2000a, b; Ginoux et al., 2001, } \\
\text { 2004; Chin et al., 2002, 2003, } 2004\end{array}$ \\
\hline SPRINTARS & $\begin{array}{l}2001 \text { whole-sky monthly average; resolution: } \\
1.125^{\circ} \times 1.125^{\circ}, 20 \text { layers; coupled with an atmospheric } \\
\text { general circulation model }(\mathrm{GCM})\end{array}$ & Takemura et al., 2000, 2002, 2005 \\
\hline SPRINTARS_clr & $\begin{array}{l}\text { SPRINTARS extraction of clear-sky conditions: the grid } \\
\text { cloud fraction less than } 0.2 \text { at each } \\
\text { model integration step. }\end{array}$ & \\
\hline GISS & $\begin{array}{l}3 \text {-year whole-sky monthly average; resolution: } 5^{\circ} \times 4^{\circ}, 20 \\
\text { vertical layers; coupled with GISS GCM }\end{array}$ & $\begin{array}{l}\text { Koch and Hansen, 2005; Koch et al., } \\
2005^{3} \text {; Miller et al., 2005 }\end{array}$ \\
\hline GISS_clr & Weighted by clear-sky fraction & \\
\hline LMDZ-INCA & $\begin{array}{l}2001 \text { whole-sky monthly average; resolution: } 3.75^{\circ} \times 2.5^{\circ}, 19 \\
\text { vertical layers; nudged with ECMWF winds }\end{array}$ & Schulz et al., $2006^{5}$; Textor et al., 2005 \\
\hline LMDZ-LOA & $\begin{array}{l}2000 \text { and } 2001 \text { whole-sky monthly average; resolution: } \\
3.75^{\circ} \times 2.5^{\circ}, 19 \text { vertical layers; nudged with ECMWF winds }\end{array}$ & $\begin{array}{l}\text { Boucher and Pham, 2002; Reddy et al., } \\
\text { 2004, 2005a, 2005b }\end{array}$ \\
\hline
\end{tabular}

Smith, 2005). In some regions and during specific seasons, such as the northern Pacific Ocean during the spring, yearto-year variations could be significant (Loeb and ManaloSmith, 2005). On the other hand, our analysis in Sect. 3.3 indicates that differences among various approaches are generally much larger than the detected seasonal variations.

The assessments fall into three broad categories: (a) satellite-based, (b) model-based, and (c) satellite-model integrated. They are briefly described below and uncertainties associated with individual methods are summarized in Sect. 3.1.4.

a. Satellited based estimates, including MODIS, MODIS_A, CERES_A, CERES_B, CERES_C, and POLDER.

- MODIS: The MODIS approach is to use the MODIS aerosol retrievals consistently in conjunction with the CLIRAD-SW radiative transfer model (Chou et al., 1992) to calculate TOA fluxes and aerosol direct radiative effects. The MODIS retrieval returns a linked set of AOT, $\omega_{0}$, and phase function that best matches spectral radiances observed at the TOA. Using these three retrieved parameters consistently with CLIRAD-SW results in fluxes that best match the observed radiances, and is preferable to inferring $\omega_{0}$ and phase function from non-MODIS sources that may be inconsistent with the MODIS-retrieved AOD (Remer and Kaufman, 2006). A similar method maintaining consistency between retrieval and flux calculations has also been done using POLDER data (Boucher and Tanré, 2000; Bellouin et al., 2003). Although a correction for cloud contamination is exercised in Remer and Kaufman (2006), we will use their uncorrected DRE values in this study. This simplifies comparisons with other methods in which cloud contamination is not corrected.

- MODIS_A: The MODIS_A approach splits the total MODIS observed AOD over ocean into three components, namely mineral dust, sea salt, and biomass-burning and pollution, with a combination of data from MODIS, TOMS, and the Special Sensor Microwave Imager (SSM-I) (Bellouin et al., 2005). Over land, the anthropogenic fraction of AOD from an ensemble of five global models is used to derive anthropogenic AOD from MODIS observed total AOD. AERONET measurements are used to derive the size distribution and single- 
Table 3. List of products participating in the intercomparison of the aerosol direct effect.

\begin{tabular}{|c|c|c|c|}
\hline Products & Brief Descriptions & Data year & Major References \\
\hline MODIS & $\begin{array}{l}\text { Using Terra-MODIS AOD with a constraint by MODIS mea- } \\
\text { sured radiances }\end{array}$ & 2001-2002 & Remer and Kaufman, 2006 \\
\hline MODIS_A & $\begin{array}{l}\text { Using Terra-MODIS AOD and AERONET measurements of } \\
\text { size distribution and single-scattering albedo }\end{array}$ & 2002 & Bellouin et al., 2005 \\
\hline CERES_A & $\begin{array}{l}\text { Using CERES fluxes in combination with standard MODIS } \\
\text { aerosol }\end{array}$ & 2000-2001 & $\begin{array}{l}\text { Loeb and Manalo-Smith, } \\
\text { 2005; Loeb and Kato, } 2002\end{array}$ \\
\hline CERES_B & $\begin{array}{l}\text { Using CERES fluxes in combination with NOAA NESDIS } \\
\text { aerosol from MODIS radiances }\end{array}$ & & \\
\hline CERES_C & $\begin{array}{l}\text { Using CERES fluxes in combination with MODIS aerosol } \\
\text { with new angular models for aerosols }\end{array}$ & $2000-2001$ & $\begin{array}{l}\text { Zhang et al., 2005a, b; } \\
\text { Christopher and Zhang, 2004 }\end{array}$ \\
\hline MODIS_G & $\begin{array}{l}\text { Using GOCART simulations to fill AOD gaps in satellite re- } \\
\text { trievals }\end{array}$ & 2001 & $\begin{array}{l}\text { *Aerosol single-scattering } \\
\text { albedo and asymmetry factor } \\
\text { are taken from GOCART } \\
\text { simulations; *Yu et al., 2003, } \\
2004\end{array}$ \\
\hline \multicolumn{4}{|l|}{ MISR_G } \\
\hline MO_GO & Integration of MODIS and GOCART AOT & & \\
\hline MO_MI_GO & $\begin{array}{l}\text { Integration of GOCART AOD with retrievals from MODIS } \\
\text { (Ocean) and MISR (Land) }\end{array}$ & & \\
\hline POLDER & $\begin{array}{l}\text { Using POLDER AOD in combination with prescribed aerosol } \\
\text { models }\end{array}$ & 1996-1997 & $\begin{array}{l}\text { Boucher and Tanré, 2000; } \\
\text { Bellouin et al., } 2003\end{array}$ \\
\hline SeaWiFS & Using SeaWiFS AOD and assumed aerosol models & 1997-1998 & Chou et al., 2002 \\
\hline GOCART & $\begin{array}{l}\text { Offline RT calculations using monthly average aerosols with } \\
\text { a time step of } 30 \mathrm{~min} \text { (without the presence of clouds) }\end{array}$ & 2001 & $\begin{array}{l}\text { Chin et al., 2001; Yu et al., } \\
2004\end{array}$ \\
\hline SPRINTARS & Online RT calculations every $3 \mathrm{~h}$ ( setting cloud fraction=0) & 2001 & Takemura et al., 2002, 2005 \\
\hline GISS & Online model simulations and weighted by clear-sky fraction & $\begin{array}{l}\text { 3-year } \\
\text { climatology }\end{array}$ & $\begin{array}{l}\text { Koch and Hansen, 2005; } \\
\text { Koch et al., } 2005^{3} \text {; Schmidt } \\
\text { et al., } 2005\end{array}$ \\
\hline LMDZ-INCA & Online RT calculations every $2 \mathrm{~h}$ (setting cloud fraction $=0$ ) & 2000 & $\begin{array}{l}\text { Balkanski et al., } 2006^{6} \text {; } \\
\text { Balkanski and Schulz, } \\
2006^{7} \text {; Kinne et al., } 2005\end{array}$ \\
\hline LMDZ-LOA & Online RT calculations every $2 \mathrm{~h}$ (setting cloud fraction=0) & 2000-2001 & Reddy et al., 2005a, 2005b \\
\hline
\end{tabular}

scattering albedo for individual components. These parameters are then used to derive the 24-h average direct radiative effect at the TOA and surface of individual components over ocean and only of the anthropogenic component over land (Bellouin et al., 2005). The land surface albedo is taken from MODIS observations. Both AOD and the direct effect are weighted by the MODIS pixel counts and averaged over $1^{\circ} \times 1^{\circ}$ boxes.

- CERES_A, B, C: For the CERES related assessments in this category, the aerosol direct effect is derived using CERES/Terra measured radiances/fluxes along with aerosol and cloud distributions from MODIS/Terra (e.g., Loeb and Manalo-Smith, 2005; Zhang et al., 2005a, b). Because of the coarse spatial resolution of CERES measurements (i.e., $20 \mathrm{~km}$ for CERES/Terra), a direct use of CERES flux measurements would exclude aerosol distributions in partly cloudy CERES scenes. Several approaches have been employed to overcome this limitation (Loeb and ManaloSmith, 2005; Zhang et al., 2005b). Loeb and Manalo-Smith (2005) combine CERES radiances and fluxes with scene information from coincident high spatial and spectral resolution MODIS measurements. Aerosol properties are determined from two sources: (1) directly from the MODIS level 2 daily aerosol retrievals at a resolution of $10 \mathrm{~km}$ (MOD04) (Remer et al., 2005); and (2) by applying the NOAA-NESDIS algorithm (Ignatov and Stowe, 2002) to the MODIS measurements determined to be cloud-free. Correspondingly, the derived aerosol direct effect is denoted here as CERES_A and CERES_B, respectively. In Zhang et al. (2005a, b), aerosol direct effects are derived from $20 \mathrm{~km}$ resolution CERES measurements by using empirical aerosol angular models. The aerosol effect are then scaled by the ratio of the MODIS aver- 
age AOD to the AOD in CERES cloud-free pixels to include the aerosol direct effect at sub-CERES footprint (e.g., CERES_C).

b. Model based estimates, including five model calculations: GOCART (Chin et al., 2001, 2002; Yu et al., 2004), SPRINTARS (Takemura et al., 2002, 2005), GISS (Koch and Hansen, 2005; Koch et al., 2005 ${ }^{3}$ ), LMDZ-INCA (Balkanski et al., 2006 ${ }^{6}$; Balkanski and Schulz, 2006 ${ }^{7}$; Kinne et al., 2005), and LMDZ-LOA (Reddy et al., 2005a, 2005b). For GOCART estimates, radiative transfer calculations driven by monthly average GOCART aerosols are performed every $30 \mathrm{~min}$ with the solar insolation condition of the 15th day of each month. Surface albedos are taken from MODIS observations over land and a look-up table over ocean, following Yu et al. (2004). GISS calculates the instantaneous DRE by assuming clear sky. The instantaneous DRE weighted by clear-sky fraction is summed up during a month, which is then divided by monthly average clear-sky fraction to derive monthly average clearsky DRE. For the other four model-based estimates, radiative transfer models are driven by model-calculated aerosol properties every 2 or $3 \mathrm{~h}$. Clouds are switched off in RT calculations to derive the clear-sky aerosol direct effect. Feedbacks of aerosol radiative effects on meteorology and hence aerosol simulations are not taken into account in these online calculations.

c. Satellite-model integrated estimates, including MODIS_G, MISR_G, MO_GO, MO_MI_GO, and SeaWiFS. This is a hybrid of satellite retrievals and model simulations, in which satellite retrievals of optical depth are used to conduct radiative transfer modeling in conjunction with GOCART simulations of single-scattering albedo and asymmetry factor (MODIS_G, MISR_G, MO_GO, MO_MI_GO) (Yu et al., 2004) or use of prescribed aerosol models (SeaWiFS) (Chou et al., 2002). For MO_GO and MO_MI_GO cases, satellite retrievals of optical depth are also adjusted by GOCART simulations through the use of optimum interpolation (Yu et al., 2003; Matsui et al., 2004). Note that except for SeaWiFS, all estimates in this category differ from GOCART estimates solely because of differences in the aerosol optical depth.

Finally, assessments from AERONET climatology (Sect. 2.2.1) and previous field experiments (Sect. 2.2.3) are also incorporated in appropriate regional comparisons. We compile AERONET measurements of aerosols and their

\footnotetext{
${ }^{6}$ Balkanski Y., Schulz, M., and Boucher, O.: Dust radiative forcing revisited, in preparation, 2006.

${ }^{7}$ Balkanski Y. and Schulz, M.: The aerosol direct radiative effect: Global model integrations of uncertainties on mixing, size and humidity growth, in preparation, 2006.
}

direct effect by averaging them over seasons and in the individual zones defined in Fig. 5. Field experiments were usually conducted in different years and only covered a portion of the individual zones defined in Fig. 5. Because of mesoscale variations of aerosols (Anderson et al., 2003b), aerosol loading during the field experiments may not be representative of the seasonal climatology over a defined zone. Here, we normalize the DRE assessments with the observed aerosol optical depth $\tau$ at $550 \mathrm{~nm}$ and then compare such a normalized DRE or radiative efficiency $E_{\tau}$ $\left(\mathrm{Wm}^{-2} \tau^{-1}\right)$. Note that the aerosol direct effect increases with $\tau$ nonlinearly because of multiple scattering, with the slope depending on latitude, season, and aerosol properties (Zhou et al., 2005). Nevertheless, such scaling or normalization would remove much of the influence of aerosol loading and so allows us to do a more fair intercomparison and see more clearly how the internal optical properties determined by aerosol size distributions and chemical compositions and environmental parameters (e.g., surface albedo) impact the direct radiative effect.

\subsubsection{Uncertainties in estimating the aerosol direct effect}

To facilitate later intercomparisons and discussion, we summarize here major uncertainties and biases associated with the individual approaches.

Despite significant improvements in cloud screening for satellite retrievals, cloud contamination still remains an unsolved common issue for satellite aerosol retrievals. For example, by examining the relationship between AOD and the cirrus reflection at $1.38 \mu \mathrm{m}$ in 13 zones over ocean (as defined in Fig. 5), it is estimated that, on average, residual cirrus causes $0.015 \pm 0.003$ high bias in the MODIS AOD at $550 \mathrm{~nm}$ over the oceans (Kaufman et al., 2005b); further analysis of the correlation of the differences in the MODIS and AERONET simultaneously measured AOD and the cloud fraction measured from MODIS shows that for average cloud conditions the total cloud contamination (including cirrus) of the AOD is about $0.02 \pm 0.005$ (Kaufman et al., 2005b). As such, the cloud contamination seems to overestimate MODIS AOD over ocean by $10-15 \%$. Other sensors may have similar but not well defined cloud contamination. We thus assume that satellite-based estimates of the aerosol direct effect over ocean generally may have been overestimated by $10-15 \%$. In addition, specific methods discussed in Sect. 3.1.3 may have their specific uncertainties and biases.

Uncertainties in the MODIS estimated DRE result primarily from the uncertainties in the MODIS radiance calibration, aerosol retrievals, scaling instantaneous flux to diurnally averaged flux, and parameterizations of radiative transfer modeling. The overall uncertainty for MODIS is estimated to be $11 \%$ for TOA DRE over ocean (Remer and Kaufman, 2006). For MODIS_A, the total aerosol direct effect over ocean is assumed to be a sum of the individual components. Since the compositional direct effects are not additive, this assumption 
may lead to an overestimation of the aerosol direct effect over ocean, especially when one of the components is strongly absorbing. The use of a single AERONET site to characterize a large region may also introduce uncertainties.

Uncertainties associated with CERES-based estimates of DRE over ocean are primarily from those uncertainties in the calibration of CERES radiances, satellite retrieval of aerosol optical depth, cloud screening schemes, ADM that converts radiances to fluxes, and scaling instantaneous fluxes to diurnally average fluxes (Zhang et al., 2005b; Loeb and ManaloSmith, 2005). For CERES_A and CERES_B, the narrow-tobroadband conversion also introduces bias and uncertainty (Loeb and Manalo-Smith, 2005). Zhang et al. (2005b) estimate that the CERES_C DRE has a relative uncertainty of $\sim 30 \%$.

From the perspective model simulations, major sources of uncertainty in the calculated aerosol direct effect include uncertainties in emissions of individual aerosol types and their precursors, parameterizations of a variety of sub-grid aerosol processes (e.g., wet and dry deposition, cloud convection, aqueous-phase oxidation), and assumptions on aerosol size, absorption, mixture, and humidification of particles (Kinne et al., 2005; Schulz et al., 2005 ${ }^{1}$; Textor et al., 2005). As a result, large model diversities have been diagnosed, especially in regional distribution and compositional mixture of aerosols (Kinne et al., 2005). Quantifying these uncertainties has been formidable, because of the lack of observations. Surface albedo schemes in global models have not been fully evaluated, which further complicates the evaluation of aerosol simulations and of the direct effect.

For a hybrid of satellite retrievals and model simulations, uncertainties associated with both satellite retrievals and model simulations should contribute. For MODIS_G, the DRE estimates over land should have been overestimated because of overestimate of MODIS AOD over land (Remer et al., 2005). Overestimates in MISR_G DRE should exist over ocean because of an overall high bias in pre-version 16 MISR AOD (Kahn et al., 2005a; Abdou et al., 2005). The model-satellite integration of AOD (MO_GO, MI_GO, and MO_MI_GO) does improve the agreement with AERONET measurements (e.g., Yu et al., 2003). In all estimates of this category, surface albedo has been observationally constrained (Yu et al., 2004). Such efforts would have constrained the satellite-model integrated DRE to some degree. However, other controlling factors, such as aerosol single scattering albedo and asymmetry factor, rely completely on GOCART simulations in this study. And uncertainties associated with them should propagate to the uncertainties in all satellite-model integrated DRE values, which have not been quantified.

\subsection{Assessments of the global aerosol direct effect} 3.2.1 Global patterns of aerosol optical depth and direct ra-
diative effect

Figure 6 shows global distributions of aerosol optical depth at $550 \mathrm{~nm}$ (left panel) and diurnally averaged clear-sky direct radiative effect at the TOA (right panel) for March-AprilMay (MAM). The MODIS direct solar effect is for 2002 and others for 2001. Satellite retrievals are from the Terra satellite. The direct effect at the surface follows the same pattern as that at the TOA but is significantly larger in magnitude because of aerosol absorption. It appears that different approaches agree on large-scale patterns of aerosol optical depth and the direct effect on solar radiation. In this season, the aerosol impacts in the Northern Hemisphere are much larger than those in the Southern Hemisphere. Dust outbreaks and biomass burning elevate the optical depth to more than 0.3 in large parts of North Africa and the tropical Atlantic. In the tropical Atlantic, TOA cooling as large as $-10 \mathrm{Wm}^{-2}$ extends westward to Central America. In highly polluted eastern China, the optical depth is as high as $0.6-0.8$, resulting from the combined effects of pollution, biomass burning in the south, and dust outbreaks in the north. The impacts from Asia also extend to the North Pacific, with a TOA cooling of more than $-10 \mathrm{Wm}^{-2}$. Other areas with large aerosol impacts include Western Europe, mid-latitude North Atlantic, and much of South Asia and the Indian Ocean. Over the "roaring forties" in the Southern Hemisphere, high winds generate a large amount of seasalt. Such elevation of optical thickness, along with high solar zenith angle and hence large backscattering to space, results in a band of TOA cooling of more than $-4 \mathrm{Wm}^{-2}$. Some differences exist between different approaches. For example, the early post-launch MISR retrieved optical depths over the southern hemisphere oceans are higher than MODIS retrievals and GOCART simulations. Over the "roaring forties", the MODIS derived TOA solar flux perturbations are larger than the estimates from other approaches.

Tables 4 and 5 show seasonal (MAM and JJA) and annual (ANN) averages of optical depth and the direct effect over 13 oceanic and continental regions, respectively. Note that the AOD values in Table 4 (MODIS) are weighted with the number of aerosol retrieval that roughly correspond to the clear-sky fraction. Because aerosol optical depth increases with cloud fraction, these weighted values are smaller than unweighted CERES_A AOD values, especially in the North Pacific. Various assessments differ in magnitude, depending on regions. Generally, model simulations of aerosol optical depth and the direct effect are smaller than satellite measurements. The integration of satellite measurements of aerosol optical depth into model simulations improves the agreement of the model simulated direct effect with measurements. 

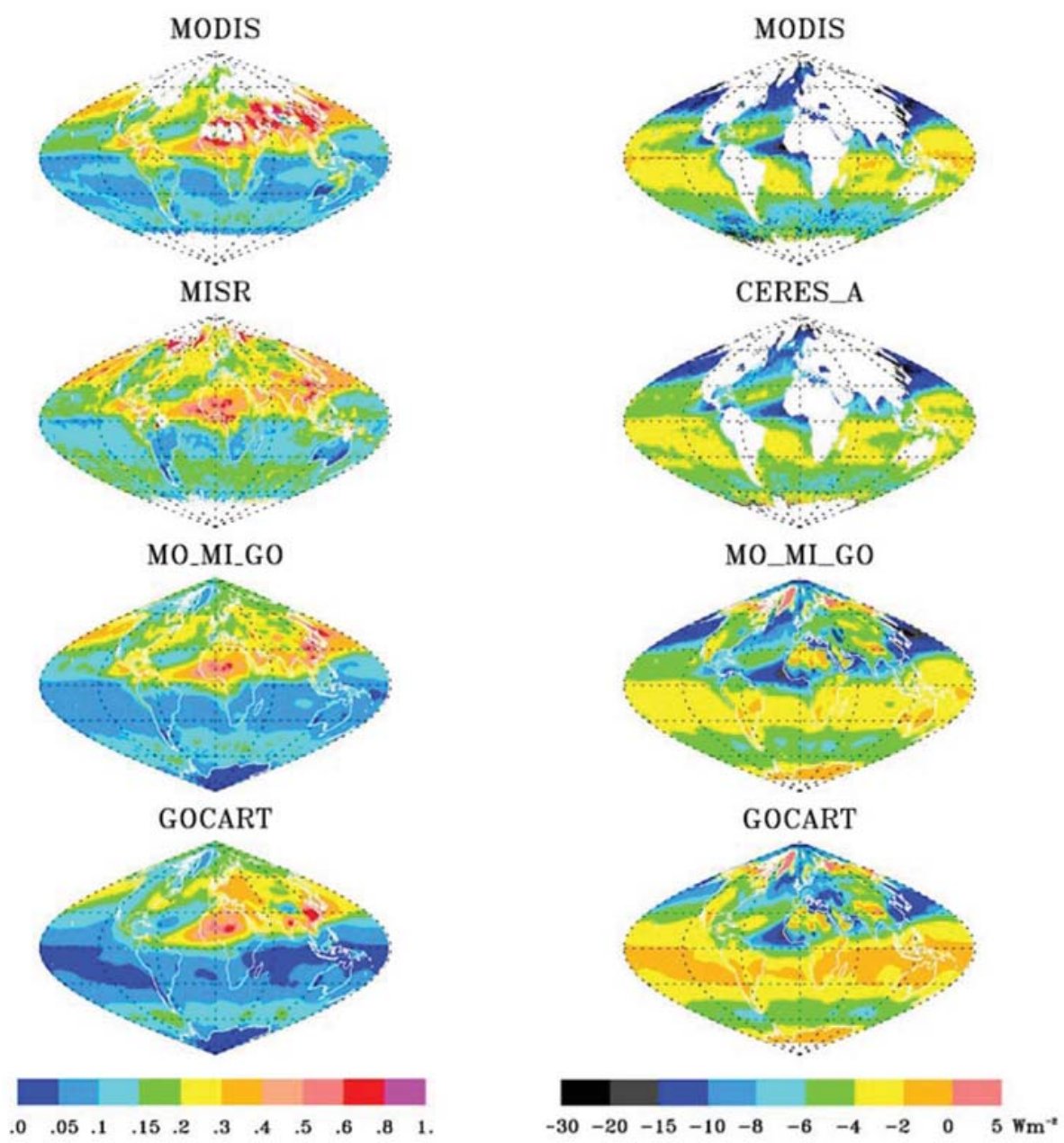

Fig. 6. Geographical patterns of seasonally (MAM) averaged aerosol optical depth at $550 \mathrm{~nm}$ (left panel) and the diurnally averaged clearsky aerosol direct solar effect $\left(\mathrm{Wm}^{-2}\right)$ at the TOA (right panel). The MODIS direct solar effect is for 2002 and others for 2001 . Satellite retrievals are from the Terra satellite.

\subsubsection{Intercomparisons of global average aerosol optical depth}

Tables 6a, b, c show the intercomparison of seasonal and annual aerosol optical depth at $550 \mathrm{~nm}$ averaged over the globe, land, and ocean, respectively (all limited to $60^{\circ} \mathrm{S}-60^{\circ} \mathrm{N}$ for reasons discussed earlier). Here gaps in MODIS retrievals and to a lesser extent in MISR retrievals are filled with the GOCART simulations. The filling process for MODIS introduces biases toward GOCART AOD over deserts and snow-melting regions. Calculations indicate that MODIS over-land AOD is $61 \%$ and $42 \%$ larger than the GOCART simulations without and with the filling gaps. For MISR, the bias is relatively small on global average, as the filling occurs mainly over persistently cloudy regions (e.g., the Amazon basin during the wet season). MODIS and MISR retrievals give a comparable average AOD on the global (land and ocean) scale, with MISR greater than MODIS by $0.01 \sim 0.02$ depending on the season. However, differences between MODIS and MISR are much larger when land and ocean are examined separately. On the one hand, over land seasonal average AODs from MODIS are larger than their MISR counterparts by $0.024 \sim 0.067$, with an annual average of 0.054 (see also Abdou et al., 2005). On the other hand, over ocean MISR AODs are larger than their MODIS counterparts by $0.030 \sim 0.036$. These differences can be reduced by improvement in radiance calibration and in aerosol retrieval algorithms. An improved low-light-level calibration of MISR radiance measurements (MISR aerosol products Version 16 and higher) reduces MISR high bias over ocean by $40 \%$ (Kahn et al., 2005b; Bruegge et al., 2004). An improved land characterization for the MODIS retrieval reduces MODIS high bias over land by about $30 \%$ (ongoing work by Lorraine Remer and MODIS team). As discussed earlier, satellite aerosol retrievals can be contaminated by thin cirrus and clouds in general, resulting in an overestimate of aerosol optical depth of about $0.02 \pm 0.005$ (Kaufman et al., 
Table 4. Seasonal (MAM and JJA) and annual averages of aerosol optical depth (upper line) and the clear-sky TOA direct radiative effect $\left(\mathrm{Wm}^{-2}\right.$, bottom line) over ocean in13 zones (light blue background - land is not included). The global averages are listed in the blue boxes in the bottom-right corners.

\begin{tabular}{|c|c|c|c|c|c|c|c|c|c|c|c|}
\hline \multicolumn{12}{|c|}{ MODIS } \\
\hline MAM & JJA & $\overline{\text { ANN }}$ & MAM & JIJA & $\overline{\text { ANN }}$ & MAM & JJA & $\overline{\text { ANN }}$ & MAM & JJA & ANN \\
\hline 0.18 & 0.14 & 0.14 & 0.18 & 0.17 & 0.15 & 0.22 & 0.20 & 0.19 & 0.28 & 0.24 & 0.21 \\
\hline-9.5 & -7.3 & -7.1 & -9.0 & -8.4 & -7.4 & -11.8 & -11.1 & -9.9 & -14.7 & -12.7 & -11.0 \\
\hline 0.14 & 0.10 & 0.11 & 0.21 & 0.25 & 0.20 & 0.25 & 0.43 & 0.29 & 0.16 & 0.11 & 0.13 \\
\hline-4.3 & -2.9 & -3.5 & -7.0 & -8.4 & -7.0 & -8.8 & -17.5 & -11.4 & -5.2 & -3.2 & -4.5 \\
\hline \multirow{5}{*}{$\begin{array}{c}0.08 \\
-3.0\end{array}$} & 0.09 & 0.09 & 0.11 & 0.12 & 0.12 & 0.11 & 0.14 & 0.13 & 0.09 & 0.11 & 0.11 \\
\hline & -3.7 & -2.9 & -4.1 & -5.4 & -4.7 & -4.2 & -6.6 & -4.9 & -3.6 & -4.9 & -4.2 \\
\hline & & & & MAM & JJA & ANN & & Global & Averag & & \\
\hline & & & & 0.10 & 0.09 & 0.11 & & GIUDA & 0.13 & 0.13 & 0.13 \\
\hline & & & & -5.3 & -4.8 & -6.2 & & & -5.8 & -6.0 & -5.9 \\
\hline \multicolumn{12}{|c|}{ CERES_A } \\
\hline MAM & JJA & ANN & MAM & JJA & ANN & MAM & JJA & ANN & MAM & JJA & ANN \\
\hline 0.29 & 0.20 & 0.19 & 0.21 & 0.19 & 0.17 & 0.26 & 0.24 & 0.21 & 0.46 & 0.36 & 0.30 \\
\hline-10.8 & -7.3 & -6.9 & -8.3 & -7.1 & -6.4 & -9.5 & -9.0 & -7.7 & -15.9 & -12.1 & -10.3 \\
\hline 0.17 & 0.12 & 0.13 & 0.24 & 0.26 & 0.23 & 0.27 & 0.46 & 0.30 & 0.18 & 0.13 & 0.15 \\
\hline-5.1 & -4.1 & -4.3 & -7.1 & -8.2 & -7.1 & -7.9 & -13.3 & -8.9 & -5.2 & -3.9 & -4.6 \\
\hline 0.09 & 0.10 & 0.10 & 0.11 & 0.12 & 0.13 & 0.11 & 0.16 & 0.14 & $0.10^{\circ}$ & 0.12 & 0.12 \\
\hline \multirow[t]{4}{*}{-3.4} & -3.5 & -3.6 & -4.0 & -4.5 & -4.7 & -3.9 & -5.6 & -4.9 & -3.7 & -4.3 & -4.2 \\
\hline & & & & MAM & JJA & ANN & & Giob: & Áveras & & \\
\hline & & & & 0.11 & 0.10 & 0.14 & & & 0.19 & 0.19 & 0.17 \\
\hline & & & & -4.7 & -3.4 & -5.6 & & & -6.1 & -5.4 & - $-5.5 \vdots$ \\
\hline \multicolumn{12}{|c|}{ GOCART } \\
\hline MAM & $\overline{\mathrm{JJA}}$ & ANN & $\overline{\text { MAM }}$ & $\overline{J J A}$ & ANN & MAM & JJA & $\overline{\text { ANN }}$ & MAM & JJA & ANN \\
\hline 0.18 & 0.11 & 0.15 & 0.18 & 0.16 & 0.16 & 0.33 & 0.30 & 0.27 & 0.30 & 0.20 & 0.22 \\
\hline-7.0 & -4.6 & -5.6 & -6.7 & -6.8 & -5.9 & -8.5 & -7.2 & -6.4 & -10.3 & -8.1 & -7.8 \\
\hline 0.09 & 0.09 & 0.08 & 0.18 & 0.26 & 0.20 & 0.17 & 0.22 & 0.16 & 0.11 & 0.08 & 0.09 \\
\hline-3.1 & -3.4 & -3.0 & -6.4 & -10.4 & -7.4 & -5.1 & -6.9 & -5.0 & -3.7 & -3.5 & -3.4 \\
\hline 0.05 & 0.06 & 0.05 & 0.07 & 0.10 & 0.09 & 0.05 & 0.12 & 0.08 & 0.05 & 0.07 & 0.06 \\
\hline \multirow[t]{4}{*}{-1.8} & -2.3 & -1.9 & -2.6 & -3.5 & -3.0 & -1.9 & -3.6 & -2.6 & -1.7 & -2.3 & -2.0 \\
\hline & & & & MAM & JIA & ANN & & Globa & Averaq & & \\
\hline & & & & 0.10 & 0.13 & 0.11 & & & 0.11 & 0.13 & $0.11:$ \\
\hline & & & & -4.0 & -4.4 & -4.4 & & & -4.0 & -4.7 & ..4.1 \\
\hline
\end{tabular}

2005b). Note that the MODIS oceanic annual average of 0.15 in the table is larger than the 0.13 derived from $1^{\circ} \times 1^{\circ}$ grid data, weighted by the number of retrievals within the $1^{\circ}$ grid square (i.e., Table 4). The latter weighted value already has reduced cloud contamination (Remer and Kaufman, 2006).

Under whole-sky conditions, the annual and global average AOD from five models is $0.191 \pm 0.017$ (mean \pm standard deviation) over land and $0.126 \pm 0.046$ over ocean, respectively. On a seasonal basis, the standard deviation accounts for $9-13 \%$ and $32-40 \%$ of the corresponding mean AOD over land and ocean, respectively. Over land, no model gives consistently high or low AOD values and differences between models depend on season. Over ocean, GISS derives the largest AODs. In general, GOCART and LMDZ-INCA give comparable AOD values that are larger than LMDZ-LOA and SPRINTARS simulations. Clearly, the model-based mean AOD is smaller than the MISR retrieval over land by 0.034 (or 15\%) and the MODIS retrieval over ocean by 0.028 (or 18\%), respectively. These differences could be attributed partially to cloud contamination in satellite retrievals, as discussed in Sect. 3.1.4. The satellite and model integrations are generally inbetween the satellite retrievals and the model simulations.

A separation of clear-sky and whole-sky aerosol optical depth in SPRINTARS and GISS allows us to examine cloud impacts on aerosol optical thickness. Clouds can increase aerosol optical depth through water vapor uptake in the humid regions adjacent to clouds. If in-cloud aqueous sulfate production in a cloud-rich airmass occurs, then this air mass contains at a later moment more sulfate aerosol, which is cor- 
Table 5. Seasonal (MAM and JJA) and annual averages of aerosol optical depth (upper line) and the clear-sky TOA direct radiative effect ( $\mathrm{Wm}^{-2}$, bottom line) over land in 13 zones (light blue background - only land is included). The global averages are listed in the blue boxes in the bottom-right corners.

MISR_G

\begin{tabular}{|c|c|c|c|c|c|c|c|c|c|c|c|}
\hline $\begin{array}{c}\text { MAM } \\
0.18 \\
-5.7\end{array}$ & $\begin{array}{c}\text { JJA } \\
0.15 \\
-5.7\end{array}$ & $\begin{array}{c}\text { ANN } \\
0.14 \\
-4.2\end{array}$ & \begin{tabular}{|c} 
MAM \\
0.22 \\
-7.0
\end{tabular} & $\begin{array}{c}\text { JJA } \\
0.22 \\
-8.7\end{array}$ & $\begin{array}{c}\text { ANN } \\
0.17 \\
-5.8\end{array}$ & \begin{tabular}{|c} 
MAM \\
0.25 \\
-5.3
\end{tabular} & $\begin{array}{c}\text { JJA } \\
0.24 \\
-5.8\end{array}$ & $\begin{array}{c}\text { ANN } \\
0.21 \\
-4.4\end{array}$ & \begin{tabular}{|c|} 
MAM \\
0.31 \\
-5.4
\end{tabular} & $\begin{array}{c}\mathrm{JJA} \\
0.24 \\
-6.4\end{array}$ & $\begin{array}{c}\text { ANN } \\
0.22 \\
-4.4\end{array}$ \\
\hline $\begin{array}{r}0.20 \\
-57\end{array}$ & $\begin{array}{r}0.19 \\
-7\end{array}$ & $\begin{array}{r}0.15 \\
-5\end{array}$ & 0.35 & 0.43 & $\begin{array}{r}0.32 \\
-6.9\end{array}$ & $\begin{array}{c}0.37 \\
-6.4\end{array}$ & $\begin{array}{r}0.45 \\
-7\end{array}$ & $\begin{array}{c}0.33 \\
-56\end{array}$ & 0.37 & $\begin{array}{r}0.32 \\
-94\end{array}$ & $\begin{array}{c}0.31 \\
-7 ?\end{array}$ \\
\hline & & & \begin{tabular}{|c}
0.13 \\
-3.9
\end{tabular} & $\begin{array}{c}0.10 \\
-3.0\end{array}$ & $\begin{array}{c}0.17 \\
-4.3\end{array}$ & \begin{tabular}{|c}
0.14 \\
-4.1
\end{tabular} & $\begin{array}{c}0.24 \\
-4.6\end{array}$ & $\begin{array}{c}0.23 \\
-5.1\end{array}$ & \begin{tabular}{|c}
0.11 \\
-3.3
\end{tabular} & $\begin{array}{c}0.10 \\
-3.1\end{array}$ & $\begin{array}{c}0.14 \\
-3.8\end{array}$ \\
\hline & & & & $\begin{array}{c}\text { MAM } \\
0.06 \\
-4.1\end{array}$ & $\begin{array}{c}\text { JJA } \\
0.07 \\
-3.0\end{array}$ & $\begin{array}{c}\text { ANN } \\
0.09 \\
-5.8\end{array}$ & & Global & $\begin{array}{c}\text { Avera } \\
0.25 \\
-5.1\end{array}$ & $\begin{array}{r}0.25 \\
-5.8\end{array}$ & $\begin{array}{r}0.23 \\
-4.9\end{array}$ \\
\hline
\end{tabular}

MO_MI_GO

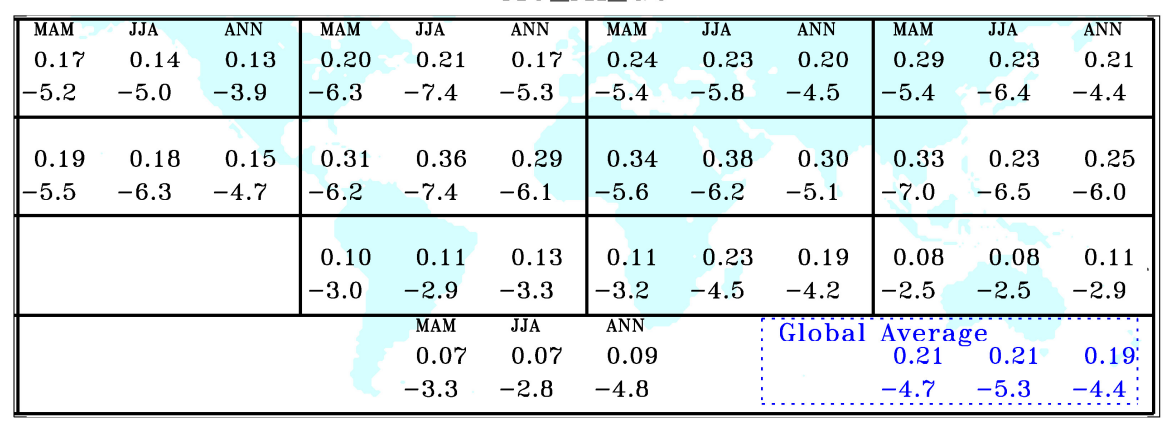

GOCART

\begin{tabular}{|c|c|c|c|c|c|c|c|c|c|c|c|}
\hline $\begin{array}{c}\text { MAM } \\
0.14 \\
-4.3\end{array}$ & $\begin{array}{c}\text { JJA } \\
0.11 \\
-4.0\end{array}$ & $\begin{array}{c}\text { ANN } \\
0.11 \\
-3.6\end{array}$ & $\begin{array}{c}\text { MAM } \\
0.19 \\
-5.8\end{array}$ & $\begin{array}{c}\text { JJA } \\
0.19 \\
-5.9\end{array}$ & $\begin{array}{c}\text { ANN } \\
0.17 \\
-4.9\end{array}$ & $\begin{array}{c}\text { MAM } \\
0.30 \\
-7.0\end{array}$ & $\begin{array}{c}\text { JJA } \\
0.25 \\
-6.3\end{array}$ & $\begin{array}{c}\text { ANN } \\
0.23 \\
-5.3\end{array}$ & $\begin{array}{c}\text { MAM } \\
0.28 \\
-5.1\end{array}$ & $\begin{array}{c}\text { JJA } \\
0.23 \\
-5.8\end{array}$ & $\begin{array}{c}\text { ANN } \\
0.22 \\
-4.4\end{array}$ \\
\hline $\begin{array}{c}0.15 \\
-3.3\end{array}$ & $\begin{array}{c}0.13 \\
-4.5\end{array}$ & $\begin{array}{c}0.11 \\
-3.2\end{array}$ & $\begin{array}{c}0.29 \\
-5.1\end{array}$ & $\begin{array}{c}0.34 \\
-6.6\end{array}$ & $\begin{array}{c}0.28 \\
-5.5\end{array}$ & $\begin{array}{c}0.33 \\
-4.7\end{array}$ & $\begin{array}{c}0.34 \\
-4.9\end{array}$ & $\begin{array}{c}0.28 \\
-4.3\end{array}$ & $\begin{array}{c}0.34 \\
-6.6\end{array}$ & $\begin{array}{c}0.18 \\
-5.0\end{array}$ & $\begin{array}{c}0.25 \\
-5.6\end{array}$ \\
\hline & & & $\begin{array}{c}0.08 \\
-2.3\end{array}$ & $\begin{array}{c}0.15 \\
-3.1\end{array}$ & $\begin{array}{c}0.12 \\
-2.6\end{array}$ & $\begin{array}{c}0.07 \\
-2.0\end{array}$ & $\begin{array}{c}0.26 \\
-4.2\end{array}$ & $\begin{array}{c}0.17 \\
-3.0\end{array}$ & $\begin{array}{c}0.06 \\
-1.6\end{array}$ & $\begin{array}{c}0.06 \\
-1.7\end{array}$ & $\begin{array}{r}0.07 \\
-1.7\end{array}$ \\
\hline & & & & $\begin{array}{c}\text { MAM } \\
0.07 \\
-3.6 \\
\end{array}$ & $\begin{array}{c}\text { JJA } \\
0.08 \\
-3.1 \\
\end{array}$ & $\begin{array}{c}\text { ANN } \\
0.08 \\
-4.0 \\
\end{array}$ & & Global & $\begin{array}{c}\text { Avera } \\
0.22 \\
-4.4 \\
. .4\end{array}$ & $\begin{array}{c}0.22 \\
-4.8\end{array}$ & $\begin{array}{r}0.20 \\
-4.1 \\
\end{array}$ \\
\hline
\end{tabular}

related with cloud occurrence as long as the airmass does not change its equilibrium values of humidity and temperature profiles. Stronger upward transport associated with lowpressure systems and cloudy skies may also increase aerosol lifetime. On the other hand, clouds remove aerosols from the atmosphere through scavenging and rainout. Meteorological conditions (e.g., relative humidity, wind speed) would be different in clear- and cloudy skies, resulting in different hygroscopic growth and mechanical generation of aerosols (dusts, sea-salt). The net effects of cloud on aerosol optical depth should depend on aerosol types. For SPRINTARS simulations, the clear-sky aerosol optical depth is smaller than the all-sky values by $14-17 \%$ on global average, with the difference somewhat larger over land than over ocean. The largest differences occur over regions dominated by sulfate (e.g., East U.S., West Europe, and East Asia) and over the "roaring forties" belt dominated by sea-salt aerosols. Such differences may suggest the importance of sulfate production through cloud processes and the hygroscopic growth of particles. Differences in wind speed would also contribute to different amounts of sea-salt production. Because different models parameterize aerosol processes differently and use or simulate different meteorological fields, cloud effects on optical depth are model-dependent. For example, the GISS clear-sky AOD is $42-53 \%$ smaller than the all-sky value on global average, with much larger differences over ocean than over land. 
Table 6a. Seasonal and annual average aerosol optical depths over land and ocean $\left(60^{\circ} \mathrm{S}-60^{\circ} \mathrm{N}\right)$. Satellite retrievals are from Terra.

\begin{tabular}{llllll}
\hline Products & DJF & MAM & JJA & SON & ANN \\
\hline MODIS & 0.170 & 0.200 & 0.200 & 0.181 & 0.188 \\
MISR & 0.188 & 0.209 & 0.212 & 0.189 & 0.199 \\
MO_GO & 0.144 & 0.174 & 0.172 & 0.157 & 0.162 \\
MI_GO & 0.130 & 0.155 & 0.161 & 0.141 & 0.147 \\
MO_MI_GO & 0.138 & 0.162 & 0.161 & 0.145 & 0.151 \\
GOCART & 0.111 & 0.141 & 0.152 & 0.132 & 0.134 \\
SPRINTARS & 0.104 & 0.110 & 0.148 & 0.117 & 0.120 \\
GISS & 0.169 & 0.208 & 0.226 & 0.197 & 0.200 \\
LMDZ-INCA & 0.113 & 0.140 & 0.174 & 0.130 & 0.139 \\
LMDZ-LOA & 0.113 & 0.123 & 0.154 & 0.125 & 0.129 \\
SPRINTARS_clr & 0.087 & 0.093 & 0.127 & 0.097 & 0.101 \\
GISS_clr & 0.079 & 0.113 & 0.131 & 0.102 & 0.106 \\
\hline
\end{tabular}

Table 6b. Seasonal and annual average aerosol optical depths over land $\left(60^{\circ} \mathrm{S}-60^{\circ} \mathrm{N}\right)$. Satellite retrievals are from Terra.

\begin{tabular}{llllll}
\hline Products & DJF & MAM & JJA & SON & ANN \\
\hline MODIS & 0.223 & 0.308 & 0.319 & 0.267 & 0.279 \\
MISR & 0.199 & 0.245 & 0.254 & 0.200 & 0.225 \\
MO_GO & 0.175 & 0.253 & 0.257 & 0.218 & 0.226 \\
MI_GO & 0.154 & 0.207 & 0.212 & 0.170 & 0.186 \\
MO_MI_GO & 0.155 & 0.209 & 0.214 & 0.172 & 0.188 \\
GOCART & 0.146 & 0.218 & 0.222 & 0.197 & 0.196 \\
SPRINTARS & 0.133 & 0.155 & 0.217 & 0.173 & 0.170 \\
GISS & 0.112 & 0.204 & 0.235 & 0.159 & 0.178 \\
LMDZ-INCA & 0.136 & 0.201 & 0.290 & 0.192 & 0.205 \\
LMDZ-LOA & 0.157 & 0.201 & 0.272 & 0.202 & 0.208 \\
SPRINTARS_clr & 0.099 & 0.127 & 0.191 & 0.138 & 0.139 \\
GISS_clr & 0.075 & 0.160 & 0.191 & 0.119 & 0.138 \\
\hline
\end{tabular}

3.2.3 Assessments of global and seasonal average aerosol direct effect

\section{Over ocean}

Table 7 summarizes estimates of the clear-sky aerosol direct radiative effect over oceans from $60^{\circ} \mathrm{S}$ to $60^{\circ} \mathrm{N}$ on a seasonal basis. For the aerosol direct effect at the TOA, 8 of 11 measurement-based and satellite-model integration-based estimates agree with each other within about $10 \%$, giving the annual average DRE at the TOA of $-5 \sim-6 \mathrm{Wm}^{-2}$. By comparisons, the CERES_B estimate is 25-33\% smaller (less negative), whereas MODIS_A and MISR_G estimates are $8-30 \%$ larger (more negative). Given that CERES_B and CERES_A have used the same flux and radiance measurements but with different algorithms for clear pixel identification and aerosol retrieval, their DRE difference emphasizes a need for more effort on clear-sky identification
Table 6c. Seasonal and annual average aerosol optical depths over ocean $\left(60^{\circ} \mathrm{S}-60^{\circ} \mathrm{N}\right)$. Satellite retrievals are from Terra.

\begin{tabular}{llllll}
\hline Products & DJF & MAM & JJA & SON & ANN \\
\hline MODIS & 0.150 & 0.160 & 0.156 & 0.150 & 0.154 \\
MISR & 0.184 & 0.196 & 0.196 & 0.185 & 0.190 \\
MO_GO & 0.132 & 0.145 & 0.142 & 0.135 & 0.138 \\
MI_GO & 0.122 & 0.136 & 0.142 & 0.130 & 0.132 \\
MO_MI_GO & 0.132 & 0.144 & 0.141 & 0.134 & 0.138 \\
GOCART & 0.098 & 0.113 & 0.126 & 0.108 & 0.111 \\
SPRINTARS & 0.093 & 0.092 & 0.121 & 0.095 & 0.100 \\
GISS & 0.189 & 0.209 & 0.222 & 0.211 & 0.208 \\
LMDZ-INCA & 0.107 & 0.117 & 0.128 & 0.106 & 0.114 \\
LMDZ-LOA & 0.097 & 0.095 & 0.111 & 0.096 & 0.099 \\
SPRINTARS_clr & 0.082 & 0.080 & 0.102 & 0.081 & 0.086 \\
GISS_clr & 0.080 & 0.096 & 0.110 & 0.096 & 0.095 \\
\hline
\end{tabular}

and improvement of aerosol retrieval algorithms and Angular Dependence Models (ADMs) (Loeb and Manalo-Smith, 2005; Zhang et al., 2005a, b). The large MODIS_A estimate may result from adding the DRE of individual components to derive the total DRE, because the aerosol direct effect is not additive and a simple summation would introduce a high bias of up to $50 \%$ in some regions, depending on aerosol absorption (Bellouin et al., 2005). The high bias in the MISR_G estimate should result from an overall overestimate of $20 \%$ in early post-launch MISR optical depth retrievals (Kahn et al., 2005). Seasonal variations derived from these approaches are generally small, with a ratio of the largest to the smallest TOA cooling no more than 1.2. On annual average, the median and standard error $\varepsilon\left(\varepsilon=\sigma /(n-1)^{1 / 2}\right.$, where $\sigma$ is standard deviation and $n$ is the number of methods) of these TOA DRE estimates are $-5.5 \mathrm{Wm}^{-2}$ and $0.21 \mathrm{Wm}^{-2}$, respectively. While the reported standard deviation or standard error in this paper is not a fully rigorous measure of a true experimental uncertainty, it is indicative of the uncertainty because independent approaches with independent sources of errors are used.

Seven measurement-based estimates give the DRE at the surface of $-8.8 \pm 0.67 \mathrm{Wm}^{-2}$ (median $\pm \varepsilon$ ) on an annual basis. This suggests that the ocean surface cooling is about $60 \%$ larger than the cooling at the TOA. Note that the SeaWiFS estimates (Chou et al., 2002) of sea surface cooling are much smaller than other measurement-based estimates, possibly resulting from biases/uncertainties in its assumed aerosol models. We notice that Chou et al. (2002) assume a spectrally independent SSA of 0.9955 for maritime aerosols, 0.9 for $\tau>0.3$ (representing dust and smoke), and a linear interpolation in between. Such oversimplification has perhaps underestimated the aerosol absorption over ocean. The notion is somewhat corroborated by comparisons with available measurement-based calculations. For example, Chou et al. (2002) derive the surface to TOA DRE ratio of 2.5 
Table 7. Summary of seasonal and annual average clear-sky DRE $\left(\mathrm{Wm}^{-2}\right)$ at the TOA and the surface (SFC) over global ocean derived with different methods and data: MODIS (Remer and Kaufman, 2006), MODIS_A (Bellouin et al., 2005), POLDER (Boucher and Tanré, 2000; Bellouin et al., 2003), CERES_A and CERES_B (Loeb and Manalo-Smith, 2005), CERES_C (Zhang et al., 2005b; Christopher and Zhang, 2004), MODIS_G, MISR_G, MO_GO, MO_MI_GO (Yu et al., 2003; 2004), SeaWiFS (Chou et al., 2002), GOCART (Chin et al., 2001, 2002; Yu et al., 2004), SPRINTARS (Takemura et al., 2002), GISS (Koch and Hansen, 2005; Koch et al., 2005 ${ }^{3}$ ), LMDZ-INCA (Balkanski et al., 2006 ${ }^{6}$; Balkanski and Schulz, 2006 ${ }^{7}$; Kinne et al., 2005), LMDZ-LOA (Reddy et al., 2005a, b). Mean, median, standard deviation ( $\sigma$ ), and standard error $(\varepsilon)$ are calculated for observations (Obs) and model simulations (Mod) separately. The last row is the ratio of model median to observational median.

\begin{tabular}{|c|c|c|c|c|c|c|c|c|c|c|}
\hline \multirow{2}{*}{ Products } & \multicolumn{2}{|c|}{ DJF } & \multicolumn{2}{|c|}{ MAM } & \multicolumn{2}{|c|}{ JJA } & \multicolumn{2}{|c|}{ SON } & \multicolumn{2}{|c|}{ ANN } \\
\hline & TOA & SFC & TOA & SFC & TOA & SFC & TOA & SFC & TOA & SFC \\
\hline MODIS & -5.9 & - & -5.8 & - & -6.0 & - & -5.8 & - & -5.9 & - \\
\hline MODIS_A & -6.0 & -8.2 & -6.4 & -8.9 & -6.5 & -9.3 & -6.4 & -8.9 & -6.4 & -8.9 \\
\hline CERES_A & -5.2 & - & -6.1 & - & -5.4 & - & -5.1 & - & -5.5 & - \\
\hline CERES_B & -3.8 & - & -4.3 & - & -3.5 & - & -3.6 & - & -3.8 & - \\
\hline CERES_C & -5.3 & - & -5.4 & - & -5.2 & - & - & - & -5.3 & - \\
\hline MODIS_G & -5.5 & -9.1 & -5.7 & -10.4 & -6.0 & -10.6 & -5.5 & -9.8 & -5.7 & -10.0 \\
\hline MISR_G & -6.4 & -10.3 & -6.5 & -11.4 & -7.0 & -11.9 & -6.3 & -10.9 & -6.5 & -11.1 \\
\hline MO_GO & -4.9 & -7.8 & -5.1 & -9.3 & -5.4 & -9.4 & -5.0 & -8.7 & -5.1 & -8.8 \\
\hline MO_MI_GO & -4.9 & -7.9 & -5.1 & -9.2 & -5.5 & -9.5 & -5.0 & -8.6 & -5.1 & -8.7 \\
\hline POLDER & -5.7 & - & -5.7 & - & -5.8 & - & -5.6 & - & $\begin{array}{r}-5.7 \\
-5.2 *\end{array}$ & $-7.7^{*}$ \\
\hline SeaWiFS & -6.0 & -6.6 & -5.2 & -5.8 & -4.9 & -5.6 & -5.3 & -5.7 & -5.4 & -5.9 \\
\hline Obs. Mean & -5.4 & -8.3 & -5.6 & -9.2 & -5.6 & -9.4 & -5.4 & -8.8 & -5.5 & -8.7 \\
\hline Obs. Median & -5.5 & -8.1 & -5.7 & -9.3 & -5.5 & -9.5 & -5.4 & -8.8 & -5.5 & -8.8 \\
\hline Obs. $\sigma$ & 0.72 & 1.26 & 0.64 & 1.89 & 0.91 & 2.10 & 0.79 & 1.74 & 0.70 & 1.65 \\
\hline Obs. $\varepsilon$ & 0.23 & 0.56 & 0.20 & 0.85 & 0.29 & 0.94 & 0.26 & 0.78 & 0.21 & 0.67 \\
\hline GOCART & -3.6 & -5.7 & -4.0 & -7.2 & -4.7 & -8.0 & -4.0 & -6.8 & -4.1 & -6.9 \\
\hline SPRINTARS & -1.5 & -2.5 & -1.5 & -2.5 & -1.9 & -3.3 & -1.5 & -2.5 & -1.6 & -2.7 \\
\hline GISS & -3.3 & -4.1 & -3.5 & -4.6 & -3.5 & -4.9 & -3.8 & -5.4 & -3.5 & -4.8 \\
\hline LMDZ-INCA & -4.6 & -5.6 & -4.7 & -5.9 & -5.0 & -6.3 & -4.8 & -5.5 & -4.7 & -5.8 \\
\hline LMDZ-LOA & -2.2 & -4.1 & -2.2 & -3.7 & -2.5 & -4.4 & -2.2 & -4.1 & -2.3 & -4.1 \\
\hline Mod. Mean & -3.0 & -4.4 & -3.2 & -4.8 & -3.5 & -5.4 & -3.3 & -4.9 & -3.2 & -4.9 \\
\hline Mod. Median & -3.3 & -4.1 & -3.5 & -4.6 & -3.5 & -4.9 & -3.8 & -5.4 & -3.5 & -4.8 \\
\hline Mod. $\sigma$ & 1.21 & 1.32 & 1.31 & 1.84 & 1.35 & 1.82 & 1.36 & 1.63 & 1.28 & 1.6 \\
\hline Mod. $\varepsilon$ & 0.61 & 0.66 & 0.66 & 0.92 & 0.67 & 0.91 & 0.68 & 0.81 & 0.64 & 0.80 \\
\hline Mod./Obs. & 0.60 & 0.51 & 0.61 & 0.50 & 0.64 & 0.52 & 0.70 & 0.61 & 0.64 & 0.55 \\
\hline
\end{tabular}

*Bellouin et al. (2003) use AERONET retrieval of aerosol absorption as a constraint to the method in Boucher and Tanré (2000), deriving aerosol direct effects both at the TOA and the surface.

in Southeast Asia due to the 1997 Indonesian fires, which is smaller than the value of 3.3 reported by Podgorny et al. (2003) on the basis of radiometric observations of aerosol single-scattering albedo in the region (e.g., Nakajima et al., 1999; von Hoyningen-Huene et al., 1999).

Model simulations give wide ranges of DRE estimates at both the TOA and surface. In particular, the SPRINTARS estimated DRE values at both the TOA and surface differ substantially from other models. Possible reasons for such large discrepancies include smaller optical thickness, stronger absorption, and potential uncertainties in other optical parameters of SPRINTARS simulations (Yu et al., 2004). Estimates from GOCART and LMDZ-INCA are generally 30-60\% larger than those from LMDZ-LOA and GISS. The ensemble of five models gives the annual average DRE $($ median $\pm \varepsilon)$ of $-3.5 \pm 0.64 \mathrm{Wm}^{-2}$ and $-4.8 \pm 0.8 \mathrm{Wm}^{-2}$ at the TOA and surface, respectively. On average, the surface cooling is about 37\% larger than the TOA cooling, smaller than the measurement-based estimate of surface and TOA difference of $60 \%$. Large DRE differences between models result from a combination of differences in parameterizations of various aerosol processes, which are being documented under the AEROCOM framework (Kinne et al., 2005; Textor et al., 2005).

The model-based ensemble estimates of DRE are 30$50 \%$ smaller than the measurement-based estimates. As discussed earlier, MODIS retrieved optical depths tend to be overestimated by about $10-15 \%$ due to the contamination of thin cirrus and clouds in general (Kaufman et al., 2005b). Such overestimation of optical depth would result 
in a comparable overestimate of the aerosol direct radiative effect. Other satellite AOD data may have similar contamination, which however has not yet been quantified. Note also that the cloud contamination in the MODIS value probably already has been reduced by the weighting with the number of aerosol retrievals (Remer and Kaufman, 2006). For simplicity, we assume a cloud contamination of 10-15\% in the measurement-based average DRE. With this correction of cloud contamination, the discrepancy between the measurement-based and model-based estimates of DRE and radiative efficiency would be reduced to $15-40 \%$.

From the perspective of model simulations, uncertainties associated with a number of factors as discussed in Sect. 3.1.4 will contribute to the measurement-model discrepancy. Factors determining the AOD should be major reasons for the DRE discrepancy and the constraint of model AOD with satellite AOD through a data assimilation approach can reduce the DRE discrepancy significantly. Other factors should also contribute, because of the existence of a large discrepancy in the radiative efficiency (i.e., DRE normalized by aerosol optical depth). As an example, we test the sensitivities of surface albedo and RH to the radiative efficiency with the GOCART aerosol fields. In the "surface albedo" test, we replace the monthly average surface albedo from the Goddard Earth Observing System Data Assimilation System v.3 (GEOS-3) with that from Jin et al. (2004) in which the dependence on solar zenith angle and wavelength is accounted for. This increases the radiative efficiency at the TOA by $15 \%$ over global ocean. In the "RH" test, we use aerosol single-scattering albedo and asymmetry factor at low-humidity $(\mathrm{RH}=40 \%)$ to replace the ambient $\mathrm{RH}$ values. This is because it is difficult to extract clear-sky aerosol that is consistent with satellite remote sensing from the global models due to their coarse spatial resolutions; using optical parameters at $40 \% \mathrm{RH}$ would be closer to the conditions in satellite retrievals since the atmosphere is drier for clear sky than for cloudy sky. This test shows that in general, the single-scattering albedo and asymmetry factor become smaller at low-humidity than at high-humidity, which further increases the TOA radiative efficiency by $9 \%$. The above sensitivity tests show that the model-satellite discrepancy can be significantly reduced after better characterizing surface albedo and using low-humidity aerosol properties. Because of the large diversity between global models (Kinne et al., 2005), however, a decisive conclusion can only be drawn after examining the above and other factors for all models. Significant endeavor is demanded in the future to conduct comprehensive assessments.

\section{Over land}

Currently, satellite measurements alone are not adequate to characterize complex aerosol properties and hence can not derive the aerosol direct effect over land with good accuracy. As such DRE estimates over land rely on model simulations and satellite-model integrations, as listed in Table 8. On a global and annual average, the satellite-model integrated approaches derive a median DRE of $-4.9 \mathrm{Wm}^{-2}$ at the TOA and $-11.7 \mathrm{Wm}^{-2}$ at the surface respectively. The surface cooling is about 2.4 times larger than the TOA cooling because of aerosol absorption. Note that the standard errors in the table are not statistically meaningful, because these satellite-model integrated approaches are not independent (e.g., same datasets for single-scattering albedo, asymmetry factor, and surface albedo are used).

For model simulations, again SPRINTARS gives the lowest DRE of $-1.7 \mathrm{Wm}^{-2}$ at the TOA and $-5.1 \mathrm{Wm}^{-2}$ at the surface on annual average. In addition to the possible reasons discussed previously for ocean DRE, differences in land surface albedo parameterizations must also be considered. On an annual and global land average, SPRINTARS derives an albedo of 0.29 in the visible and 0.26 in the near-infrared, respectively. The seemingly high visible albedo would reduce the aerosol direct effect at both the TOA and surface. GOCART and LMDZ-INCA derive larger DRE than LMDZLOA and GISS do. An ensemble of five model simulations derives a DRE (median $\pm \varepsilon$ ) of $-2.8 \pm 0.59 \mathrm{Wm}^{-2}$ at the TOA and $-7.2 \pm 0.93 \mathrm{Wm}^{-2}$ at the surface, respectively. These are about $40 \%$ smaller than the measurement-based estimates. However, the model-derived surface/TOA DRE ratio of about 2.6 is not inconsistent with the value of 2.4 derived from the measurement-based estimates. The measurementmodel differences are a combination of differences in aerosol amount (optical thickness), single-scattering albedo, phase function, surface albedo, and radiative transfer schemes. We also find that seasonal variations of DRE over land, as derived from both measurements and models, are larger than that over ocean as discussed earlier.

\subsection{Assessments of the regional aerosol direct effect}

\subsubsection{Intercomparisons over ocean}

Table 9 compares individual assessments of the clear-sky average aerosol direct effect at the TOA for MAM, JJA, and ANN over five zones (excluding land), i.e., zone 2, 4, 6, 7, and 9 as defined in Fig. 5. These zones are chosen to represent regions significantly influenced by pollution (zone 2 and zone 4) and dust (zone 4 in MAM and zone 6 and 7) and the most pristine region (zone 9). Clearly, model simulations are generally smaller than measurement-based estimates by 30-50\%. Differences between measurement-based estimates are generally moderate, with the standard deviation accounting for about $15-25 \%$ of the average. Differences among various approaches are generally much larger than the detected seasonal variations. While the different approaches tend to agree on the global distribution of aerosol impacts in MAM, they tend to disagree in JJA. In MAM all approaches show the Northwest Pacific (zone 4) having the largest impact followed by the North Atlantic (zone 2 and 6) and the 
Table 8. Summary of seasonal and annual average clear-sky DRE $\left(\mathrm{Wm}^{-2}\right)$ at the TOA and the surface over global land derived with different methods and data: MODIS_G, MISR_G, MO_GO, MO_MI_GO (Yu et al., 2003; 2004), GOCART (Chin et al., 2001, 2002; Yu et al., 2004), SPRINTARS (Takemura et al., 2002), GISS (Koch and Hansen, 2005; Koch et al., 2005³), LMDZ-INCA (Balkanski et al., 2006 ${ }^{6}$; Balkanski and Schulz, 20067; Kinne et al., 2005), LMDZ-LOA (Reddy et al., 2005a, b). Mean, median, standard deviation $(\sigma)$, and standard error $(\varepsilon)$ are calculated for observations (Obs) and model simulations (Mod) separately. The last row is the ratio of model median to observational median.

\begin{tabular}{lrrrrrrrrrr}
\hline \multirow{2}{*}{ Products } & \multicolumn{2}{c}{ DJF } & \multicolumn{2}{c}{ MAM } & \multicolumn{2}{c}{ JJA } & \multicolumn{2}{c}{ SON } & \multicolumn{2}{c}{ ANN } \\
& TOA & SFC & TOA & SFC & TOA & SFC & TOA & SFC & TOA & SFC \\
\hline MODIS_G & -4.1 & -9.1 & -5.8 & -14.9 & -6.6 & -17.4 & -5.4 & -12.8 & -5.5 & -13.5 \\
MISR_G & -3.9 & -8.7 & -5.1 & -13.0 & -5.8 & -14.6 & -4.6 & -10.7 & -4.9 & -11.8 \\
MO_GO & -3.5 & -7.5 & -5.1 & -12.9 & -5.8 & -14.9 & -4.8 & -10.9 & -4.8 & -11.6 \\
MO_MI_GO & -3.4 & -7.4 & -4.7 & -11.8 & -5.3 & -13.5 & -4.3 & -9.7 & -4.4 & -10.6 \\
Obs. Mean & -3.7 & -8.2 & -5.2 & -13.2 & -5.9 & -15.1 & -4.8 & -11.0 & -4.9 & -11.9 \\
Obs. Median & -3.7 & -8.1 & -5.1 & -13.0 & -5.8 & -14.8 & -4.7 & -10.8 & -4.9 & -11.7 \\
Obs. $\sigma$ & 0.33 & 0.85 & 0.46 & 1.29 & 0.54 & 1.65 & 0.46 & 1.29 & 0.45 & 1.20 \\
Obs. $\varepsilon$ & 0.17 & 0.49 & 0.26 & 0.74 & 0.31 & 0.85 & 0.27 & 0.75 & 0.26 & 0.70 \\
GOCART & -2.9 & -6.1 & -4.4 & -10.9 & -4.8 & -12.3 & -4.3 & -9.3 & -4.1 & -9.7 \\
SPRINTARS & -1.4 & -4.0 & -1.5 & -4.6 & -2.0 & -6.7 & -1.7 & -5.2 & -1.7 & -5.1 \\
GISS & -1.6 & -3.9 & -3.2 & -7.9 & -3.6 & -9.3 & -2.5 & -6.6 & -2.8 & -7.2 \\
LMDZ-INCA & -3.0 & -5.8 & -4.0 & -9.2 & -6.0 & -13.5 & -4.3 & -8.2 & -4.3 & -9.2 \\
LMDZ-LOA & -1.3 & -5.4 & -1.8 & -6.4 & -2.7 & -8.9 & -2.1 & -6.7 & -2.0 & -6.9 \\
Mod. Mean & -2.0 & -5.0 & -3.0 & -7.8 & -3.8 & -10.1 & -3.0 & -7.2 & -3.0 & -7.6 \\
Mod. Median & -1.6 & -5.4 & -3.2 & -7.9 & -3.6 & -9.3 & -2.5 & -6.7 & -2.8 & -7.2 \\
Mod. $\sigma$ & 0.84 & 1.03 & 1.29 & 2.44 & 1.61 & 2.74 & 1.24 & 1.58 & 1.19 & 1.86 \\
Mod. $\varepsilon$ & 0.42 & 0.51 & 0.65 & 1.22 & 0.80 & 1.37 & 0.62 & 0.79 & 0.59 & 0.93 \\
Mod./Obs. & 0.43 & 0.67 & 0.63 & 0.61 & 0.62 & 0.63 & 0.53 & 0.62 & 0.58 & 0.62 \\
\hline
\end{tabular}

Arabian Sea (zone 7). In JJA the measurement-based assessments indicate that the Arabian Sea (zone 7) has the greatest impact, while the model-satellite integrated assessments indicate zones 4, 6, and 7 are more or less equivalent. Different model simulations appear to suggest different patterns. For example, GOCART simulations suggest that zone 6 has the greatest aerosol effect, whereas LMDZ-INCA suggests that zone 4 and zone 7 have a comparable and greater effect. A number of factors discussed in Sect. 3.1.4 should contribute to the differences among methods and major factors could be different from region to region.

To further examine pattern differences (e.g., peak, broadness, and skewness) between different approaches, we also calculate the probability density function (PDF) for DRE in individual zones, as shown in Figs. 7 and 8 for MAM and JJA, respectively. To avoid over crowding plots, we only examine six approaches that are representative for measurement, satellite-model integration, and model simulation. Our sensitivity tests show that differences in the spatial resolution between individual approaches does not introduce any significant difference in the PDF. In general, the model simulation shows a more uniform spatial distribution (i.e., a narrower $\mathrm{PDF}$ ) than the measurements do, especially in polluted regions (e.g., zone 2). MODIS also detects a more heterogeneous distribution (i.e., a broader PDF) than other measure- ments do. The following discussion focuses on major characteristics as revealed by satellite observations.

- Zone 2: The region is perturbed by pollution outflows from North America and to a lesser extent from West Europe. In MAM, the largest TOA cooling of -8.5 to $-9 \mathrm{Wm}^{-2}$ is estimated by MODIS, MODIS_A, CERES_C, and MISR_G. As evidenced in Fig. 7a, MODIS and MISR_G have a similar PDF, except that MISR_G is biased slightly toward less negative DRE. CERES_A, MODIS_G, and MO_MI_GO derive less negative DRE values of around $-8 \mathrm{Wm}^{-2}$ because of a less frequent occurrence at more negative DRE ranges. The GOCART simulation peaks at a relatively less negative DRE, giving an average of $-6.8 \mathrm{Wm}^{-2}$ that is smaller than other estimates discussed above but greater than the CERES_B estimate of $-5.6 \mathrm{Wm}^{-2}$. In JJA, MODIS has a relatively constant PDF from -3 to $-14 \mathrm{Wm}^{-2}$, while GOCART simulations give a narrow PDF that is well within -4 to $-8 \mathrm{Wm}^{-2}$. Other methods give comparable PDFs that fall inbetween MODIS and GOCART. The largest DRE of $\sim-8.5 \mathrm{Wm}^{-2}$ is estimated by MODIS and MISR_G, though their PDFs are different.

- Zone 4: In MAM, the region is profoundly influenced by continental outflows from East Asia and aerosols 
Table 9. Summary of seasonal (MAM, JJA) and annual (ANN) average clear-sky DRE $\left(\mathrm{Wm}^{-2}\right)$ at the TOA in five selected oceanic zones (Z2 - midlatitude North Atlantic, Z4 - Northwest Pacific, Z6 - Tropical Atlantic, Z7 - Arabian Sea and Northern Indian Ocean, Z9 - Tropical Southeastern Pacific). Mean, median, standard deviation $(\sigma)$, and standard error $(\varepsilon)$ are calculated for observations and model simulations separately. The last row is the ratio of model median to observational median.

\begin{tabular}{|c|c|c|c|c|c|c|c|c|c|c|c|c|c|c|c|}
\hline \multirow[t]{2}{*}{ Products } & \multicolumn{5}{|c|}{ MAM } & \multicolumn{5}{|c|}{ JJA } & \multicolumn{5}{|c|}{ ANN } \\
\hline & $\mathrm{Z} 2$ & $\mathrm{Z4}$ & Z6 & $\mathrm{Z7}$ & Z9 & $\mathrm{Z} 2$ & $\mathrm{Z4}$ & Z6 & $\mathrm{Z7}$ & Z9 & $\mathrm{Z} 2$ & $\mathrm{Z4}$ & Z6 & $\mathrm{Z7}$ & Z9 \\
\hline MODIS & -9.0 & -14.7 & -7.0 & -8.8 & -3.0 & -8.4 & -12.7 & -8.4 & -17.5 & -3.7 & -7.4 & -11.0 & -7.0 & -11.4 & -2.9 \\
\hline MODIS_A & -8.7 & -12.4 & -9.1 & -9.0 & -3.9 & -8.7 & -10.4 & -10.3 & -15.5 & -4.6 & -7.4 & -9.2 & -8.5 & -9.9 & -4.2 \\
\hline CERES_A & -8.3 & -15.9 & -7.1 & -7.9 & -3.4 & -7.1 & -12.1 & -8.2 & -13.3 & -3.5 & -6.4 & -9.3 & -7.4 & -8.6 & -3.6 \\
\hline CERES_B & -5.6 & -8.7 & -5.2 & -5.8 & -2.8 & -4.4 & -5.7 & -5.7 & -8.5 & -3.0 & -4.5 & -6.2 & -5.5 & -6.5 & -2.9 \\
\hline CERES-C & -8.5 & -17.3 & -8.3 & -9.0 & -3.4 & -6.7 & -11.4 & -8.9 & -15.4 & -3.6 & -6.8 & -11.8 & -8.3 & -10.8 & -3.5 \\
\hline MODIS_G & -7.9 & -14.2 & -8.6 & -8.1 & -3.6 & -8.0 & -12.5 & -11.2 & -12.0 & -3.8 & -6.4 & -9.6 & -8.7 & -8.4 & -3.7 \\
\hline MISR_G & -8.7 & -12.8 & -9.7 & -7.6 & -4.8 & -8.6 & -11.9 & -12.8 & -12.0 & -5.9 & -7.2 & -9.6 & -9.9 & -8.0 & -4.9 \\
\hline MO_GO & -7.8 & -13.9 & -8.3 & -7.2 & -2.8 & -7.9 & -11.4 & -11.0 & -10.8 & -3.3 & -6.3 & -9.2 & -8.5 & -7.4 & -3.0 \\
\hline MO_MI_GO & -7.8 & -13.5 & -8.2 & -6.7 & -2.8 & -7.7 & -11.0 & -11.0 & -10.5 & -3.3 & -6.3 & -9.0 & -8.4 & -6.9 & -3.0 \\
\hline Obs. Mean & -8.0 & -13.7 & -7.9 & -7.8 & -3.4 & -7.5 & -11.0 & -9.7 & -12.8 & -3.9 & -6.5 & -9.4 & -8.0 & -8.7 & -3.5 \\
\hline Obs. Median & -8.3 & -13.9 & -8.3 & -7.9 & -3.4 & -7.9 & -11.4 & -10.3 & -12.0 & -3.6 & -6.4 & -9.3 & -8.4 & -8.4 & -3.5 \\
\hline Obs. $\sigma$ & 1.01 & 2.41 & 1.24 & 1.09 & 0.66 & 1.34 & 2.12 & 2.13 & 2.86 & 0.89 & 0.89 & 1.54 & 1.25 & 1.71 & 0.68 \\
\hline Obs. $\varepsilon$ & 0.36 & 0.85 & 0.47 & 0.39 & 0.23 & 0.47 & 0.75 & 0.75 & 1.01 & 0.31 & 0.31 & 0.54 & 0.44 & 0.61 & 0.24 \\
\hline GOCART & -6.8 & -10.3 & -6.4 & -5.1 & -1.8 & -6.8 & -8.1 & -10.4 & -6.9 & -2.3 & -5.9 & -7.8 & -7.4 & -5.0 & -1.9 \\
\hline SPRINTARS & -2.0 & -2.5 & -2.5 & -3.0 & -0.7 & -3.4 & -4.1 & -3.7 & -3.4 & -1.3 & -2.1 & -2.4 & -3.4 & -3.2 & -1.1 \\
\hline GISS & -5.4 & -6.7 & -3.9 & -4.6 & -1.1 & -3.5 & -3.6 & -6.8 & -6.8 & -1.7 & -3.9 & -5.0 & -3.9 & -3.9 & -1.6 \\
\hline LMDZ-INCA & -6.1 & -9.0 & -6.0 & -7.5 & -3.7 & -7.5 & -11.7 & -9.5 & -11.1 & -3.2 & -5.7 & -8.2 & -6.4 & -7.5 & -3.1 \\
\hline LMDZ-LOA & -3.4 & -4.4 & -3.3 & -4.3 & -1.0 & -3.8 & -5.2 & -5.8 & -6.0 & -1.2 & -3.2 & -4.2 & -4.0 & -4.2 & -1.0 \\
\hline Mod. Mean & -4.7 & -6.6 & -4.4 & -4.9 & -1.7 & -5.0 & -6.5 & -7.2 & -6.8 & -1.9 & -4.2 & -5.5 & -5.0 & -4.8 & -1.7 \\
\hline Mod. Median & -5.4 & -6.7 & -3.9 & -4.6 & -1.1 & -3.8 & -5.2 & -6.8 & -6.8 & -1.7 & -3.9 & -5.0 & -4.0 & -4.2 & -1.6 \\
\hline Mod. $\sigma$ & 1.99 & 3.21 & 1.70 & 1.65 & 1.21 & 1.98 & 3.37 & 2.73 & 2.77 & 0.83 & 1.63 & 2.46 & 1.77 & 1.66 & 0.84 \\
\hline Mod. $\varepsilon$ & 0.99 & 1.60 & 0.85 & 0.82 & 0.60 & 0.99 & 1.69 & 1.37 & 1.39 & 0.41 & 0.82 & 1.23 & 0.88 & 0.83 & 0.42 \\
\hline Mod./Obs. & 0.65 & 0.48 & 0.47 & 0.58 & 0.32 & 0.48 & 0.46 & 0.64 & 0.57 & 0.47 & 0.61 & 0.54 & 0.48 & 0.50 & 0.46 \\
\hline
\end{tabular}

in the region are a complex mixture of Asian pollution, mineral dust, and sea-salt. Various methods derive the TOA DRE ranging from -8.7 (CERES_B) to $-17.3 \mathrm{Wm}^{-2}$ (CERES_C), which is the largest among the regions examined. In JJA, the impacts from Asian continental outflow become weaker. The CERES_B aerosol direct effect can be reduced from MAM to JJA by as much as $50 \%$. For other approaches, such reductions generally range from 8 to $30 \%$, which is comparable to the differences among different approaches. Note that in both seasons, the PDF of the GOCART simulation is narrower than other PDFs and peaks at a less negative DRE.

- Zone 6: The region is influenced by dust outflow from North Africa throughout the year, and by biomass burning smoke in winter and early spring. Different approaches, except CERES_C, yield more negative DRE in JJA than in MAM. The PDFs exhibit a larger breadth and peak at a more negative DRE in JJA than in MAM. However, such seasonal variations are smaller by as much as a factor of 2 than differences existing between different approaches.
- Zone 7: The region is influenced by dust from the Arabian Peninsula and North Africa, and pollution from the Indian subcontinent. While pollution impacts occur mainly in the Northern Indian Ocean and in winter and spring, dust impacts dominate in the Arabian Sea and in summer. Different approaches derive broad PDFs in both seasons. In summer, the DRE ranges from about $-6.9 \mathrm{Wm}^{-2}$ (GOCART) to as much as $-17.5 \mathrm{Wm}^{-2}$ (MODIS), larger than those in spring (e.g., -5.1 to $-12.7 \mathrm{Wm}^{-2}$ ). Such seasonal variations are comparable to those in zone 4 and somewhat smaller than differences among various approaches.

- Zone 9: The tropical Southeast Pacific is the most pristine region in the world and has the smallest DRE of -2 to $-6 \mathrm{Wm}^{-2}$ without significant seasonal variations. Various approaches give PDFs with similar breadth but with somewhat different peaks. While GOCART simulates the lowest DRE $\left(\sim-2 \mathrm{Wm}^{-2}\right)$ in this remote region, MISR derives the largest DRE $\left(-5\right.$ to $\left.-6 \mathrm{Wm}^{-2}\right)$ because of the high bias of aerosol optical depth in the early post-launch version of MISR aerosol data (preVersion 16). 

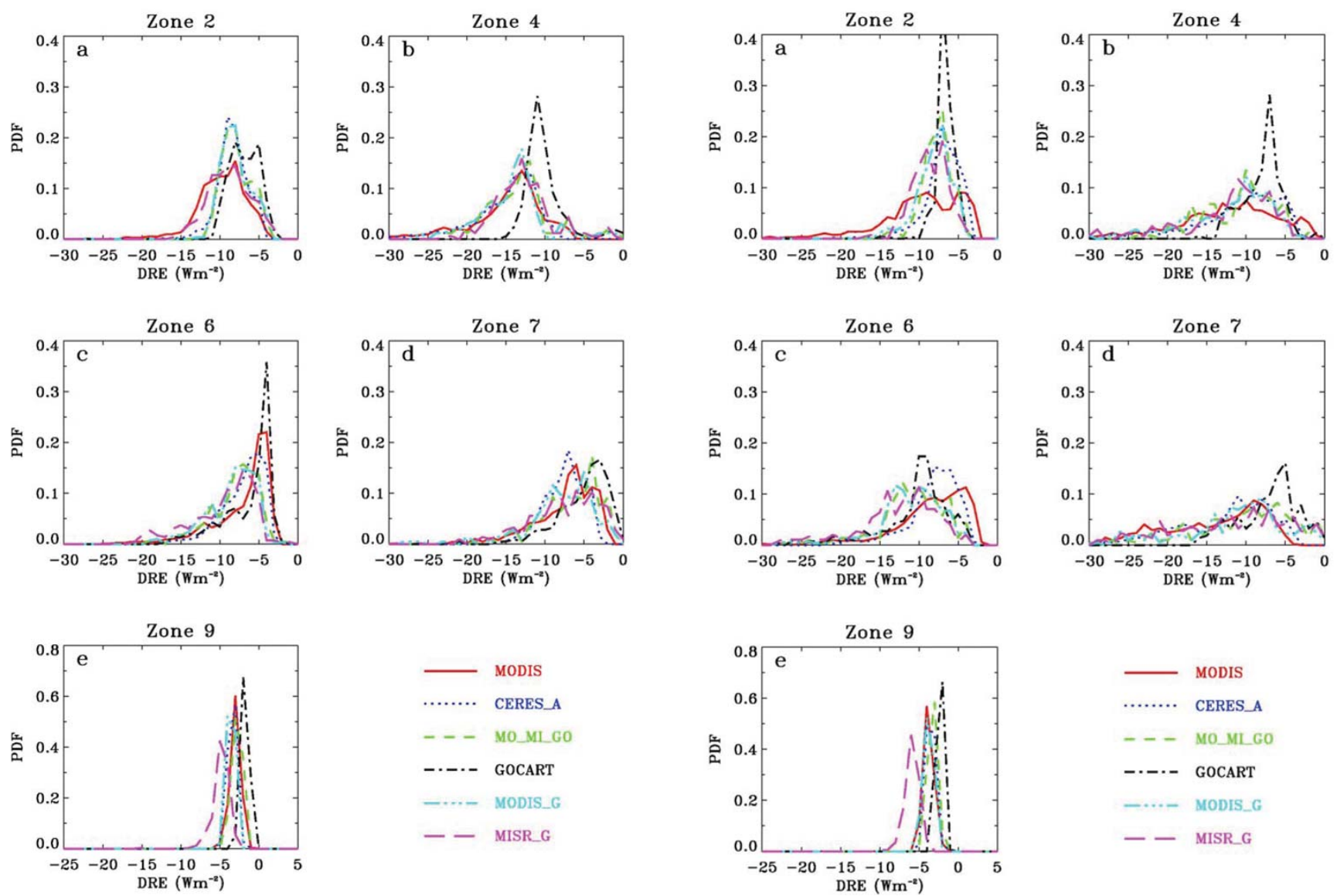

Fig. 7. Comparisons of probability density function (PDF) of clearsky DRE estimates at the TOA over ocean in 5 different zones (see Fig. 5) for MAM.

Table 10a. Statistical measures of seasonal and regional average clear-sky TOA DRE estimates with respect to MODIS DRE over ocean (Remer and Kaufman, 2006), including linear correlation coefficient $(r)$, mean ratio $(B)$, and standard deviation of $B\left(\sigma_{B}\right)$.

\begin{tabular}{lccc}
\hline Products & $r$ & $B$ & $\sigma_{B}$ \\
\hline MODIS_A & 0.94 & 1.14 & 0.24 \\
CERES_A & 0.93 & 0.99 & 0.23 \\
CERES_B & 0.91 & 0.77 & 0.19 \\
CERES_C & 0.93 & 1.03 & 0.21 \\
MODIS_G & 0.86 & 1.03 & 0.28 \\
MISR_G & 0.68 & 1.20 & 0.42 \\
MO_GO & 0.86 & 0.93 & 0.22 \\
MO_MI_GO & 0.82 & 0.91 & 0.24 \\
GOCART & 0.80 & 0.71 & 0.20 \\
SPRINTARS & 0.57 & 0.32 & 0.14 \\
GISS & 0.72 & 0.53 & 0.20 \\
LMDZ-INCA & 0.83 & 0.81 & 0.23 \\
LMDZ-LOA & 0.82 & 0.41 & 0.11 \\
\hline
\end{tabular}

Fig. 8. Same as Fig. 7, but for JJA.

Table 10b. Statistical measures of seasonal and regional average clear-sky surface DRE estimates with respect to MODIS_A DRE over ocean (Bellouin et al., 2005), including linear correlation coefficient $(r)$, mean ratio $(B)$, and standard deviation of $B\left(\sigma_{B}\right)$.

\begin{tabular}{lccc}
\hline Products & $r$ & $B$ & $\sigma_{B}$ \\
\hline MO_MI_GO & 0.91 & 0.98 & 0.16 \\
MO_GO & 0.93 & 1.02 & 0.17 \\
MODIS_G & 0.93 & 1.17 & 0.21 \\
MISR_G & 0.88 & 1.30 & 0.23 \\
GOCART & 0.88 & 0.80 & 0.21 \\
SPRINTARS & 0.61 & 0.34 & 0.19 \\
GISS & 0.82 & 0.49 & 0.18 \\
LMDZ-INCA & 0.81 & 0.69 & 0.24 \\
LMDZ-LOA & 0.83 & 0.50 & 0.18 \\
\hline
\end{tabular}




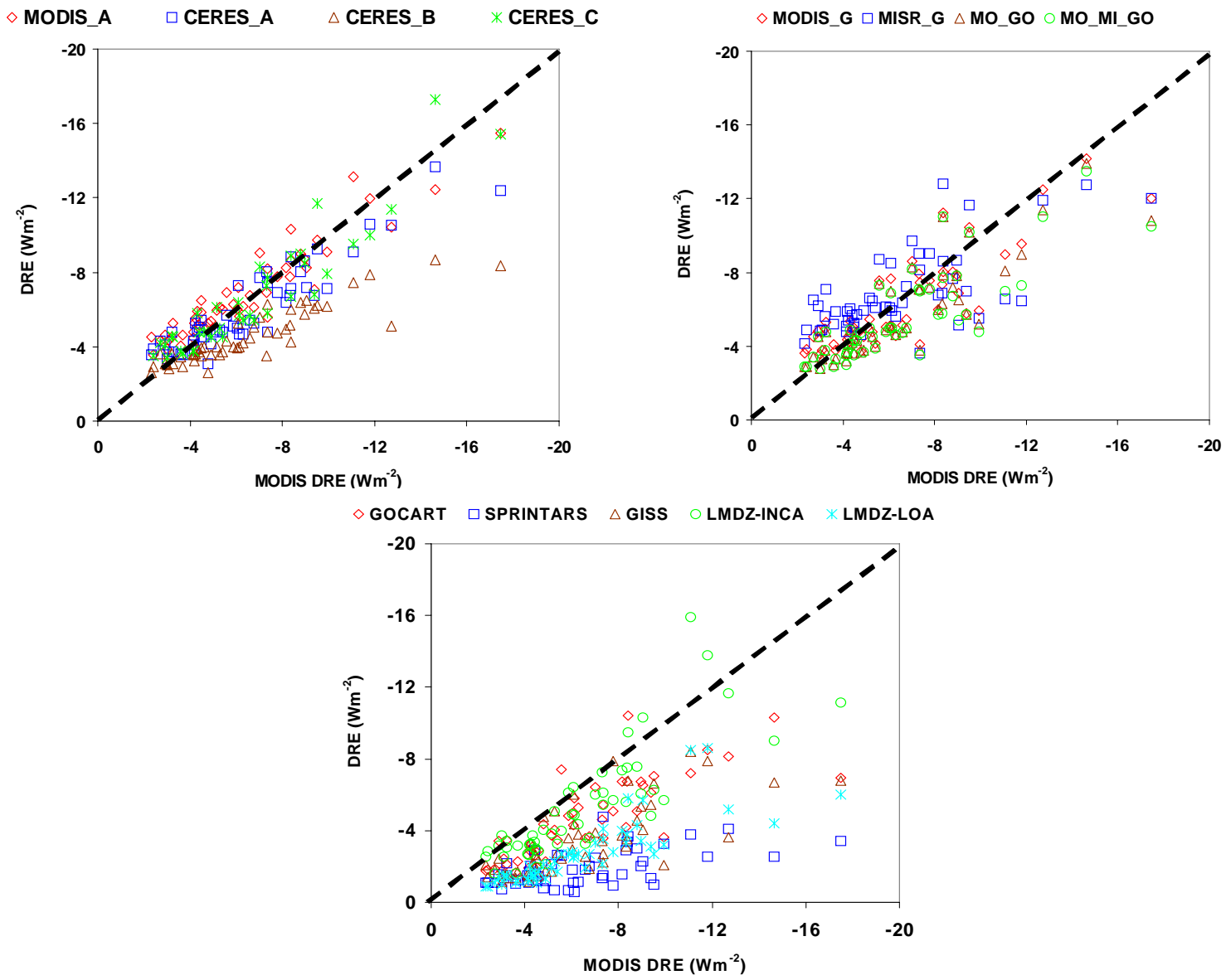

Fig. 9a. Scatterplots of the clear-sky and seasonal DRE estimates at the top of atmosphere (TOA) and over ocean. Each point represents a seasonal average in a particular zone.

Figure 9a shows scatterplots of seasonal and regional (zonal) average DRE estimates at the TOA over oceans versus the MODIS estimate. Each data point represents a seasonal average DRE in one of 13 zones defined in Fig. 5. Table 10a summarizes some statistical measures of individual DRE estimates (Y) with respect to the MODIS assessment $(\mathrm{X})$, including linear correlation coefficient (r), mean ratio $\left(B=\frac{1}{N} \sum_{i=1}^{N} \frac{Y_{i}}{X_{i}}\right.$, where $\mathrm{i}$ denotes a specific season for a specific zone, $\mathrm{N}=39$ for CERES_C and $N=52$ for the other estimates), and the standard deviation of the ratio $\left(\sigma_{B}\right)$. A value of 1 for $B$ denotes no difference of an individual assessment with respect to MODIS. $B<1$ and $B>1$ indicates less and more negative DRE, respectively. Clearly, CERES_A, CERES_C, and MODIS_G compare very well with the MODIS estimate, with the ratios of $0.99 \pm 0.23$, $1.03 \pm 0.21$ and $1.03 \pm 0.28$, respectively. The correlation coefficient for CERES_A and CERES_C (0.93) is higher than 0.86 for MODIS_G. CERES_B also has a high correlation of 0.91 but is smaller in magnitude with a ratio of $0.77 \pm 0.19$. Due to the overall high bias of the early post-launch aerosol optical depth over ocean as discussed earlier, the MISRderived DRE has a high bias of $1.20 \pm 0.42$ with a moderate correlation of 0.68 . MODIS_A also shows a high ratio of $1.14 \pm 0.24$ but with a high correlation of 0.94 . The two satellite-model integration-based assessments (MO_GO and MO_MI_GO) have a correlation of $0.82-0.86$, comparable to GOCART simulations. However they are much closer in magnitude to the MODIS estimate than GOCART simulations. All model simulations are lower than the MODIS estimate. Among them, LMDZ-INCA and GOCART are relatively close to the MODIS estimate with a mean ratio of $0.7 \sim 0.8$, followed by GISS and LMDZ-INCA with the mean ratio of $0.4 \sim 0.5$. SPRINTARS simulations have the weakest correlation (0.57) and lowest DRE (with a ratio of $0.32 \pm 0.14$ ) with respect to the MODIS estimate.

Figure 9b shows scatterplots similar to Fig. 9a, but for seasonal and regional average DRE estimates at the surface with respect to the MODIS_A estimate. Corresponding statistical measures are listed in Table 10b. Note that MODIS, CERES_A, CERES_B, and CERES_C are not included because they don't estimate DRE at the surface. It appears 

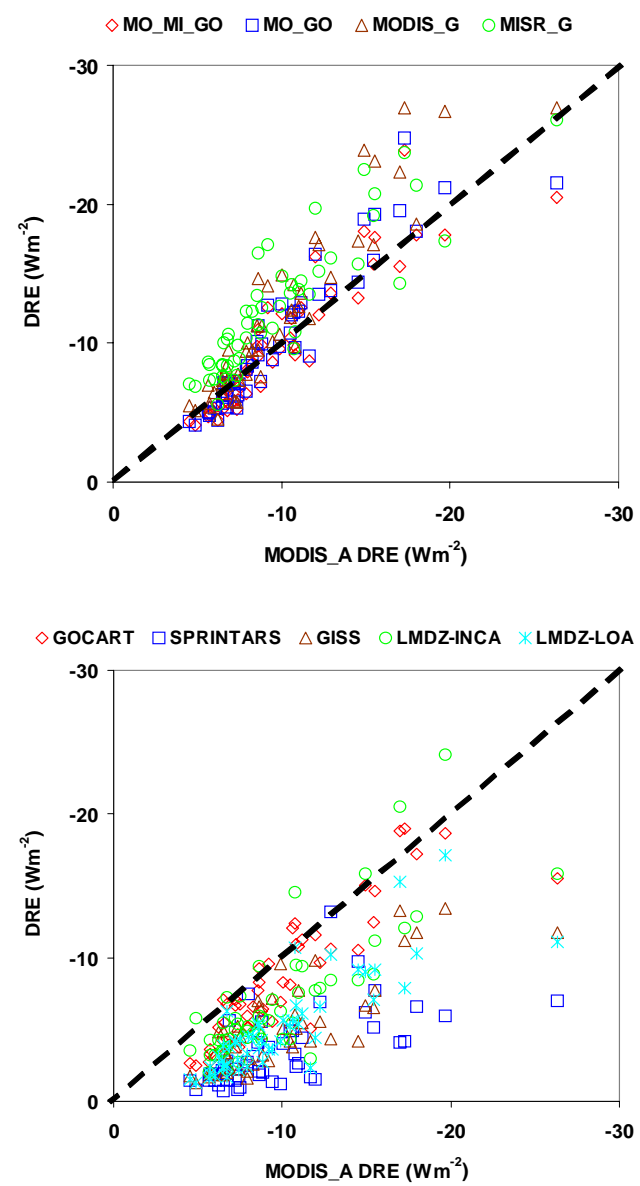

Fig. 9b. Scatterplots of the clear-sky and seasonal DRE estimates vs MODIS_A DRE at the surface and over ocean. Each point represents a seasonal average in a particular zone.

that all satellite-GOCART integration-based estimates (i.e., MO_MI_GO, MO_GO, MODIS_G, MISR_G) correlate well with the MODIS_A estimate $(r=0.88 \sim 0.93)$. On average, MODIS_G and MISR_G are higher by $17-30 \%$. MO_MI_GO and MO_GO agree with MODIS_A reasonably well, suggesting a significant reduction of lower bias $(B=0.80)$ for $\mathrm{GO}$ CART estimates. A large majority of model-based estimates are lower than the MODIS_A estimate, with SPRINTARS showing the largest deviations.

\subsubsection{Comparisons with AERONET derived DRE over land}

Monthly mean values of observed aerosol optical depth, retrieved single scattering albedo, and derived aerosol direct solar effect based on the AERONET measurements (Zhou et al., 2005) are compiled to seasonal averages in individual zones, as shown in Table 11. There are 8 zones (i.e., zone 1-4, 6-7, and 10-11), in which 3-25 AERONET sites are available in individual seasons. Since most AERONET sites are established over land, the regional averages so derived are not representative of conditions over ocean. Note also that regional representativeness of AERONET measurements may be undermined by the limited number of stations and/or possibly their general proximity to source regions (e.g., urban areas, biomass burning regions) in some zones. Nevertheless, these averages do show some seasonal variations and geographical differences that are consistent with previous studies. In the US (zone 1 and zone 2), the aerosol effect is greatest in summer and least in winter, with magnitudes larger by $36-113 \%$ for the TOA DRE and $27-66 \%$ for the surface DRE in the Eastern US than in the Western US, depending on season. In the Western Europe (zone 3), the TOA DRE has no significant seasonal variations, while the surface DRE is greatest in summer and least in winter. The TOA/surface ratios from spring to autumn are smaller than those over East US, due to stronger absorption in West Europe than in East US. In East Asia (zone 4), the aerosol impacts are greatest in summer and spring and least in winter. The surface cooling of about $-30 \mathrm{Wm}^{-2}$ in summer and spring is much greater than that in the US and West Europe. Zone 6 and zone 7 are significantly influenced by mineral dust from the Saharan region and Arabian Peninsula during the whole year and by biomass burning from tropical Africa in winter. The aerosol optical depth is among the largest but the absorption of dust is weaker than pollution, resulting in a larger TOA cooling and smaller surface cooling than those in East Asia. South America and South Africa (zone 10 and zone 11) are greatly influenced by absorptive smoke from biomass burning in the austral spring (SON) and winter (JJA). Such a heavy smoke cools the surface by more than $30 \mathrm{Wm}^{-2}$ in SON and by about $23 \mathrm{Wm}^{-2}$ in JJA, a factor of 2-3 more than that in wet seasons.

These AERONET measurements are used to evaluate a variety of DRE estimates from model simulations (GOCART, SPRINTARS, GISS, LMDZ-INCA, LMDZ-LOA), and model-satellite integrations (MODIS_G, MISR_G, MO_GO, MO_MI_GO), as shown in Fig. 10. Correlation coefficient (r) and mean bias (B) are calculated for weak cooling (DRE $>-8$ at the TOA or $>-23 \mathrm{Wm}^{-2}$ at the surface) and strong cooling (DRE $<-8$ at the TOA or $<-23 \mathrm{Wm}^{-2}$ at the surface), respectively, as shown in Table 12. Clearly, these estimates are quite scattered, with at most a modest correlation in the weak cooling regime and a very weak or even negative correlation in the strong cooling regime. The scatter is also larger for TOA DRE than for surface DRE. The correlation is higher for the surface DRE than for the TOA DRE. Note that those correlation coefficients in the strong cooling regime may not be statistically meaningful because of limited data points. DRE estimates from GOCART and LMDZINCA simulations and the integrations of GOCART simulations and satellite data sets generally have mean biases much smaller than other models. The biases are also relatively smaller in the weak cooling regime than in the strong cooling regime. Further examination indicates that those consistent underestimates of DRE in the strong cooling regime 
Table 11. AERONET aerosol and DRE climatology. Top panel: seasonal and zone averages of AOD (upper lines) and SSA (lower lines) at $550 \mathrm{~nm}$; Middle panel: seasonal and zone averages of clear-sky aerosol direct radiative effect (DRE, $\mathrm{Wm}^{-2}$ ) at the TOA (upper lines) and at the surface (lower lines) (Zhou et al., 2005); Bottom panel: blue dots indicate AERONET stations. Light blue shadows the continents.

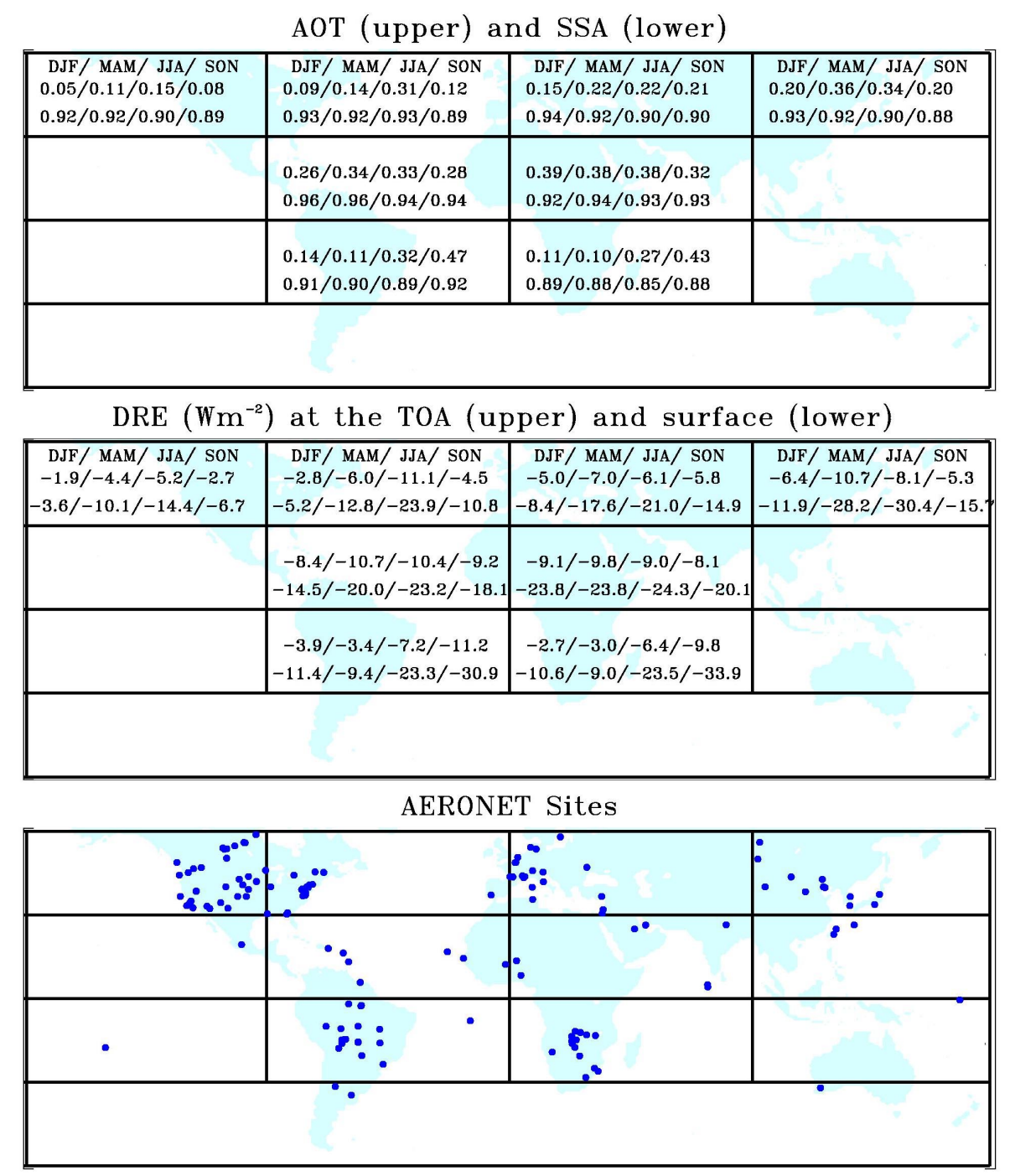

generally occur in South Africa and South America (zone 10 and 11) during the austral spring and winter (biomass burning season), North Africa and mid-East (zone 6 and 7) year around, East Asia (zone 4) during non-summer seasons, and Europe in winter. Such discrepancies may result from inadequacies in both model simulations and satellite retrievals. They would also come from the poor regional representativeness of AERONET stations due to the limited number of sites (zones $4,6,7$ ) and/or proximity to biomass burning and dust storm areas (zones 6-7, 10-11). Other model simulations generally show much larger deviations from the AERONET measurements.
3.3.3 Comparisons of the radiative efficiency with results from the literature

In the following, we discuss aerosol direct radiative effect in six distinct aerosol regimes where results from intensive field experiments and/or independent satellite analyses have been published. We will concentrate on comparisons of the radiative efficiency $E_{\tau}$ from different measurement-based methods collected in this review (see Table 3 ) with ranges of five models and those from the literature. We also convert published $E_{\tau}$ values with respect to the AOD at wavelengths other than $550 \mathrm{~nm}$ to that with respect to AOD at $550 \mathrm{~nm}$ by using aerosol Ångström exponents either from available observations or from the MODIS retrievals. In all cases, $E_{\tau}$ is calculated as the mean DRE divided by the mean AOT. 
$\diamond$ MO_MI_GO $\square$ MO_GO $\triangle$ MODIS_G + MISR_G

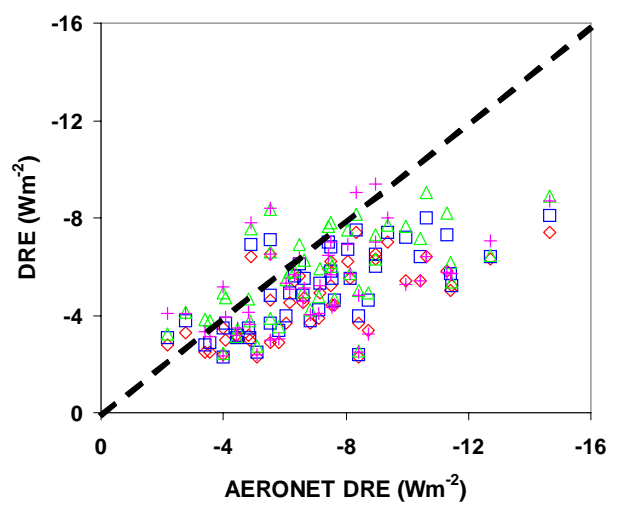

$\diamond$ GOCART $\square$ SPRINTARS $\triangle$ GISS + LMDZ-INCA $*$ LMDZ-LOA

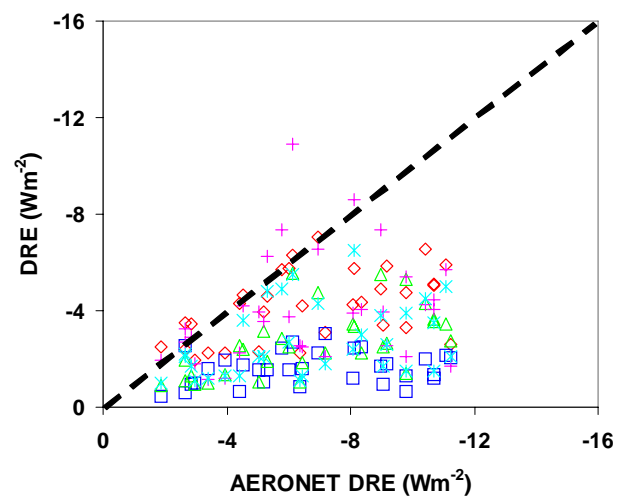

Fig. 10a. Scatterplots of the clear-sky and seasonal DRE estimates vs AERONET DRE at the TOA. Each point represents a seasonal average in a particular zone.

Table 12a. Statistical measures of seasonal and regional average clear-sky TOA DRE estimates with respect to AERONET over land (Zhou et al., 2005), including linear correlation coefficient $(r)$ and mean ratio $(B)$ for DRE $>-8 \mathrm{Wm}^{-2}$ (weak cooling) and $\mathrm{DRE}<$ $-8 \mathrm{Wm}^{-2}$ (strong cooling), respectively.

\begin{tabular}{lcccc}
\hline & \multicolumn{2}{c}{ DRE $>-8 \mathrm{Wm}^{-2}$} & \multicolumn{2}{c}{$\mathrm{DRE}<-8 \mathrm{Wm}^{-2}$} \\
\hline Products & $r$ & $B$ & $r$ & $B$ \\
\hline MODIS_G & 0.36 & 1.15 & -0.12 & 0.78 \\
MISR_G & 0.16 & 1.02 & 0.30 & 0.67 \\
MO_GO & 0.50 & 1.01 & -0.12 & 0.69 \\
MO_MI_GO & 0.38 & 0.91 & 0.09 & 0.61 \\
GOCART & 0.57 & 0.85 & -0.23 & 0.54 \\
SPRINTARS & 0.51 & 0.35 & -0.37 & 0.19 \\
GISS & 0.57 & 0.45 & -0.25 & 0.40 \\
LMDZ-INCA & 0.46 & 0.81 & -0.64 & 0.57 \\
LMDZ-LOA & 0.44 & 0.53 & -0.34 & 0.38 \\
\hline
\end{tabular}

$\diamond$ MO_MI_GO $\square$ MO_GO $\triangle$ MODIS_G + MISR G
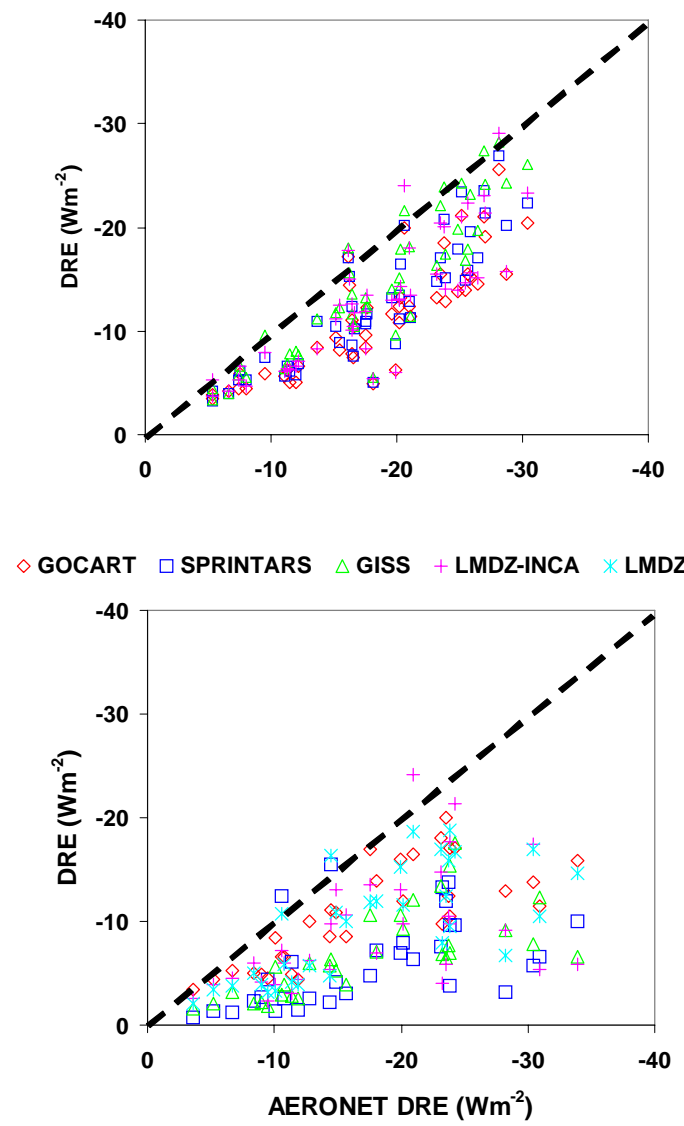

Fig. 10b. Scatterplots of the clear-sky and seasonal DRE estimates vs AERONET DRE at the surface. Each point represents a seasonal average in a particular zone.

Table 12b. Statistical measures of seasonal and regional average clear-sky surface DRE estimates with respect to AERONET over land (Zhou et al., 2005), including linear correlation coefficient $(r)$ and mean ratio $(B)$ for DRE $>-23 \mathrm{Wm}^{-2}$ (weak cooling) and $\mathrm{DRE}<-23 \mathrm{Wm}^{-2}$ (strong cooling) respectively.

\begin{tabular}{lcccc}
\hline & \multicolumn{2}{c}{ DRE $>-23 \mathrm{Wm}^{-2}$} & \multicolumn{2}{c}{$\mathrm{DRE}<-23 \mathrm{Wm}^{-2}$} \\
\hline Products & $r$ & $B$ & $r$ & $B$ \\
\hline MODIS_G & 0.85 & 0.96 & 0.45 & 0.81 \\
MISR_G & 0.71 & 0.86 & 0.17 & 0.71 \\
MO_GO & 0.89 & 0.84 & 0.26 & 0.72 \\
MO_MI_GO & 0.83 & 0.75 & 0.14 & 0.64 \\
GOCART & 0.89 & 0.69 & -0.14 & 0.56 \\
SPRINTARS & 0.46 & 0.36 & -0.34 & 0.34 \\
GISS & 0.88 & 0.39 & -0.22 & 0.39 \\
LMDZ-INCA & 0.77 & 0.59 & -0.23 & 0.43 \\
LMDZ-LOA & 0.83 & 0.60 & -0.07 & 0.52 \\
\hline
\end{tabular}


Table 13. Summary of the clear-sky radiative efficiency $E_{\tau}$, defined as the aerosol radiative effect $\left(\mathrm{Wm}^{-2}\right)$ per unit aerosol optical depth $(\tau$ at $550 \mathrm{~nm}$ ), in East US and mid-latitude North Atlantic.

\begin{tabular}{lllll}
\hline \multirow{2}{*}{ Region } & \multirow{2}{*}{ Period } & Source & \multicolumn{2}{c}{$E_{\tau}$} \\
& & & TOA & Surface \\
\hline Zone 2 (land) & \multirow{2}{*}{ Summer } & AERONET & -37 & -84 \\
& & Models & $-21 \sim-37$ & $-38 \sim-66$ \\
& Annual & AERONET & -37 & -80 \\
SCAR-A (Land) & Summer & Models & $-23 \sim-34$ & $-43 \sim-55$ \\
US & Kinne and Pueschel, 2001 & -24 & -65 \\
Zone 2 (ocean) & Summer & Delene and Ogren (2002) & -25 & n/a \\
& & MODIS & -50 & n/a \\
& & MODIS_A & -52 & -67 \\
& & CERES_A & -37 & n/a \\
TARFOX (Ocean) & Summer & CERES_B & -31 & n/a \\
& & Hignett et al., 1999 & $-27 \sim-42$ & $-42 \sim-76$ \\
& & Kinne and Pueschel, 2001 & -30 & -87 \\
ACE-2 & Russell et al., 1999 & $-40 \sim-60$ & $-80 \sim-90$
\end{tabular}

a. East US and mid-latitude North Atlantic

In the Eastern US and mid-latitude North Atlantic (zone 2 ), the aerosol optical depth in spring and summer is larger than that in fall and winter (Malm et al., 2004; Bergstrom and Russell, 1999). A number of field campaigns have been conducted in summer (see Table 1). Table 13 compares various $E_{\tau}$ estimates in the region. AERONET $E_{\tau}$ values are much greater than measurement-based estimates from Kinne and Pueschel (2001) and Delene and Ogren (2002). Ranges of model simulations are generally inbetween. Over the midlatitude North Atlantic, MODIS and MODIS_A derive $E_{\tau}$ values at the TOA that are greater than CERES estimates and model ranges. Nevertheless, all these TOA values fall into a wide range of estimates $(-30$ to $-60 \mathrm{Wm}^{-2} \tau^{-1}$ ) from field experiments in the region (Hignett et al., 1999; Russell et al., 1999; Kinne and Pueschel, 2001). The MODIS_A and model estimates of surface $E_{\tau}$ are generally less than observations.

\section{b. Europe}

Europe is influenced by regional pollution and dust from the Saharan Desert. In spring, Arctic haze also influences the region with a TOA DRE comparable to values in heavily polluted regions, as documented by measurements in Leipzig, Germany in April 2002 (Heintzenberg et al., 2003). Comparisons of $E_{\tau}$ estimates in Europe are summarized in Table 14. Clearly, there is good agreement between AERONET, and observations during the MINOS experiment (Markowicz et al., 2002), for $E_{\tau}$ at both TOA and surface. However, these values are much greater than observations in urban and coastal areas (Horvath et al., 2002) and model estimates.

\section{c. East Asia and Northwest Pacific}

The midlatitude north Pacific regions are perturbed by a mixture of Asian pollution and dust, particularly in spring and summer. Comparisons of radiative efficiency estimates are summarized in Table 15. Over the Northwest Pacific, the TOA $E_{\tau}$ estimates from MODIS are greater than all other measurements including MODIS_A, the observations during ACE-Asia (Seinfeld et al., 2004), calculations based on several SKYNET sites in East China Sea and Korean Peninsula (Kim et al., 2005), CERES measurements and model simulations. For surface DRE, MODIS_A and the model-derived $E_{\tau}$ values are much less than the observations in the ACE-Asia region (Seinfeld et al., 2004), measurements in Korea (Bush and Valero, 2003) and all SKYNET measurements (Kim et al., 2005). Over land, AERONET measurements give an $E_{\tau}$ of $-28 \mathrm{Wm}^{-2}$ at the TOA, which agrees well with an independent sunphotometer measurement in November at a background air monitoring station sitting in the Yangtze delta region (Linan, China) (Xu et al., 2003). However, these TOA $E_{\tau}$ values are much greater than SKYNET observations (Kim et al., 2005). At the surface, the $E_{\tau}$ from AERONET measurements is generally larger than other observations (Xu et al., 2003; Kim et al., 2005). The model-derived $E_{\tau}$ values at the surface are less than the observations.

\section{d. Tropical North Atlantic and coastal North Africa}

This region is influenced by biomass burning from the tropical Savanna in winter and early spring, and mineral dust year round. Some measurements using CERES and ERBE fluxes in conjunction with MODIS and TOMS 
Table 14. Summary of the clear-sky radiative efficiency $E_{\tau}$, defined as the aerosol radiative effect $\left(\mathrm{Wm}^{-2}\right)$ per unit aerosol optical depth $(\tau$ at $550 \mathrm{~nm})$, in Europe.

\begin{tabular}{lllll}
\hline \multirow{2}{*}{ Region } & Period & Source & \multicolumn{2}{c}{$E_{\tau}$} \\
& & & TOA & Surface \\
\hline Zone 3 (land) & Summer & AERONET & -29 & -98 \\
& & Models & $-13 \sim-26$ & $-36 \sim-68$ \\
Almeria, Spain & Summer & Horvath et al., 2002 & -11 & -57 \\
Vienna, Austria & & & -24 & -68 \\
Mediterranean Area & \multirow{2}{*}{ July-August, 2001 } & Markowicz et al., 2002 & -34 & -94 \\
\hline
\end{tabular}

Table 15. Summary of the clear-sky radiative efficiency $E_{\tau}$, defined as the aerosol radiative effect $\left(\mathrm{Wm}^{-2}\right)$ per unit aerosol optical depth $(\tau$ at $550 \mathrm{~nm})$, in East Asia and Northwest Pacific.

\begin{tabular}{|c|c|c|c|c|}
\hline \multirow{2}{*}{ Region } & \multirow{2}{*}{ Period } & \multirow{2}{*}{ Source } & \multicolumn{2}{|c|}{$E_{\tau}$} \\
\hline & & & TOA & Surface \\
\hline \multirow[t]{5}{*}{ Zone 4 (ocean) } & MAM & MODIS & -52 & $\mathrm{n} / \mathrm{a}$ \\
\hline & & CERES_A & -35 & $\mathrm{n} / \mathrm{a}$ \\
\hline & & CERES_B & -31 & $\mathrm{n} / \mathrm{a}$ \\
\hline & & MODIS_A & -44 & -61 \\
\hline & & Models & $-25 \sim-42$ & $-45 \sim-61$ \\
\hline Northwest Pacific & April 2001 & Seinfeld et al., 2004 & -41 & -71 \\
\hline Gosan, Korea & April, 2001 & Bush and Valero, 2003 & $\mathrm{n} / \mathrm{a}$ & $-80 \pm 11$ \\
\hline \multirow[t]{2}{*}{$\begin{array}{l}\text { Anmyon, Japan } \\
\text { (ocean albedo) }\end{array}$} & $\begin{array}{l}\text { Dust events } \\
(1998,2000)\end{array}$ & Kim et al., 2005 & -26 & -91 \\
\hline & Non-dust events (2000) & & -22 & -82 \\
\hline \multirow{2}{*}{$\begin{array}{l}\text { Gosan, Korea } \\
\text { (ocean albedo) }\end{array}$} & Dust events (2001) & & -21 & -104 \\
\hline & Non-dust events (2001) & & -29 & -69 \\
\hline \multirow{2}{*}{$\begin{array}{l}\text { Amami-Oshima } \\
\text { (ocean albedo) }\end{array}$} & Dust events (2001) & & -12 & -106 \\
\hline & $\begin{array}{l}\text { Non-dust events (2000, } \\
\text { 2001) }\end{array}$ & & -18 & -90 \\
\hline \multirow[t]{2}{*}{ Zone 4 (land) } & Fall & AERONET & -28 & -82 \\
\hline & & Models & $-19 \sim-27$ & $-40 \sim-54$ \\
\hline $\begin{array}{l}\text { Linan, East China } \\
\text { (rural) }\end{array}$ & November, 1999 & Xu et al., 2003 & -33 & -51 \\
\hline $\begin{array}{l}\text { Dunhuang, China } \\
\text { (desert) }\end{array}$ & April-July, 1998-2000 & Kim et al., 2005 & -9 & -76 \\
\hline $\begin{array}{l}\text { Yinchuan, China } \\
\text { (urban) }\end{array}$ & $\begin{array}{l}\text { September-December, } \\
\text { 1997-2000 }\end{array}$ & & -16 & -55 \\
\hline $\begin{array}{l}\text { Sri-Samrong } \\
\text { (SE Asia) }\end{array}$ & $\begin{array}{l}\text { December-March, } \\
\text { 1997-2000 }\end{array}$ & & -10 & -63 \\
\hline
\end{tabular}

aerosols (Li et al., 2004; Hsu et al., 2000) show that the TOA $E_{\tau}$ in winter is smaller than in summer, as shown in Table 16, presumably because biomass burning smoke is more absorbing than mineral dust. But such seasonal variations are not shown in other measurements. In winter, both MODIS and MODIS_A give a much greater value of $E_{\tau}$ than other measurements and model estimates. In summer, MODIS_A gives a
TOA cooling that is greater than other measurements and model estimates. For the surface $E_{\tau}$ and in both seasons, MODIS_A values are reasonably consistent with the results from Li et al. (2004), but are the upper bounds of the model estimates.

e. Arabian Sea and Northern Indian Ocean

The Northern Indian Ocean and Arabian Sea are in- 
Table 16. Summary of the clear-sky radiative efficiency $E_{\tau}$, defined as the aerosol radiative effect $\left(\mathrm{Wm}^{-2}\right)$ per unit aerosol optical depth $(\tau$ at $550 \mathrm{~nm})$, in tropical North Atlantic.

\begin{tabular}{|c|c|c|c|c|}
\hline \multirow{2}{*}{ Region } & \multirow{2}{*}{ Period } & \multirow{2}{*}{ Source } & \multicolumn{2}{|c|}{$E_{\tau}$} \\
\hline & & & TOA & Surface \\
\hline \multirow{10}{*}{ Zone 6 (ocean) } & DJF & MODIS & -45 & $\mathrm{n} / \mathrm{a}$ \\
\hline & & CERES_A & -33 & $\mathrm{n} / \mathrm{a}$ \\
\hline & & CERES_B & -28 & $\mathrm{n} / \mathrm{a}$ \\
\hline & & MODIS_A & -40 & -63 \\
\hline & & Models & $-16 \sim-35$ & $-36 \sim-63$ \\
\hline & JJA & MODIS & -34 & $\mathrm{n} / \mathrm{a}$ \\
\hline & & CERES_A & -32 & $\mathrm{n} / \mathrm{a}$ \\
\hline & & CERES_B & -25 & $\mathrm{n} / \mathrm{a}$ \\
\hline & & MODIS_A & -41 & -72 \\
\hline & & Models & $-16 \sim-41$ & $-27 \sim-68$ \\
\hline West coast of & NDJ & Li et al. (2004) & -26 & -81 \\
\hline \multirow[t]{4}{*}{ North Africa } & JJA & & -35 & -65 \\
\hline & July 1998 & Liu et al. (2003) & -18 & $\mathrm{n} / \mathrm{a}$ \\
\hline & February 1985 & Hsu et al. (2000) & $-62(14: 30 \mathrm{LT})$ & $\mathrm{n} / \mathrm{a}$ \\
\hline & July, 1985 & & $-69(14: 30 \mathrm{LT})$ & \\
\hline Puerto Rico & $\begin{array}{l}\text { June-July, } 2000 \\
\text { (daytime average) }\end{array}$ & Christopher et al. (2003) & -52 & -78 \\
\hline
\end{tabular}

fluenced by anthropogenic aerosols from South and Southeast Asia (Ramanathan et al., 2001b) and by local sea-salt and dust transported from the Arabian and Saharan regions (Satheesh and Srinivasan, 2002), with compositional contributions changing with season. While during the premonsoon period (JanuaryMarch) pollution dominates (Ramanathan et al., 2001b), the dust contribution becomes larger in April-May, as documented by the observations that show larger nearinfrared aerosol optical depth in April-May than during February-March (Satheesh and Srinivasan, 2002). This, along with weaker absorption by dust than by pollution, results in a more negative TOA DRE in May (Satheesh and Srinivasan, 2002). The aerosol direct solar effect also has large spatial variations over the tropical Indian Ocean (Rajeev and Ramanathan, 2001). The observed TOA solar effect north of the equator is about a factor of 2 greater than that south of the equator, with the minimum effect occurring around the Inter-Tropical Convergence Zone (ITCZ). The aerosol radiative effect also shows as much as a factor of 2 of interannual variation (Satheesh et al., 2002; Satheesh and Srinivasan, 2002) in the region.

Table 17 summarizes assessments of radiative efficiency in the region and field measurements in the Arabian Sea, northern Indian Ocean, and Bay of Bengal. In all seasons, MODIS and MODIS_A produce radiative efficiencies at the TOA in zone 7 that are greater than CERES measurements and model estimates. The MODIS_A $E_{\tau}$ values at the surface generally agree with the great- est efficiency of the model estimates. The values of $E_{\tau}$ at the TOA derived from MODIS and MODIS_A are consistently greater than a number of field experiments conducted in the northern Indian Ocean. Such differences may result from contrasts in aerosol compositions between the Arabian Sea (i.e., natural aerosol dominated) and the northern Indian Ocean (a mix of pollution and natural aerosol). Our analyses of several products over the east and west parts of the region separated at $65^{\circ} \mathrm{E}$ suggest geographical differences in aerosol composition and hence in the forcing efficiency. The MODIS_A algorithm's anthropogenic fraction of AOD during January-March is 0.76 and 0.30 in the east and west parts of the region, respectively. Following Kaufman et al. (2005a), a combination of MODIS/Terra AOD and fine-mode fraction gives the respective anthropogenic fractions of 0.81 and 0.45 . GOCART simulations also give the anthropogenic fractions of 0.72 and 0.42 in the east and west parts of the region, respectively. Note that these anthropogenic fractions in the east part of the region are consistent with chemical measurements during the INDOEX experiment (Satheesh et al., 2002). The MODIS_A algorithm also calculates the DRE efficiency for anthropogenic aerosol to be about $30 \%$ less negative than that from natural aerosols in the region.

\section{f. South America and South Africa}

During the austral winter and spring, biomass burning smoke significantly influences South America, 
Table 17. Summary of the clear-sky radiative efficiency $E_{\tau}$, defined as the aerosol radiative effect $\left(\mathrm{Wm}^{-2}\right)$ per unit aerosol optical depth $(\tau$ at $550 \mathrm{~nm}$ ), in Arabian Sea, Northern Indian Ocean, and South Asia.

\begin{tabular}{|c|c|c|c|c|}
\hline \multirow{2}{*}{ Region } & \multirow{2}{*}{ Period } & \multirow{2}{*}{ Source } & \multicolumn{2}{|c|}{$E_{\tau}$} \\
\hline & & & TOA & Surface \\
\hline \multirow[t]{15}{*}{ Zone 7 (ocean) } & \multirow[t]{5}{*}{ DJF } & MODIS & -45 & $\mathrm{n} / \mathrm{a}$ \\
\hline & & CERES_A & -33 & $\mathrm{n} / \mathrm{a}$ \\
\hline & & CERES_B & -26 & $\mathrm{n} / \mathrm{a}$ \\
\hline & & MODIS_A & -40 & -64 \\
\hline & & Models & $-15 \sim-34$ & $-39 \sim-69$ \\
\hline & \multirow[t]{5}{*}{ MAM } & MODIS & -35 & $\mathrm{n} / \mathrm{a}$ \\
\hline & & CERES_A & -29 & $\mathrm{n} / \mathrm{a}$ \\
\hline & & CERES_B & -23 & $\mathrm{n} / \mathrm{a}$ \\
\hline & & MODIS_A & -42 & -72 \\
\hline & & Models & $-14 \sim-37$ & $-35 \sim-77$ \\
\hline & \multirow[t]{5}{*}{ SON } & MODIS & -36 & $\mathrm{n} / \mathrm{a}$ \\
\hline & & CERES_A & -32 & $\mathrm{n} / \mathrm{a}$ \\
\hline & & CERES_B & -23 & $\mathrm{n} / \mathrm{a}$ \\
\hline & & MODIS_A & -41 & -65 \\
\hline & & Models & $-15 \sim-36$ & $-34 \sim-63$ \\
\hline \multirow{2}{*}{$\begin{array}{l}\text { Indian Ocean } \\
\text { (INDOEX) }\end{array}$} & \multirow{2}{*}{$\begin{array}{l}\text { January-March, } \\
\text { 1998, } 1999\end{array}$} & Satheesh and & \multirow{2}{*}{$-25 \sim-30$} & \multirow[t]{2}{*}{$-80 \sim-86$} \\
\hline & & $\begin{array}{l}\text { Ramanathan, 2000; Bush } \\
\text { and Valero, } 2002\end{array}$ & & \\
\hline Tropical Indian Ocean & Februray-March, 1998 & Conant, 2000 & $\mathrm{n} / \mathrm{a}$ & -76 \\
\hline Tropical Indian Ocean & $\begin{array}{l}\text { January-March, } \\
\text { 1998, } 1999\end{array}$ & Podgorny et al., 2000 & $\mathrm{n} / \mathrm{a}$ & -82 \\
\hline Arabian Sea & March, 2001 & Satheesh, 2002 & -29 & -74 \\
\hline Tropical Indian Ocean & & & -33 & -52 \\
\hline Bay of Bengal & & & -16 & -86 \\
\hline Bay of Bengal & October, 2003 & Sumanth et al., 2004 & -33 & -60 \\
\hline Arabian Sea & $\begin{array}{l}\text { January-March, 1996- } \\
2000\end{array}$ & $\begin{array}{l}\text { Tahnk and Coakley, } \\
2002\end{array}$ & $-32 \sim-34$ & $-57 \sim-67$ \\
\hline Bay of Bengal & & & $-31 \sim-32$ & $-62 \sim-71$ \\
\hline NH Indian Ocean & & & $-31 \sim-33$ & $-58 \sim-68$ \\
\hline Nepal & Winter, 2003 & Ramana et al. (2004) & $\mathrm{n} / \mathrm{a}$ & -73 \\
\hline
\end{tabular}

Table 18. Summary of the clear-sky radiative efficiency $E_{\tau}$, defined as the aerosol radiative effect $\left(\mathrm{Wm}^{-2}\right)$ per unit aerosol optical depth $(\tau$ at $550 \mathrm{~nm})$, in South America.

\begin{tabular}{|c|c|c|c|c|}
\hline Region & Period & Source & $E_{\tau}$ & Surface \\
\hline Zone 10 (Land) & SON & $\begin{array}{l}\text { AERONET } \\
\text { Models }\end{array}$ & $\begin{array}{l}-25 \\
-10 \sim-44\end{array}$ & $\begin{array}{l}-71 \\
-43 \sim-80\end{array}$ \\
\hline South America & SCAR-B & $\begin{array}{l}\text { Kinne and Pueschel, } 2001 \\
\text { Ross et al., } 1998 \\
\text { Christopher et al. (2000) }\end{array}$ & $\begin{array}{l}-13 \\
-20 \pm 7 \text { (tropical froest) } \\
-8 \pm 9 \text { (cerrado) } \\
-20 \sim-60 \text { (depending on land cover) }\end{array}$ & $\begin{array}{l}-72 \\
\mathrm{n} / \mathrm{a} \\
\mathrm{n} / \mathrm{a} \\
\mathrm{n} / \mathrm{a}\end{array}$ \\
\hline
\end{tabular}


Southern Africa and the South Atlantic. Table 18 summarizes the $E_{\tau}$ assessments in South America. The AERONET measurements give $E_{\tau}$ of $-25 \mathrm{Wm}^{-2} \tau^{-1}$ and $-71 \mathrm{Wm}^{-2} \tau^{-1}$ at the TOA and at the surface, respectively. Model estimates cover a wide range of $-14 \sim-44 \mathrm{Wm}^{-2} \tau^{-1}$ at the TOA and $-43 \sim-80 \mathrm{Wm}^{-2} \tau^{-1}$ at the surface. Several studies demonstrate that the TOA radiative effect depends strongly on surface land cover (Ross et al., 1998; Christopher et al., 2000).

The above compilation of literature values of aerosol radiative efficiency shows large differences among measurements in some regions, but reasons for these differences remain largely unknown. Substantial effort is needed to explain the differences among methods. This generally requires a close look into all factors that determine the magnitude of radiative efficiency, including assumptions or measurements of wavelength-dependent aerosol properties, and comparison of radiative transfer schemes, surface parameterizations, and the numerics of the radiative transfer calculations. However, lack of complete documentation of all relevant parameters in previous publications makes any complete analysis, not only formidable, but impossible. Because understanding the reasons for differences in $E_{t}$ is so important, the research community should document all parameters determing the radiative efficiency in future publications.

3.4 Estimating anthropogenic aerosol direct climate forcing

Estimates of anthropogenic aerosol optical depth and direct forcing so far have been predominantly model-based. The determination of anthropogenic aerosols requires a quantification of biomass burning ignited by lightning (natural origin) and mineral dust due to human induced changes of land cover change and climate (anthropogenic origin), which remains uncertain. In addition, dust emission could be affected by land use changes and changes of atmospheric dynamics and thermodynamics (e.g., wind and humidity) due to radiative forcing from other climate agents, which is also difficult to quantify. Recent modeling (Tegen et al., 2004) suggests that the anthropogenic sources of dust contribute less than $10 \%$ of the total dust optical thickness, although early studies speculated the fraction to be between $0 \%$ (Ginoux et al., 2001) and 50\% (Tegen and Fung, 1995). Three global chemical transport models, namely GOCART, LMDZ-LOA, and SPRINTARS, consistently give the anthropogenic aerosol optical depth of $0.03 \sim 0.036$ over global oceans (Kaufman et al., 2005a).

Satellite instruments do not measure the aerosol chemical composition needed to discriminate anthropogenic from natural aerosol components. Because anthropogenic aerosols are predominately sub-micron, the fine-mode fraction de- rived from new-generation satellite sensors like POLDER, MODIS, or MISR, might be used as a surrogate for deriving anthropogenic aerosol optical thicknesses. This could provide a feasible way to conduct measurement-based estimates of anthropogenic aerosol forcing (Kaufman et al., 2002a). Kaufman et al. (2005a) show that the fraction of the aerosol originating from anthropogenic activity can be estimated from MODIS measurements with an uncertainty of $\pm 30 \%$ over the oceans. The so-derived average anthropogenic aerosol optical depth is about 0.033 , consistent with assessments of $0.03 \sim 0.036$ from three global chemical transport models even though the total AOD from MODIS is 25$40 \%$ higher than the models (Kaufman et al., 2005a). This accounts for $21 \pm 7 \%$ of the MODIS observed total aerosol optical depth, compared with about $33 \%$ of anthropogenic contributions estimated by the three models. The anthropogenic fraction of AOD should be much larger over land and several model simulations derive a fraction of $47 \pm 9 \%$ (Bellouin et al., 2005). To improve satellite estimates of anthropogenic aerosols and their direct forcing, satellite programs should concentrate on validating and improving retrievals of the aerosol Ångström exponent, and suborbital measurements should be used to derive relationships between the Ångström exponent and fine-mode fraction to allow interpretation of the satellite derived fine-mode optical depth (Anderson et al., 2005b).

There have been some estimates of DCF by anthropogenic aerosols. Kaufman et al. (2005a) estimate that the anthropogenic DCF at the TOA is $-1.4 \pm 0.4 \mathrm{Wm}^{-2}$ over ocean. Bellouin et al. (2005) decompose MODIS total AOD into three generic aerosol types, namely marine aerosol, mineral dust, and biomass burning and pollution, by using the MODIS fine-mode fraction in combination with the TOMS aerosol index (a semi-quantitative measure of UV-absorbing aerosol loading) and SSM/I wind speed (for estimating the marine AOT). They estimate that on a global and annual average, the clear-sky DCF is $-1.9 \pm 0.3 \mathrm{Wm}^{-2}$ and $-4.4 \pm 0.6 \mathrm{Wm}^{-2}$ at the TOA and surface, respectively. $\mathrm{Yu}$ et al. (2004) combine MODIS retrievals and GOCART simulations to yield the clear-sky DCF of -1.4 and $-4.2 \mathrm{Wm}^{-2}$ at the TOA and surface, respectively. These respectively account for about $31 \%$ and $42 \%$ of the DRE. Recent model simulations report similar DCF/DRE ratios, but a factor of 2 smaller DCF in magnitude (Reddy et al., 2005b).

Anderson et al. (2005a) establish a conceptual framework for achieving an observationally based quantification of DCF through the use of satellite observations coordinated with suborbital remote and in-situ measurements and with chemical transport models. The clear-sky DCF at a specific time and location can be expressed as:

$\mathrm{DCF}=\tau f_{f} f_{a f} E_{a}$

Its integration over time and space (weighted by surface area) gives the regional or global average DCF. In this conceptual model, the clear-sky DCF is determined by optical depth $(\tau)$, 
fine-mode fraction of $\tau\left(f_{f}\right)$, anthropogenic fraction of finemode $\tau\left(f_{a f}\right)$, and forcing efficiency with respect to anthropogenic $\tau\left(E_{a}\right)$. By dividing each variable into mean and perturbation (uncertainty) and applying Reynold's averaging, the uncertainty analysis can therefore be approached in terms of our knowledge of the global-mean value of each parameter and their complex correlations. Given the absence of knowledge about correlations between the deterministic parameters of DCF, the current calculation is framed in terms of mean values only.

Table 19 presents an uncertainty analysis for land and ocean separately, in which observational constraints derived from this review are imposed and for other parameters that lack observational constraints, assumptions are made based on model simulations. Assignment of these values is detailed in the table footnote. The clear-sky DCF is $64 \%$ larger in magnitude (more negative) over land than over ocean. Its uncertainty is also larger over land than over ocean. When weighted by the fractional area of land (0.3) and ocean (0.7), the global clear-sky DCF is estimated to be $-1.3 \mathrm{~W} / \mathrm{m}^{2}$ with an uncertainty of $62 \%$. The uncertainty partitions to the land and ocean more or less evenly. The parameter uncertainty contribution to DCF further suggests that five parameters, namely $f_{f}$ and $\mathrm{f}_{a f}$ over both land and ocean, and $\tau$ over ocean, introduce nearly $80 \%$ of the overall uncertainty in the DCF estimate, with individual shares ranging from 13$20 \%$. The smallest contribution comes from $\tau$ over land. We should point out that these uncertainties presumably represent a lower bound because the sources of error are assumed to be independent. Uncertainties associated with several parameters are also not well defined. Nevertheless, such uncertainty analysis would be useful for guiding future research and documenting advance of our understanding.

\section{Discussion: outstanding issues}

Despite substantial progress in the assessment of the aerosol direct effect as summarized above, several important issues remain, and significant efforts are required to address them. As discussed earlier, most measurement-based studies so far have concentrated on the influences by the sum of natural and anthropogenic aerosols on solar radiation in clear sky conditions. Current DCF estimates are poorly constrained by observations. Because of a lack of measurements of aerosol absorption and difficulty in characterizing land surface reflection, estimates of DRE over land and at the ocean surface are currently realized through a combination of satellite retrievals, surface measurements, and model simulations, and are less constrained than the estimate of TOA DRE over ocean. There is also a need to quantify aerosol impacts on the thermal infrared radiation and characterize the cloud modulation of aerosol-radiation interactions. In addition, quantifying aerosol absorption remains a pressing issue. It is also essential to adequately characterize diurnal variations of the aerosol radiative effect. Finally, aerosol measurements from different platforms generally are not consistent in terms of their spatial and temporal representativeness. A great effort is necessary to account for such inconsistencies when comparing and integrating different aerosol measurements.

\subsection{Direct effect in the thermal infrared range and in cloudy conditions}

Due to their large size, mineral dust and sea-salt aerosols can cause warming in the thermal infrared, both at the TOA and at the surface. Such a warming effect could be significant, as suggested by a few observational studies summarized in Table 20. Therefore, our estimates of aerosol direct effect on solar radiation should represent an upper bound of the aerosol net direct effect (on total radiative fluxes). The thermal infrared effect of Saharan dust could account for $10 \%$ (Highwood et al., 2003) to $30 \%$ (Hsu et al., 2000) of the observed instantaneous solar effect. Haywood et al. (2005) demonstrate that mineral dust in July can exert a thermal infrared forcing by as much as $50 \mathrm{Wm}^{-2}$ in the monthly mean for 12:00 UTC in cloud-free regions, which accounts for the discrepancy between model calculations and the satellite observations. Zhang and Christopher (2003) derived a thermal infrared warming of $15 \mathrm{Wm}^{-2} \tau^{-1}$ at the satellite overpassing time over the Saharan desert that would cancel $\sim 40 \%$ of the solar cooling at the TOA. Satheesh and Lubin (2003) show that aerosols in the northern Indian Ocean, a mixture of dust, sea-salt and pollution, would impose a thermal infrared warming that could reduce the solar radiative effect by about $45 \%$ at modest winds $\left(4-6 \mathrm{~ms}^{-1}\right)$ and by more than $70 \%$ at high winds $\left(>10 \mathrm{~ms}^{-1}\right)$, because sea-salt production increases with wind speed. Nevertheless, current estimates of aerosol warming effects in the thermal infrared remain highly uncertain, because assessment of the effects requires vertical distributions of aerosol extinction and atmospheric temperature that are not well characterized by either observations or simulations (Sokolik et al., 2001; Lubin et al., 2002). Aerosol optical properties in the thermal infrared range are rarely measured directly, hence the estimates of the thermal infrared effect depend largely on assumed aerosol models. In addition, the scattering effect in the thermal infrared domain is generally neglected in most GCMs, which may lead to an underestimate of the thermal infrared aerosol effect (Dufresne et al., 2002).

Like most studies, our assessments in section 3 have focused on the clear-sky direct effect. Calculations of the cloudy-sky aerosol direct effect require an adequate characterization of vertical distributions of aerosols and three-dimensional fields of clouds, especially for absorbing aerosols (Haywood and Shine, 1997; Liao and Seinfeld, 1998; Podgorny and Ramanathan, 2001; Zhou et al., 2005). Neglect of aerosol impacts in cloudy conditions generally would introduce large errors to the aerosol direct effect, as documented by observations. In the tropical Indian 
Table 19. Uncertainty analysis of DCF at the TOA using only mean-values (regional and annual averages) of individual parameters $\tau$, $f_{f}$, $f_{a f}$, and $E_{a}$.

\begin{tabular}{|c|c|c|c|c|c|c|c|c|c|c|c|}
\hline \multirow[b]{2}{*}{ Parameter } & \multicolumn{4}{|c|}{ Land } & \multicolumn{4}{|c|}{ Ocean } & \multicolumn{3}{|c|}{ Globe } \\
\hline & Mean & Uncert. & $\begin{array}{l}\text { Relative } \\
\text { Uncert. }\end{array}$ & $\begin{array}{l}\text { Param. } \\
\text { Uncert. } \\
\text { Contrib. } \\
\text { to DCF }\end{array}$ & Mean & Uncert & $\begin{array}{l}\text { Relative } \\
\text { Uncert. }\end{array}$ & $\begin{array}{l}\text { Param. } \\
\text { Uncert. } \\
\text { Contrib. } \\
\text { to } \mathrm{DCF}^{\mathrm{a}}\end{array}$ & Mean & Uncert. & $\begin{array}{l}\text { Relative } \\
\text { Uncert. }\end{array}$ \\
\hline$\tau^{\mathrm{b}}$ & 0.22 & 0.05 & $23 \%$ & $3 \%$ & 0.14 & 0.03 & $21 \%$ & $13 \%$ & 0.16 & 0.04 & $22 \%$ \\
\hline$f_{f}^{\mathrm{c}}$ & 0.50 & 0.25 & $50 \%$ & $14 \%$ & 0.40 & 0.10 & $25 \%$ & $17 \%$ & 0.43 & 0.15 & $34 \%$ \\
\hline$\tau_{f}$ & 0.110 & 0.062 & $55 \%$ & & 0.056 & 0.018 & $33 \%$ & & 0.072 & 0.031 & $43 \%$ \\
\hline$f_{a f}^{\mathrm{d}}$ & 0.80 & 0.40 & $50 \%$ & $14 \%$ & 0.55 & 0.15 & $27 \%$ & $20 \%$ & 0.625 & 0.225 & $36 \%$ \\
\hline$\tau_{a}$ & 0.088 & 0.065 & $74 \%$ & & 0.031 & 0.013 & $43 \%$ & & 0.048 & 0.039 & $60 \%$ \\
\hline$E_{a}{ }^{\mathrm{e}}$ & -20 & 8 & $40 \%$ & $9 \%$ & -37 & 7 & $19 \%$ & $10 \%$ & -31.9 & 7.3 & $23 \%$ \\
\hline $\mathrm{DCF}$ & -1.8 & 1.5 & $84 \%$ & & -1.1 & 0.5 & $47 \%$ & & -1.33 & 0.82 & $62 \%$ \\
\hline $\mathrm{DCF}_{\text {wght }}{ }^{\mathrm{f}}$ & -0.53 & 0.45 & $84 \%$ & $54 \%$ & -0.80 & 0.37 & $47 \%$ & $46 \%$ & & & \\
\hline
\end{tabular}

a Parameter uncertainty contribution to DCF: contribution of this parameter (over land or ocean ) to the uncertainty of global-mean DCF.

b Aerosol optical depth $(\tau)$ : taken from MISR measurements over land (Kahn et al., 2005a) and MODIS measurements over ocean (Remer et al., 2005).

${ }^{\mathrm{c}}$ Fine-mode fraction of $\tau\left(f_{f}\right)$ : over ocean, based on MODIS-AERONET comparisons (Kleidman et al., 2005); lack of observation constraint over land.

d Anthropogenic fraction of fine-mode $\tau\left(f_{a f}\right)$ : lack of observational constraint. Over ocean, the value is assigned so that the anthropogenic $\tau$ is consistent with estimate by Kaufman et al. (2005a).

${ }^{\mathrm{e}}$ Forcing efficiency $E_{a}\left(\mathrm{Wm}^{-2}\right.$ per unit $\left.\tau_{a}\right)$ : assuming $E_{a}=E_{\tau}$ (for total aerosols). There should be some differences between $E_{a}$ and $E_{\tau}$ because of differences in chemical composition and size of natural and anthropogenic aerosols. On the one hand, anthropogenic aerosol should be more absorptive than total aerosol (i.e., smaller single-scattering albedo) and hence has a smaller radiative efficiency. On the other hand, the smaller size may suggest a larger radiative efficiency consistent with larger backscattering and larger single-scattering albedo. $E_{a}$ values over ocean are based on mean and one standard deviation of measurement-based $E_{\tau}$. Over land, the measurement-based estimates are rare and the values assigned here are based on a combination of observations and models in this review.

${ }^{\mathrm{f}} \mathrm{DCF}_{\mathrm{wght}}$ : the value of DCF weighted by fractional area of land $(0.3)$ or ocean $(0.7)$.

Ocean, the surface cooling in climatologically cloudy conditions is comparable to that under clear conditions, while the TOA effect could switch from cooling in clear conditions to warming in overcast conditions (Podgorny and Ramanathan, 2001). Observations over the South Atlantic show a clear separation between the elevated smoke layer from southern Africa (2-4 km) and low-level stratiform clouds (below $1 \mathrm{~km}$ ) during the SAFARI 2000 experiment. In the presence of clouds, the smoke causes a net TOA warming of $12 \mathrm{Wm}^{-2}$, compared to a cooling of $-13 \mathrm{Wm}^{-2}$ in clear conditions for average smoke conditions and at a SZA of $60^{\circ}$ (Keil and Haywood, 2003). Note that substantial differences currently exist in aerosol vertical distributions simulated by different models (Penner et al., 2002; Textor et al., 2005) and limited measurements do not suffice for the estimate of the cloudy-sky effect. Hopefully, the emerging ground-based aerosol lidar network (as discussed in Sect. 2.2) and launch of spaceborne lidars and radars (Stephens et al., 2001) will help improve the understanding of the aerosol direct effect in cloudy conditions and the thermal infrared range.

\subsection{Deriving aerosol direct effect over land from satellite}

It has been easier to estimate the aerosol direct effect from satellite measurements over ocean than over land because the dark ocean surface reflection is easier to characterize for this purpose. As such, the direct effects over land presented in Sect. 3 are poorly constrained. The land surface reflection is large, heterogeneous, and anisotropic, which complicates the determination of the aerosol direct effect. For example, Hsu et al. (2000) detect a significant impact of Saharan dust on solar radiation over the Atlantic Ocean but no clear signal over the nearby Saharan deserts. We believe that the lack of dust signal over the deserts is attributable to the large heterogeneity of surface reflectance as documented by high-resolution MODIS land albedo retrievals (Tsvetsinskaya et al., 2002). The new-generation satellite sensors like MODIS and MISR are improving the characterization of land surface reflection by measuring its wavelength dependence and angular distribution at high resolution. This offers a promising opportunity for inferring the aerosol direct effect over land from satellite measurements of radiative fluxes (e.g., CERES). 
Table 20. Summary of measurement-based clear-sky aerosol direct radiative effect estimates in the thermal infrared from the literature. The values generally refer to the clear-sky radiative efficiency $E_{\tau}$ at the TOA if not specified.

\begin{tabular}{|c|c|c|c|c|}
\hline Region & Period & Thermal infrared effect & References & Notes \\
\hline \multirow[t]{2}{*}{$\begin{array}{l}\text { West Coast of } \\
\text { North Africa }\end{array}$} & SHADE & $\begin{array}{l}+6 \mathrm{Wm}^{-2} \\
+11 \mathrm{Wm}^{-2}(\text { surface })\end{array}$ & Highwood et al., 2003 & $\begin{array}{l}10 \% \text { of instantaneous } \\
\text { solar effect }\end{array}$ \\
\hline & $\begin{array}{l}\text { February, } 1985 \\
\text { July } 1985\end{array}$ & $\begin{array}{l}+24 \mathrm{Wm}^{-2} \tau^{-1} \\
+28 \mathrm{Wm}^{-2} \tau^{-1}\end{array}$ & Hsu et al., 2000 & $\begin{array}{l}1 / 3 \text { of solar effect } \\
\text { at } 14: 30 \mathrm{LT}\end{array}$ \\
\hline \multirow[t]{2}{*}{ Saharan deserts } & September, 2000 & $+7 \mathrm{Wm}^{-2}$ or $15 \mathrm{Wm}^{-2} \tau^{-1}$ & $\begin{array}{l}\text { Zhang and Christopher, } \\
2003\end{array}$ & $\begin{array}{l}\text { Satellite overpassing } \\
\text { time }\end{array}$ \\
\hline & $\begin{array}{l}\text { February, } 1985 \\
\text { July } 1985\end{array}$ & $\begin{array}{l}+36 \mathrm{Wm}^{-2} \tau^{-1} \\
+44 \mathrm{Wm}^{-2} \tau^{-1}\end{array}$ & Hsu et al., 2000 & $14: 30 \mathrm{LT}$ \\
\hline $\begin{array}{l}\text { Equator to } 30 \mathrm{~N}, \\
60 \mathrm{~W} \text { to } 40 \mathrm{E}\end{array}$ & SHADE & $\begin{array}{l}+1 \mathrm{Wm}^{-2} \\
+0.8 \mathrm{Wm}^{-2}\end{array}$ & Myhre et al., 2003 & $\begin{array}{l}\text { Clear-sky } \\
\text { Whole-sky }\end{array}$ \\
\hline $\begin{array}{l}\text { West Coast of } \\
\text { Europe }\end{array}$ & ACE-2 & $+1.2 \mathrm{Wm}^{-2}$ & Kinne and Pueschel, 2001 & \\
\hline Northwest Pacific & $\begin{array}{l}\text { April, } 2001 \\
\text { (ACE-Asia) }\end{array}$ & A few to $10 \mathrm{Wm}^{-2}$ & $\begin{array}{l}\text { Markowicz et al., 2003; } \\
\text { Vogelmann et al., } 2003\end{array}$ & $\begin{array}{l}\text { Daytime average; } \\
\text { Depending on aerosol } \\
\text { loading }\end{array}$ \\
\hline Northwest Pacific & March, 1994 & $+3 \mathrm{Wm}^{-2}$ & Kinne and Pueschel, 2001 & $\begin{array}{l}\text { Asian continental } \\
\text { outflow }\end{array}$ \\
\hline \multirow[t]{2}{*}{ Arabian Sea } & INDOEX & $\begin{array}{l}+1.3 \mathrm{Wm}^{-2} \\
+7.7 \mathrm{Wm}^{-2} \text { (surface) }\end{array}$ & Lubin et al., 2002 & Within ABL \\
\hline & & $\begin{array}{l}+2.7 \mathrm{Wm}^{-2} \\
+11 \mathrm{Wm}^{-2}(\text { surface })\end{array}$ & & $\begin{array}{l}\text { High loading, more } \\
\text { extended in the vertical }\end{array}$ \\
\hline
\end{tabular}

\subsection{Aerosol single-scattering albedo and absorption}

Aerosol absorption and single-scattering albedo are strong functions of the size of particles, the state of mixture, the wavelength and the relative humidity. A characterization of aerosol absorption or SSA is complicated by instrumental errors and modeling inadequacies, as summarized in Heintzenberg et al. (1997) and Reid et al. (2005). The global assessment of aerosol absorption and SSA represents a major challenge in efforts to quantify direct forcing. Aerosol direct effects over land and at the bottom of the atmosphere depend strongly on aerosol single-scattering albedo and the estimates discussed in Sect. 3 are poorly constrained because of lack of reliable data on global scale.

Instrument calibration for aerosol absorption measurements is challenging, because aerosol absorption typically has a much smaller magnitude than aerosol scattering (Heintzenberg et al., 1997). Determining aerosol absorption by subtracting measured scattering from measured extinction could have large uncertainties (e.g., Reid et al., 2005; and references therein). In-situ measurements are generally conducted at low relative humidity and effects of water uptake on aerosol absorption are poorly understood (Redemman et al., 2001), making the determination of ambient aerosol absorption and single-scattering albedo difficult (Heintzenberg et al., 1997). Model simulations of aerosol compositions have large diversities because of large uncertainties in emission inventories and in parameterizations of a variety of aerosol processes (Kinne et al., 2003; 2005). The state of mixture is also empirically assumed in model simulations. As such, large uncertainties exist in model calculations of single-scattering albedo (Kinne et al., 2005).

Inverse methods have been widely used both in ground and satellite remote sensing, providing aerosol absorption information at large geographical areas and during long time periods. The theoretical uncertainty of the AERONET retrieval of SSA is 0.03 for AOD greater than 0.3 (Dubovik et al., 2002). Similarly, at large AOD the estimated AERONET uncertainty for absorptive optical depth is 0.01 (Dubovik and King, 2000; Dubovik et al., 2001). These estimated accuracies have yet to be validated by independent measurements. It is important to pursue such validation because a recent study has shown a factor of 2-4 discrepancy between the AERONET retrievals and the simulated absorptive optical depths from two models (Sato et al., 2003). This discrepancy would imply significant errors in the global burden of black carbon and/or the absorptive efficiency of black carbon (perhaps related to aerosol mixing state, morphology, or size distribution) (Sato et al., 2003; Martins et al., 1998; Jacobson, 2000, 2001). On the other hand, a recent comparison of in-situ to AERONET absorption over the Chesapeake Bay in- 
dicated that the latter may be biased high (Magi et al., 2005). Satellite methods for quantifying SSA and absorption have been developed and partially validated at UV wavelengths (Torres et al., 1998, 2002, 2005), although the retrieval has large uncertainties associated with its sensitivity to the height of the aerosol layer and it is unclear at present how these UV results can be extended to visible wavelengths. Kaufman et al. (2002b) developed an algorithm using views in and out of sunglint to retrieve total aerosol extinction and scattering, respectively, thus constraining aerosol absorption over oceans. The technique is going to be applied to the collocated MODIS and PARASOL data in the A-Train. Note that the MODIS and CERES methods described in Sect. 3 bypass the need for estimates of aerosol single-scattering albedo and other aerosol characteristics to calculate DRE at the TOA. Instead aerosol characteristics are intrinsically included in the basic satellite retrieval.

\subsection{Diurnal cycle}

The assessments in previous sections have focused on the diurnally averaged aerosol direct effect and forcing, because of lack of observations of diurnal variability of aerosols from space. Significant efforts are demanded to capture the diurnal cycle of aerosol direct forcing in order to better assess aerosol impacts on climate. In this context, diurnal variability of aerosol and cloud needs to be adequately characterized. AERONET measurements show that the daytime variability depends on location and aerosol type, with the variation as large as $40 \%$ for biomass burning smoke and urban/industrial pollution near the sources, and essentially negligible for dust (Smirnov et al., 2002). From the perspective of satellite remote sensing, the diurnal variation of aerosols can be better characterized by geostationary satellites (GOES) (Christopher and Zhang, 2002; Wang et al., 2003a, b). However, these satellites generally lack the information required to characterize aerosol types. Costa et al. (2004a, b) developed a method based on the synergistic use of low earth orbit and geostationary earth orbit satellite data for aerosol-type characterization, AOD retrieval and aerosol monitoring over the ocean. They use multiple spectral measurements from the low earth orbit satellite to characterize aerosol types dynamically. The derived aerosol type information is then used for retrieving aerosols from geostationary satellite measurements. By so doing, the diurnal variation of aerosols can be monitored. MODIS flying on the twin EOS satellites, namely Terra and Aqua, can also be used to some extent to characterize aerosol diurnal variations, i.e., from late morning (10:30 LT) to early afternoon (13:30 LT) (Ichoku et al., 2005). Clouds can modulate the aerosol direct solar effect significantly and daytime variations of clouds need to be adequately characterized.

The aerosol direct effect depends on surface reflection, and the anisotropy of surface reflection further complicates the calculation of the diurnal cycle of the aerosol radiative effect.
As discussed in Sect. 2.3, neglecting anisotropy of surface reflection could lead to significant overestimation of the diurnal range of the aerosol direct effect (Yu et al., 2004). With satellite remote sensing providing angular and spectral variations of surface reflection (e.g., Moody et al., 2005; Martonchik et al., 1998, 2002), it is feasible to better characterize the complexity of surface reflection and its interaction with aerosol extinction through the use of the black-sky and white-sky albedo for direct beam and diffuse light, respectively (Yu et al., 2004; Bellouin et al., 2004).

\subsection{Spatial and temporal scaling}

Aerosol measurements from different platforms provide information representing different spatial and temporal scales. A unified picture of the global aerosol system would emerge only after these differences are fully understood and accounted for (e.g., Diner et al., 2004). Polar-orbiting satellites can only observe global aerosols once a day. The geostationary satellites can monitor evolutions of aerosols at an hourly scale but usually cover limited regions. Aerosols can be substantially under-sampled by satellite sensors in regions with a high frequency of cloud presence. Ground-based sun photometers sample aerosols only during daylight hours, without clouds. Such point-type measurements may not be representative of the $10^{2} \mathrm{~km}^{2}$ grid boxes of current global aerosol models. These inconsistencies complicate intercomparison and integration of aerosol products from different sources because aerosols generally show significant variability over meso-scales (e.g., 40-400 km and 2-48 hours) (Anderson et al., 2003b). Several studies have examined these spatial and temporal scaling issues. For example, Kaufman et al. (2000) demonstrate that MODIS measurements onboard Terra and Aqua on average well represent the daily aerosols by analyzing the daytime variations of AERONET optical thickness. New results from MODIS on Terra and Aqua confirm this analysis (Kaufman et al., 2005b). High-resolution satellite retrievals prove to be extremely useful for examining spatial variability of aerosols and comparing satellite retrieved or model simulated grid-box averages with point measurements from ground-based networks (Ichoku et al., 2002). Alexandrov et al. (2004b) derive statistics of temporal and spatial variations of aerosols based on high-frequency MFRSR measurements at two ARM sites located in Oklahoma and Kansas. However, the aerosol variability controlled by emissions and meteorological conditions should depend on location and time, making it challenging to account for these variations in regional- and global-scale intercomparisons and in data assimilation and integration.

\subsection{Long-term trends of aerosols and their radiative effects}

To detect long-term trends of aerosols, satellite retrievals of aerosol optical depth should have an accuracy of $\pm 0.02 \sim 0.04$ (Mishchenko et al., 2004) and a synergy of 
aerosol products from multiple sensors (historical sensors and modern sensors) is needed to construct as long a record as possible. Historical sensors like TOMS and AVHRR have provided multi-decadal climatology of aerosol optical depth (Torres et al., 2002; Geogdzhayev et al., 2002), which have been used to analyze trends of aerosol optical depths between 1979 and 2002 in Asia (e.g., Massie et al., 2004). These products should be extended to a longer period by incorporating data from modern sensors (e.g., MODIS, MISR, OMI, and others). Such extensions should be built upon our understanding and reconciliation of AOD differences among different sensors or platforms. A good deal of effort is needed to address this fundamental issue. Broadband direct solar radiation is measured at meteorological stations around the world. These long-term observations can be used to derive average aerosol optical depth over the solar spectrum, thus having the potential to detect changing aerosol conditions on a decadal scale (Luo et al., 2001). The accuracy of such retrieved aerosol optical depth depends on the quality of the observations, including cloud-screening procedures and parameterizations of Rayleigh scattering, gaseous absorption, and aerosol extinction. These aerosol optical depth retrievals from meteorological stations still need to be evaluated using independent measurements from other surface observations, such as AERONET and MFRSR.

Analysis of long-term records of surface solar radiation, either in clear-sky or all-sky conditions, suggests significant trends during past decades (e.g., Stanhill and Cohen, 2001; Wild et al., 2005; Pinker et al., 2005). While a significant and widespread decline in surface solar radiation occurred up to 1990 (so-called global dimming), a sustained increase has been observed in the most recent decade. Speculation suggests that such trends result from decadal changes of aerosols and an interplay of aerosol direct and indirect effects (Stanhill and Cohen, 2001; Wild et al., 2005). However, reliable observations of aerosol trends are needed before these speculations can be proven. In addition to the aerosol optical depth, we also need to quantify changes in aerosol composition because of changes in industrial practices, environmental regulations, and biomass burning emissions will affect the aerosol single-scattering albedo and size distribution, which in turn will affect surface solar radiation. Such data currently do not exist.

\section{Concluding remarks}

\subsection{Summary}

Since the concept of aerosol-radiation-climate interactions was first proposed around 1970, substantial progress has been made in determining the mechanisms and magnitudes of these interactions, particularly in the last ten years. Such advancement has greatly benefited from significant improvements in aerosol measurements and increasing sophistica- tion of model simulations. In particular, the establishment of ground-based aerosol networks such as AERONET and the execution of intensive field experiments in a variety of aerosol regimes have collected invaluable datasets that have been serving as a baseline for constraining and evaluating satellite retrievals and model simulations. New and enhanced satellite sensors, such as POLDER, MODIS, and MISR, are measuring aerosols on a global scale and with good accuracy. CERES measures broadband solar and thermal infrared fluxes that are used to derive aerosol radiative effect and forcing.

As a result of these improvements, we now have a much improved knowledge of aerosol properties and their interaction with solar radiation on a global scale. The multispectral MODIS measures global distributions of aerosol optical depth $(\tau)$ on a daily scale, with high accuracy of $\pm 0.03 \pm 0.05 \tau$ over oceans. The annual average $\tau$ is about 0.14 over the global oceans. Based on the MODIS fine-mode and background aerosol fraction, about $21 \%$ of the 0.14 is estimated to be contributed by human activities.. The multiangle MISR can evaluate the surface reflectance and retrieve aerosols simultaneously over all kinds of surfaces, including bright deserts. MISR derives an annual average AOD of 0.23 over global land with an uncertainty of $\sim 20 \%$ or \pm 0.05 . A combination of MODIS over-ocean and MISR over-land retrievals gives a global average of aerosol optical depth of about 0.17 , which is $21 \%$ larger than an ensemble average of 0.14 of five global aerosol models. It is possible that such discrepancy can be largely reduced by correcting cloud contamination in satellite retrievals.

The high-accuracy of MODIS and MISR aerosol products and broadband flux measurements from CERES, together with simultaneous improvements in surface and cloud characterizations in these sensors, make it feasible to obtain observational constraints for the aerosol direct effect. Figure 11 summarizes the measurement- and model-based estimates of clear-sky annual average DRE at both the TOA and surface. A number of measurement-based approaches consistently estimate the clear-sky DRE (on solar radiation) at the top-ofatmosphere to be about $-5.5 \pm 0.2 \mathrm{Wm}^{-2}$ (median \pm standard error from various methods) over global ocean. At the ocean surface, the DRE is estimated to be $-8.8 \pm 0.7 \mathrm{Wm}^{-2}$ with a combination of MODIS optical depth, AERONET measurements, and CTM simulations. Over land, deriving the aerosol direct effect from the flux measurements such as that from CERES is complicated by a large and highly heterogeneous surface reflection. An integration of satellite retrievals and model simulations yields a DRE of $-4.9 \pm 0.7 \mathrm{Wm}^{-2}$ and $-11.8 \pm 1.9 \mathrm{Wm}^{-2}$ at the TOA and surface, respectively. Overall, in comparison to that over ocean, the DRE estimates over land are more poorly constrained by observations and have larger uncertainties. An ensemble of five model simulations gives a DRE that is about 30-50\% smaller than the measurement-based estimate. Such discrepancy could be reduced to $15-40 \%$ after accounting for cloud 

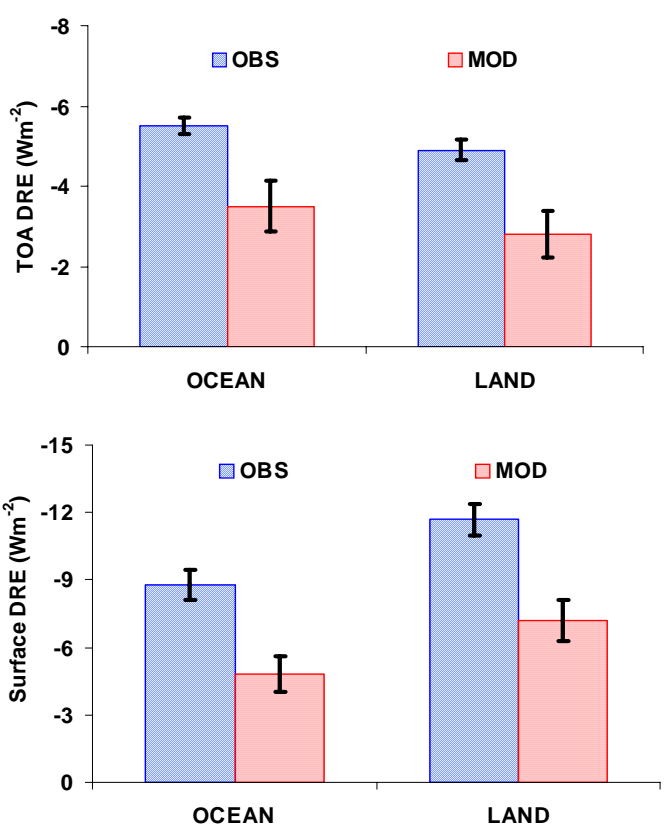

Fig. 11. Summary of observation- and model-based (denoted as OBS and MOD, respectively) estimates of clear-sky, annual average DRE at the TOA (top) and at the surface (bottom). The box and vertical bar represent median and standard error, respectively.

contamination in satellite retrievals. The integration of satellite and surface measurements into a CTM proves to be a promising and essential approach to producing an optimal description of global aerosol distributions.

\subsection{Future research}

Despite significant achievements in the past decade several issues associated with measurement-based assessments remain open. We hope enhanced measurement capabilities and a high-level of scientific cooperation will further advance our knowledge in the following subjects:

- Measurements of aerosol direct effect over land: While various measurement-based methods derive a consistent estimate of global aerosol direct effect over ocean, the direct effect over land is poorly constrained. Deriving the aerosol direct effect from the broadband flux measurements (e.g., CERES) requires high quality retrievals of aerosol optical depth and adequate characterization of the heterogeneity and anisotropy of the land surface reflection. The aerosol direct effect over land also depends strongly on aerosol absorption. Large uncertainties in spatial and temporal variations of aerosol singlescattering albedo may constitute the largest source of uncertainty in aerosol forcing and climate response.

- Measurements of anthropogenic aerosol and direct climate forcing: Measurement-based assessment of direct climate forcing by anthropogenic aerosol has been only applied to oceans because of the limited capability of satellite sensors in retrieving aerosol size information over land. The NASA Glory Mission using a multiangle, multi-spectral polarimeter will acquire information on aerosol size distribution, absorption, and chemical composition with good accuracy (Mishchenko et al., 2004). Such new observations could help determine the anthropogenic contribution of aerosols.

- Quantification of cloud impacts on aerosol direct forcing: The aerosol forcing in cloudy conditions remains relatively unexplored and quite uncertain because of a lack of measurements of the diurnal cycle and vertical profiles of aerosols and clouds. The constellation of the new-generation satellite sensors (e.g., A-Train) provides an unprecedented opportunity to improve aerosol characterization. In particular, satellite-borne lidar systems in ICESat and CALIPSO will improve aerosol profiling and assessment of the aerosol direct effect in cloudy conditions. Networks of surface-based lidars will also be of value. These new lidar observations can also help constrain the estimate of the thermal infrared radiative forcing.

- A synergistic use of data from multiple paltforms: The constellation of new satellite sensors, the so-called A-Train, will improve the characterization of global aerosols, clouds and land properties, and hence the assessment of aerosol forcing. A combination of polarorbiting and geostationary satellites would monitor the daytime cycle of aerosols with a better accuracy than a geostationary satellite alone, because multi-spectral measurements from a polar-orbiting satellite can provide an important constraint to aerosol retrievals from a geostationary satellite. A good deal of effort is needed to address this fundamental issue. A merger of aerosol products from historic and modern satellite sensors is necessary for examining the long-term trend of aerosols, and this requires a good understanding and reconciliation of AOD differences between different sensors or platforms. More coordinated suborbital measurements are required for validating and complementing satellite observations (Anderson et al., 2005a, b). To digest and make the best use of a pool of measurements from different platforms, a coordinated research strategy and international collaboration need to be developed.

- Integration and assimilation of satellite measurements into models: Aerosol models provide a unique tool for estimating the past aerosol forcing and projecting future climate change. To reduce model uncertainties, continuous efforts are required for improving the characterization of the aerosol life cycle. It is also important to use satellite measurements to constrain model simulations, including integration and assimilation of satellite measurements into global models. There have 
been some preliminary efforts that integrate satellite retrieved columnar AOD with model simulations (e.g., Yu et al., 2003). However, it remains difficult to quantify and remove biases associated with both satellite retrievals and model simulations. A coordinated research strategy needs to be developed for integrating satellite observed three-dimensional aerosol extinction into aerosol models. Schemes of surface albedo characterization in global models also need to be evaluated and constrained with emerging measurements from new-generation satellite sensors.

Finally, aerosol indirect effects on clouds continue to be an enormous challenge from both the observational and modeling perspectives, and progress is crucial if we are to improve our ability to predict climate change. 
Acronyms and symbols.

\begin{tabular}{|c|c|}
\hline \multicolumn{2}{|l|}{ A } \\
\hline $\mathrm{ABC}$ & Atmospheric Brown Cloud \\
\hline $\mathrm{ACE}$ & Aerosol Characterization Experiment \\
\hline AD-Net & Asian Dust Network \\
\hline ADEOS & Advanced Earth Observation Satellite \\
\hline $\mathrm{ADM}$ & Angular Dependence Models \\
\hline AERONET & Aerosol Robotic Network \\
\hline $\operatorname{AOD}(\tau)$ & Aerosol optical depth \\
\hline AVHRR & Advanced Very High Resolution Radiometer \\
\hline \multicolumn{2}{|r|}{ (1) } \\
\hline BASE-A & Biomass Burning Airborne and Spaceborne Experiment Amazon and Brazil \\
\hline BRDF & Bidirectional Reflectance Distribution Function \\
\hline \multicolumn{2}{|r|}{ 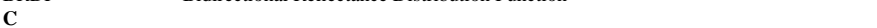 } \\
\hline CALIPSO & Cloud Aerosol Infrared Pathfinder Satellite Observations \\
\hline CCRI & Climate Change Research Initiative \\
\hline CCSP & Climate Change Science Program \\
\hline CERES & Clouds and the Earth's Radiant Energy System \\
\hline CLAMS & Chesapeake Lighthouse and Aircraft Measurements for Satellite campaign \\
\hline CMDL & Climate Modeling and Diagnostic Laboratory (NOAA) \\
\hline \multicolumn{2}{|r|}{ 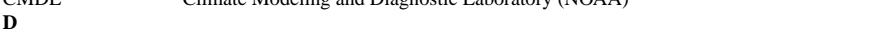 } \\
\hline DAAC & Distributed Active Archive Center \\
\hline DCF & Direct climate forcing (anthropogenic aerosols) \\
\hline DRE & Direct radiative effect (total aerosols) \\
\hline \multicolumn{2}{|l|}{$\mathbf{E}$} \\
\hline EARLINET & European Aerosol Research Lidar Network \\
\hline ERBE & Earth Radiation Budget Experiment \\
\hline$E_{\tau}$ & Radiative efficiency (DRE normalized by aerosol optical depth $\tau$ ) \\
\hline G & \\
\hline GEOS & Goddard Earth Observing System \\
\hline GFDL & Geophysical Fluid Dynamics Laboratory (NOAA) \\
\hline GISS & Goddard Institute for Space Studies (NASA) \\
\hline GLAS & Geoscience Laser Altimeter System \\
\hline GOCART & Goddard Global Ozone Chemistry Aerosol Radiation and Transport \\
\hline GOES & Geostationary Operational Environmental Satellite \\
\hline GSFC & Goddard Space Flight Center (NASA) \\
\hline H & \\
\hline HG phase function & Henyey-Greenstein phase function \\
\hline I 1 & \\
\hline ICARTT & International Consortium for Atmospheric Research on Transport and Transformation \\
\hline ICESat & Ice, Cloud, and Land Elevation Satellite \\
\hline IMPROVE & Interagency Monitoring of Protected Visual Environments \\
\hline INCA & INteractions between Chemistry and Aerosol (LMDz model) \\
\hline INDOEX & Indian Ocean Experiment \\
\hline INTEX-NA & Intercontinental Transport Experiment - North America \\
\hline IPCC & Intergovermental Panel on Climate Change \\
\hline ISCCP & International Satellite Cloud Climatology Project \\
\hline $\mathbf{L}$ & \\
\hline LACE 98 & Lindenberg Aerosol Characterization Experiment 1998 (Germany) \\
\hline LBA & Large-Scale Biosphere-Atmosphere Experiment in Amazonia \\
\hline LMDZ & Laboratoire de Météorologie Dynamique with Zoom \\
\hline LOA & Laboratoire d' Optique Atmosphérique \\
\hline $\mathbf{M}$ & \\
\hline MFRSR & Multifilter Rotating Shadowband Radiometer \\
\hline MINOS & Mediterranean Intensive Oxidant Study \\
\hline MISR & Multi-angle Imaging SpectroRadiometer \\
\hline MODIS & Moderate Resolution Imaging Spectroradiometer \\
\hline MPLNET & Micro Pulse Lidar Network \\
\hline $\mathbf{N}$ & \\
\hline NASA & National Aeronautics and Space Administration \\
\hline NEAQS & New England Air Quality Study \\
\hline NOAA & National Oceanography and Atmosphere Administration \\
\hline o & \\
\hline OMI & Ozone Monitoring Instrument \\
\hline $\mathbf{P}$ & \\
\hline PEM-West & Western Pacific Exploratory Missions \\
\hline POLDER & Polarization and Directionality of the Earth's Reflectance \\
\hline PRIDE & Puerto Rico Dust Experiment \\
\hline $\mathbf{R}$ & \\
\hline RH & Relative Humidity \\
\hline RT & Radiative Transfer \\
\hline $\mathbf{S}$ & \\
\hline SAFARI & South African Regional Science Experiment \\
\hline SCAR-A & Smoke, Clouds, and Radiation - America \\
\hline SCAR-B & Smoke, Clouds, and Radiation - Brazil \\
\hline SeaWiFs & Sea-viewing Wide Field-of-view Sensor \\
\hline SHADE & SaHAran Dust Experiment \\
\hline SMOCC & Smoke, Aerosols, Clouds, Rainfall and Climate \\
\hline SPRINTARS & Spectral Radiation-Transport Model for Aerosol Species \\
\hline $\operatorname{SSA}\left(\omega_{0}\right)$ & aerosol Single-Scattering Albedo \\
\hline $\mathbf{T}$ & \\
\hline TARFOX & Tropospheric Aerosol Radiative Forcing Observational Experiment \\
\hline TOA & Top-Of-Atmosphere \\
\hline TOMS & Total Ozone Mapping Spectrometer \\
\hline TRACE-A & TRAnsport and Chemical Evolution over the Atlantic \\
\hline TRACE-P & TRAnsport and Chemical Evolution over the Pacific \\
\hline $\mathbf{U}$ & \\
\hline $\mathrm{UAE}^{2}$ & United Arab Emirates Unified Aerosol Experiment \\
\hline
\end{tabular}


Acknowledgements. The paper was derived from a report prepared for the U.S. Climate Change Science Program (CCSP). The work of the U.S. authors was supported by NASA (Radiation Science Program, Atmospheric Chemistry Modeling and Analysis Program, Earth Observing System Project, Interdisciplinary Sciences Program), NOAA, and the National Science Foundation (NSF). The work of N. Bellouin and O. Boucher forms part of the Climate Prediction Programme of the UK Department for the Environment, Food and Rural Affairs (DEFRA) under contract PECD 7/12/37. We are grateful to J. Redemann and an anonymous reviewer for their insightful comments. H. Yu thanks R. Levy and G. Engel-Cox for editorial assistance.

Edited by: W. Conant

\section{References}

Abdou, W. A., Diner, D. J., Martonchik, J. V., Bruegge, C. J., Kahn, R. A., Gaitley, B. J., and Crean, K. A.: Comparison of conincident MISR and MODIS aerosol optical depths over land and ocean scenes containing AERONET sites, J. Geophys. Res., 110, D10S07, doi:10.1029/2004JD004693, 2005.

Abel, S. J., Highwood, E. J., Haywood, J. M., and Stringer, M. A.: The direct radiative effect of biomass burning aerosols over southern Africa, Atmos. Chem. Phys., 5, 1999-2018, 2005.

Ackerman, A. S., Toon, O. B., Stevens, D. E., Heymsfield, A. J., Ramanathan, V., and Welton, E. J.: Reduction of tropical cloudiness by soot, Science, 288, 1042-1047, 2000.

Albrecht, B. A.: Aerosols, cloud microphysics, and fractional cloudiness, Science, 245, 1227-1230, 1989.

Alexandrov, M. D., Lacis, A., Carlson, B. E., and Cairns, B.: Remote sensing of atmospheric aerosols and trace gases by means of Multifilter Rotating Shadowband Radiometer. Part I: Retrieval algorithm, J. Atmos. Sci., 59(3), 524-543, 2002a.

Alexandrov, M. D., Lacis, A., Carlson, B. E., and Cairns, B.: Remote sensing of atmospheric aerosols and trace gases by means of Multifilter Rotating Shadowband Radiometer. Part II: climatological applications, J. Atmos. Sci., 59(3), 544-566, 2002 b.

Alexandrov, M. D., Marshak, A., Cairns, B., Lacis, A., and Carlson, B. E.: Automatic cloud screening algorithm for MFRSR data, Geophy. Res. Lett., 31, 4, L04118, 10.1029/2003GL019105, 2004a.

Alexandrov, M. D., Marshak, A., Cairns, B., Lacis, A., and Carlson, B. E.: Scaling properties of aerosol optical thickness retrieved from ground-based measurements, J. Atmos. Sci., 61, 1024-1039, 2004b.

Anderson, T. L., Charlson, R. J., Schwartz, S. E., Knutti, R., Boucher, O., Rodhe, H., and Heintzenberg, J.: Climate forcing by aerosols - A hazy picture, Science, 300, 1103-1104, 2003 a.

Anderson, T. L., Charlson, R. J., Winker, D. M., Ogren, J. A., and Holmén, K.: Mesoscale variations of tropospheric aerosols, J. Atmos. Sci., 60, 119-136, 2003b.

Anderson, T. L., Charlson, R. J., Bellouin, N., Boucher, O., Chin, M., Christopher, S. A., Haywood, J., Kaufman, Y. J., Kinne, S., Ogren, J. A., Remer, L. A., Takemura, T., Tanré, D., Torres, O., Trepte, C. R., Wielicki, B. A., Winker, D. M., Yu, H.: An "ATrain" strategy for quantifying direct aerosol forcing of climate, Bull. Am. Met. Soc., 86(12), 1795-1809, 2005a.
Anderson, T. L., Wu, Y., Chu, D. A., Schmid, B., Redemann, J., and Dubovik, O.: Testing the MODIS satellite retrieval of aerosol fine-mode fraction, J. Geophys. Res., 110, D18204, doi:10.1029/2005JD005978, 2005b.

Andreae, M. O., Rosenfeld, D., Artaxo, P., Costa, A. A., Frank, G. P., Longo, K. M., Silva-Dias, M. A. F.: Smoking Clouds over the Amazon, Science, 303 (5662), 1337-1342, doi:10.1126/science.1092779, 2004.

Ångstrõm, A.: On the atmospheric transmission of sun radiation and on dust in the air, Geogr. Ann. H., 11, 156-166, 1929.

Ångstrõm, A.: On the atmospheric transmission of Sun radiation, II, Geogr. Ann., 2, 156-165, 1930.

Ansmann, A., Wandinger, U., Wiedensohler, A., and Leiterer, U.: Lindenderg Aerosol Characterization Experiment 1998 (LACE 98): Overview, J. Geophys. Res., 107, 8129, doi:10.1029/2000JD000233, 2002.

Atwater, M. A.: Planetary albedo changes due to aerosols, Science, 170(3953), 64-66, 1970.

Bates, T. S., Huebert, B. J., Gras, J. L., Griffiths, F. B., and Durkee, P. A.: International Global Atmospheric Chemistry (IGAC) Project's First Aerosol Characterization Experiment (ACE 1): Overview, J. Geophys. Res., 103, 16 297-16318, 1998.

Bates, T. S., Quinn, P. K., Coffman, D. J., Johnson, J. E., Miller, T. L., Covert, D. S., Wiedensohler, A., Leinert, S., Nowak, A., and Neusüb, C.: 2001: Regional physical and chemical properties of the marine boundary layer aerosol across the Atlantic during Aerosols99: An overview, J. Geophys. Res., 106, 20 767-20 782, 2001.

Bellouin, N., Boucher, O., Tanré, D., and Dubovik, O.: Aerosol absorption over the clear-sky oceans deduced from POLDER1 and AERONET observations, Geophys. Res. Lett., 30, 1748, doi:10.1029/2003GL017121, 2003.

Bellouin, B., Boucher, O., Vesperini, M., and Tanré, D.: Estimating the direct aerosol radiative perturbation: Impact of ocean surface representation and aerosol non-sphericity, Q. J. Roy. Meteorol. Soc., 130(601), 2217-2232, 2004.

Bellouin, B., Boucher, O., Haywood, J., and Reddy, M. S.: Global estimates of aerosol direct radiative forcing from satellite measurements, Nature, 438, 1138-1140, doi:10.1038/nature04348, 2005.

Bergstrom R. W. and Russell, P. B.: Estimation of aerosol direct radiative effects over the mid-latitude North Atlantic from satellite and in-situ measurements, Geophys. Res. Lett., 26, 1731-1734, 1999.

Blanchet, J.-P.: Application of the Chandrasekhar mean to aerosol optical parameters, Atmosphere-Ocean, 20, 189-206, 1982.

Bohren, C. F. and Huffman, D. R.: Absorption and Scattering of Light by Small Particles, Wiley, New York, 1983.

Boucher, O., Schwartz, S. E., Ackerman, T. P., et al.: Intercomparison of models representing shortwave radiative forcing by sulfate aerosols, J. Geophys. Res., 103, 16979-16998, 1998.

Boucher, O.: On aerosol direct shortwave forcing and the HenyeyGreenstein phase function, J. Atmos. Sci., 55, 128-134, 1998.

Boucher, O. and Tanré, D.: Estimation of the aerosol perturbation to the Earth's radiative budget over oceans using POLDER satellite aerosol retrievals, Geophys. Res. Lett., 27, 1103-1106, 2000.

Boucher, O. and Pham, M.: History of sulfate aerosol radiative forcings, Geophys. Res. Lett., 29(9), 1308, 10.1029/2001GL014048, 2002 . 
Brennan, J. I., Kaufman, Y. J., Koren, I., and Li, R.-R.: Aerosolcloud interaction - misclassification of MODIS clouds in heavy aerosol, IEEE Trans. Geos. Rem. Sens., 43(4), 911-915, 2005.

Bréon, F. and Doutriaux-Boucher, M.: A comparison of cloud droplet radii measured from space, IEEE Trans. Geoscience and Remote Sensing, 43(8), 1796-1805, 2005.

Bruegge, C. J., Abdou, W. A., Diner, D. J., Gaitley, B. J., Helmlinger, M. C., Kahn, R. A., and Martonchik, J. V.: Validating the MISR radiometric scale for the ocean aerosol science communities, in: Post-launch calibration of satellite sensors, edited by: Morain, S. A. and Budge, A. M., A.A. Balkema Publishers, Leiden, Netherlands, 103-115, 2004.

Bush, B. C. and Valero, F. P. J.: Surface aerosol radiative forcing at Gosan during the ACE-Asia campaign, J. Geophys. Res., 108(D23), 8660, doi:10.1029/2002JD003233, 2003.

Chameides, W. L., Yu, H., Liu, S. C., et al.: A case study of the effects of atmospheric aerosols and regional haze on agriculture: An opportunity to enhance crop yields in China through emission controls? Proc. Natl. Acad. Sci., 96, 24, 13 626-13 633, 1999.

Charlson, R. J. and Pilat, M. J.: Climate: The influence of aerosols, J. Appl. Meteorol., 8, 1001-1002, 1969.

Charlson, R. J., Langner, J., Rodhe, H., Leovy, C. B., and Warren, S. G.: Perturbation of the Northern Hemisphere radiative balance by backscattering from anthropogenic sulfate aerosols, Tellus, 43AB, 152-163, 1991.

Charlson, R. J., Schwartz, S. E., Hales, J. H., Cess, R. D., Coakley Jr., J. A., Hansen, J. E., and Hofmann, D. J.: Climate forcing by anthropogenic aerosols, Science, 255, 423-430, 1992.

Chin, M., Rood, R. B., Lin, S.-J., Muller, J.-F., and Thompson, A. M.: Atmospheric sulfur cycle simulated in the global model GOCART: Model description and global properties, J. Geophys. Res., 105, 24 671-24 687, 2000a.

Chin, M., Savoie, D. L., Huebert, B. J., Bandy, A. R., Thornton, D. C., Bates, T. S., Quinn, P. K., Saltzman, E. S., and De Bruyn, W. J.: Atmospheric sulfur cycle simulated in the global model GOCART: Comparison with field observations and regional budgets, J. Geophys. Res., 105, 24 689-24 712, 2000b.

Chin, M., Ginoux, P., Holben, B. N., Chou, M.-D., Kinne, S., and Weaver, C.: The GOCART model study of aerosol composition and radiative forcing, paper presented at 12th Symposium on Global Change and Climate Variations, Am. Meteorol. Soc., Albuquerque, New Mexico, 2001.

Chin, M., Ginoux, P., Kinne, S., Torres, O., Holben, B., Duncan, B. N., Martin, R. V., Logan, J. A., Higurashi, A., and Nakajima, T.: Tropospheric aerosol optical thickness from the GOCART model and comparisons with satellite and sun photometer measurements, J. Atmos., Sci., 59, 461-483, 2002.

Chin, M., Ginoux, P., Lucchesi, R., Huebert, B., Weber, R., Anderson, T., Masonis, S., Blomquist, B., Bandy, A., and Thornton, D.: A global aerosol model forecast for the ACEAsia field experiment, J. Geophys. Res., 108(D23), 8654, doi:10.1029/2003JD003642, 2003.

Chin, M., Chu, D. A., Levy, R., Remer, L. A., Kaufman, Y. J., Holben, B. N., Eck, T., and Ginoux, P.: Aerosol distribution in the northern hemisphere during ACE-Asia: Results from global model, satellite observations, and sunphotometer measurements, J. Geophy. Res., 109, D23S90, doi:10.1029/2004JD004829, 2004.

Chou, M. D., Suarez, M. J., Ho, C. H., Yan, M. M. H., and Lee,
K. T.: Parameterizations for cloud overlapping and shortwave single-scattering properties in the Goddard GCM, J. Climate, 11, 201-214, 1998.

Chou, M.-D., Chan, P.-K., and Wang, M.: Aerosol radiative forcing derived from SeaWiFS-retrieved aerosol optical properties, J. Atmos. Sci., 59, 748-757, 2002.

Christopher, S. A., Li, X., Welch, R. M., et al.: Estimation of surface and top-of-atmosphere shortwave irradiance in biomassburning regions during SCAR-B, J. Appl. Meteorol., 39, 17421753, 2000.

Christopher, S.A., and Zhang, J.: Shortwave aerosol radiative forcing from MODIS and CERES observations over the oceans, Geophys. Res. Lett., 29, 1859, doi:10.1029/2002GL014803, 2002a.

Christopher, S. A. and Zhang, J.: Daytime Variation of Shortwave Direct Radiative Forcing of Biomass Burning Aerosols from GOES-8 Imager, J. Atmos. Sci., 59(3), 681-691, 2002b.

Christopher, S. A., Wang, J., Ji, Q., and Tsay, S.-C.: Estimation of shortwave dust aerosol radiative forcing during PRIDE, J. Geophys. Res., 108(D19), 8956, doi:10.1029/2002JD002787, 2003.

Christopher, S. A. and Zhang, J.: Cloud-free shortwave aerosol radiative effect over oceans: Strategies for identifying anthropogenic forcing from Terra satellite measurements, Geophys. Res. Lett., 31, L18101, doi:10.1029/2004GL020510, 2004.

Chu, D. A., Kaufman, Y. J., Ichoku, C., Remer, L. A., Tanré, D., and Holben, B.: Validation of MODIS aerosol optical depth retrieval over land, Geophys. Res. Lett., 29(12), doi:10.1029/2001/GL013205, 2002.

Chylek, P., Videen, G., Ngo, D., Pinnick, R. G., and Klett, J. D.: Effects of black carbon on the optical properties and climate forcing of sulfate aerosols, J. Geophys. Res., 100, 16325-16332, 1995.

Chylek, P. and Wong, J.: Effect of absorbing aerosol on global radiation budget, Geophys. Res. Lett., 22, 929-931, 1995.

Clarke, A. D. and Kapustin, V.: A Pacific aerosol survey: Part I: A decade of data on production, transport, evolution, and mixing in the troposphere, J. Atmos. Sci., 59, 363-382, 2002.

Coakley Jr., J. A., Cess, R. D., and Yurevich, F. B.: The effect of tropospheric aerosols on the earth's radiation budget: A parameterization for climate models, J. Atmos. Sci., 40, 116-138, 1983.

Collins, W. D., Rasch, P. J., Eaton, B. E., Khattatov, B. V., Lamarque, J., and Zender, C. S.: Simulating aerosols using a chemical transport model with assimilation of satellite aerosol retrievals: Methodology for INDOEX, J. Geophys. Res., 106(D7), 73137336, 2001.

Conant, W. C.: An observational approach for determining aerosol surface radiative forcing: results from the first field phase of INDOEX, J. Geophys. Res., 105, 15 347-15 360, 2000.

Costa, M. J., Silva, A. M., and Levizzani, V.: Aerosol characterization and direct radiative forcing assessment over the ocean. Part I: Methodology and sensitivity analysis, J. Appl. Meteorol., 43(12), 1799-1817, 2004a.

Costa, M. J., Silva, A. M., and Levizzani, V.: Aerosol characterization and direct radiative forcing assessment over the ocean. Part II: Application to test cases and validation, J. Appl. Meteorol., 43(12), 1818-1833, 2004b.

Delene, D. J. and Ogren, J. A.: Variability of aerosol optical properties at four North American surface monitoring sites, J. Atmos Sci., 59, 1135-1150, 2002.

Deuzé, J. L., Bréon, F. M., Devaux, C., Goloub, P., Herman, M., Lafrance, B., Maignan, F., Marchand, A., Nadal, F., Perry, G., 
and Tanré, D.: Remote sensing of aerosols over land surfaces from POLDER-ADEOS-1 polarized measurements, J. Geophys. Res., 106, 4913-4926, 2001.

Dickerson, R. R., Kondragunta, S., Stenchikov, G., Civerolo, K. L., Doddridge, B. G., and Holben, B. N.: The impacts of aerosols on solar ultraviolet radiation and photochemical smog, Science, 278, 827-830, 1997.

Dickinson, R. E.: Land surface processes and climate - surface albedos and energy balance, Adv. Geophys., 25, 305-353, 1983.

Dickinson, R. E., Henderson-Seller, A., and Kennedy, P. J.: Biosphere-Atmosphere Transfer Scheme (BATS) version 1e as Coupled to the NCAR Community Model, Tech. Note NCAR/TN-387+STR, 72pp., Natl. Cent. of Atmos. Res., Boulder, Colo., 1993.

Diner, D. J., Beckert, J. C., Reilly, T. H., et al.: Multiangle Imaging SptectrRadiometer (MISR) description and experiment overview, IEEE Trans. Geosci. Remote. Sens., 36, 1072-1087, 1998.

Diner, D. J., Beckert, J. C., Bothwell, G. W., and Rodriguez, J. I.: Performance of the MISR instrument during its first 20 months in Earth orbit, IEEE Trans. Geosci. Remote Sens., 40, 1449-1466, 2002.

Diner, D. J., Ackerman, T. P., Anderson, T. L., et al.: Progressive Aerosol Retrieval and Assimilation Global Observing Network (PARAGON): An integrated approach for characterizing aerosol climatic and environmental interactions, Bull. Amer. Meteo. Soc., 85(10), 1491-1501, 2004.

Dubovik, O., Smirnov, A., Holben, B. N., King, M. D., Kaufman, Y. J., and Slutsker, I.: Accuracy assessments of aerosol optical properties retrieved from AERONET sun and sky radiance measurements, J. Geophys. Res., 105, 9791-9806, 2000.

Dubovik, O. and King, M. D.: A flexible inversion algorithm for retrieval of aerosol optical properties from Sun and sky radiance measurements, J. Geophys. Res., 105, 20 673-20 696, 2000.

Dubovik, O., Holben, B. N., Eck, T. F., Smirnov, A., Kaufman, Y. J., King, M. D., Tanré, D., and Slutsker, I.: Variability of absorption and optical properties of key aerosol types observed in worldwide locations, J. Atmos. Sci., 59, 590-608, 2002.

Dufresne, J., Gautier, C., Ricchizzi, P., and Fouquart, Y.: Longwave scattering effects of mineral aerosols, J. Atmos. Sci., 59(12), 1959-1966, 2002.

Eck, T. F., Holben, B. N., and Reid, J. S., et al.: High aerosol optical depth biomass burning events: A comparison of optical properties for different source regions, Geophys. Res. Lett., 30, 2035, doi:10.1029/2003GL017861, 2003.

Feingold, G., Eberhard, W. L., Veron, D. E., and Previdi, M.: First measurements of the Twomey aerosol indirect effect using ground-based remote sensors, Geophys. Res. Lett., 30(6), 1287, doi:10.1029/2002GL016633, 2003.

Ferrare, R. A, Turner, D. D., Brasseur, L. H., Feltz, W. R., Dubovik, O., and Tooman, T. P.: Raman lidar measurements of the aerosol extinction-to-backscatter ratio over the Southern Great Plains, J. Geophys. Res., 106(D17), 20 333-20 347, 2001.

Fishman, J., Hoell Jr., J. M., Bendura, R. D., McNeal, R. J., and Kirchhoff, V.: NASA GTE TRACE A experiment (SeptemberOctober 2002): Overview, J. Geophys. Res., 101, 23 865-23 880, 1996.

$\mathrm{Fu}, \mathrm{Q}$. and Liou, K. N.: Parameterization of the radiative properties of cirrus clouds, J. Atmos. Sci., 50, 2008-2025, 1993.
Geogdzhayev, I. V., Mishchenko, M. I., Rossow, W. B., Cairns, B., and Lacis, A.: Global two-channel AVHRR retrievals of aerosol properties over the ocean for the period of NOAA-9 observations and preliminary retrievals using NOAA-7 and NOAA-11 data, J. Atmos. Sci., 59(3), 262-278, 2002.

Ginoux, P., Chin, M., Tegen, I., Prospero, J., Holben, B., Dubovik, O., and Lin, S.-J.: Sources and distributions of dust aerosols simulated with the GOCART model, J. Geophys. Res., 106, 20225 $20273,2001$.

Ginoux, P., Prospero, J., Torres, O., and Chin, M.: Long-term simulation of dust distribution with the GOCART model: Correlation with the North Atlantic Oscillation, Environ. Model. Software, 19, 113-128, 2004.

Gras, J. L., Jensen, J. B., Okada, K., Ikegami, M., Zaizen, Y., and Makino, Y.: Some optical properties of smoke aerosol in Indonesia and tropical Australia, Geophys. Res. Lett., 26(10), 13931396, 1999.

Hansen, J. and Travis, L. D.: Light scattering in planetary atmospheres, Space Sci. Rev., 16, 527-610, 1974.

Hansen, J., Sato, M., and Ruedy, R.: Radiative forcing and climate response, J. Geophys. Res., 102, 6831-6864, 1997.

Harrison, L., Michalsky, J., and Berndt, J.: Automated multifilter rotating shadowband radiometer: An instrument for optical depth and radiation measurements, Appl. Opt., 33, 5118-5125, 1994.

Hart, W.D., Spinhirne, J. D., Palm, S. P., and Hlavka, D.: Height distribution between cloud and aerosol layers from the GLAS space borne lidar in the Indian Ocean Region, Geophs. Res. Let., 32, L22S06, doi:10.1029/2005GL023671, 2005.

Haywood, J. M. and Shine, K. P.: Multi-spectral calculations of the radiative forcing of tropospheric sulfate and soot aerosols using a column model, Q. J. R. Meteorol. Soc., 123, 1907-1930, 1997.

Haywood, J., Ramaswamy, V., and Soden, B.: Tropospheric aerosol climate forcing in clear-sky satellite observations over the oceans, Science, 283, 1299-1303, 1999.

Haywood, J. and Boucher, O.: Estimates of the direct and indirect radiative forcing due to tropospheric aerosols: A review, Rev. Geophys., 38, 513-543, 2000.

Haywood, J., Francis, P., Osborne, S., Glew, M., Loeb, N., Highwood, E., Tanré, D., Myhre, E., Formenti, P., and Hirst, E.: Radiative properties and direct radiative effect of Saharan dust measured by the C-130 aircraft during SHADE: 1.Solar spectrum, J. Geophys. Res., 108(D18), 8577, doi:10.1029/2002JD002687, 2003.

Haywood, J. M., Osborne, S. R., and Abel, S. J.: The effect of overlying absorbing aerosol layers on remote sensing retrievals of cloud effective radius and cloud optical depth, Q. J. R. Meteorol. Soc., 130, 779-800, 2004.

Haywood, J., Allan, R., Culverwell, I., Slingo, T., Milton, S., Edwards, J., and Clerbaux, N.: Can desert dust explain the outgoing longwave radiation anomaly over the Sahara during July 2003? J. Geophys. Res., 110, D05105, doi:10.1029/2004JD005232, 2005.

Heintzenberg, J., Graf, H.-F., Charlson, R. J., and Warneck, P.: Climate forcing and the physico-chemical life cycle of the atmospheric aerosol - Why do we need an integrated, interdisciplinary global research programme? Beitr. Phys. Atmosph., 69, 261-271, 1996.

Heintzenberg J., Charlson, R. J., Clarke, A. D., et al.: Measurements and modeling of aerosol single-scattering albedo: progress, problems and prospects, Beitr. Phys. Atmosph., 70, 
249-263, 1997.

Heintzenberg, J., Tuch, J., Wehner, B., et al.: Arctic haze over central Europe, Tellus, 55B, 796-807, 2003.

Henyey, L. G. and Greenstein, T. L.: Diffuse radiation in the galaxy, Astrophys. J., 93, 70-83, 1941.

Herman, J. R., Bhartia, P. K., Torres, O., Hsu, C., Seftor, C., and Celarier, E.: Global distribution of UV-absorbing aerosols from Nimbus-7/TOMS data, J. Geophys. Res., 102, 16911-16922, 1997.

Highwood, E. J., Haywood, J. M., Silverstone, M. D., Newman, S. M., and Taylor, J. P.: Radiative properties and direct effect of Saharan dust measured by the C-130 aircraft during Saharan Dust Experiment (SHADE): 2. Terrestrial spectrum, J. Geophys. Res., 108(D18), 8578, doi:10.1029/2002JD002552, 2003.

Hignett, P., Taylor, J. P., Francis, P. N., and Glew, M. D.: Comparison of observed and modeled direct aerosol forcing during TARFOX, J. Geophys. Res., 104, 2279-2287, 1999.

Hlavka, D. L., Palm, S. P., Hart, W. D., Spinhirne, J. D., McGill, M. J., and Welton, E. J.: Aerosol and Cloud Optical depth Retrievals from GLAS satellite lidar: Results and Verification for October 2003 Case Including California fire smoke, Geophs. Res. Let., 32, L22S07, doi:10.1029/2005GL023413, 2005.

Hobbs, P. V., Reid, J. S., Kotchenruther, R. A., Ferek, R. J., and Weiss, R.: Direct radiative forcing by smoke from biomass burning, Science, 275, 1776-1778, 1997.

Hoell, J. M., Davis, D. D., Liu, S. C., Newell, R., Shipham, M., Akimoto, H., McNeal, R. J., Bemdura, R. J., and Drewry, J. W.: Pacific Exploratory Mission-West A (PEM-WEST A): SeptemberOctober, 1991, J. Geophys. Res., 101, 1641-1653, 1996.

Hoell, J. M., Davis, D. D., Liu, S. C., Newell, R., Shipham, M., Akimoto, H., McNeal, R. J., Bemdura, R. J., and Drewry, J. W.: The Pacific Exploratory Mission-West Phase B: FebruaryMarch, 1994, J. Geophys. Res., 102, 28 223-28 239, 1997.

Holben, B. N., Eck, T. F., Slutsker, I., et al.: AERONET - A federated instrument network and data archive for aerosol characterization, Rem. Sens. Environ., 66, 1-16, 1998.

Holben, B. N., Tanré, D., Smirnov, A., et al.: An emerging ground-based aerosol climatology: aerosol optical depth from AERONET, J. Geophys. Res., 106, 12 067-12 098, 2001.

Horvath, H.: Atmospheric light absorption - A review, Atmos. Environ., 27A, 293-317, 1993.

Horvath, H., Arboledas, L. A., Olmo, F. J., Jovanovic, O., Gangl, M., Kaller, W., Sanchez, C., Sauerzopf, H., and Seidl, S.: Optical properties of the aerosol in Spain and Austria and its effect on radiative forcing, J. Geophys. Res., 107(D19), 4386, doi:10.1029/2001JD001472, 2002.

Hsu, N. C., Herman J. R., and Weaver C. J.: Determination of radiative forcing of Saharan dust using combined TOMS and ERBE data, J. Geophys. Res., 105, 20 649-20 661, 2000.

Huebert, B. J., Bates, T., Russell, P. B., Shi, G., Kim, Y. J., Kawamura, K., Carmichael, G., and Nakajima, T.: An overview of ACE-Asia: Strategies for quantifying the relationships between Asian aerosols and their climatic impacts, J. Geophys. Res., 108(D23), 8633, doi:10.1029/2003JD003550, 2003.

Husar, R. B., Prospero, J. M., and Stowe, L. L.: Characterization of tropospheric aerosols over the oceans with the NOAA advanced very high resolution radiometer optical thickness operational product, J. Geophys. Res., 102, 16889-16 909, 1997.

Ichoku, C., Chu, D. A., Chu, S., Kaufman, Y. J., Remer,
L. A., Tanré, D., Slutsker, I., and Holben, B. N.: A spatio-temporal approach for global validation and analysis of MODIS aerosol products, Geophys. Res. Lett., 29(12), 8006, doi:10.1029/2001GL013206, 2002.

Ichoku, C., Remer, L. A., and Eck, T. F.: Quantitative evaluation and intercomparison of morning and afternoon MODIS aerosol measurements from Terra and Aqua satellites, J. Geophys. Res., 110, D10S03, doi:10.1029/2004JD004987, 2005.

Ignatov, A. and Stowe, L. L.: Aerosol retrievals from individual AVHRR channels: I. Retrieval algorithm and transition from Dave to 6S radiative transfer model, J. Atmos. Sci., 59, 313-334, 2002.

Intergovernmental Panel on Climate Change (IPCC): Radiative forcing of climate change, in Climate Change 2001, Cambridge Univ. Press, New York, Cambridge University Press, 2001.

Jacob, D. J., Crawford, J. H., Kleb, M. M., Connors, V. S., Bendura, R. J., Raper, J. L., Sachse, G. W., Gille, J. C., Emmons, L., and Heald, C. L.: The Transport and Chemical Evolution over the Pacific (TRACE-P) aircraft mission: design, execution, and first results, J. Geophys. Res., 108, 9000, 10.1029/2002JD003276, 2003.

Jacobson, M. Z.: A physically-based treatment of elemental carbon optics: Implications for global direct forcing of aerosols, Geophys. Res. Lett., 27, 217-220, 2000.

Jacobson, M. Z.: Strong radiative heating due to the mixing state of black carbon in atmospheric aerosols, Nature, 409, 695-697, 2001.

Jin, Z., Charlock, T. P., and Rutledge, K.: Analysis of broadband solar radiation and albedo over the ocean surface at COVE, J. Atmos. Oceanic Technol., 19, 1585-1601, 2002.

Jin, Z., Charlock, T. P., Smith Jr., W. L., and Rutledge, K.: A parameterization of ocean surface albedo, Geophys. Res. Lett., 31, L22301, doi:10.1029/2004GL021180, 2004.

Kahn, R., Gaitley, R., Martonchik, J. V., Diner, D. J., Crean, K. A., and Holben, B. N.: MISR global aerosol optical depth validation based on two years of coincident AERONET observations, J. Geophys. Res., 110, D10S04, doi:10.1029/2004JD004706, 2005a.

Kahn, R., Li, W.-H., Martonchik, J. V., Bruegge, C., Diner, D. J., Gaitley, B., Abdou, W., Dubovik, O., Holben, B., Smirnov, A., Jin, Z., and Clark, D.: MISR low-light-level calibration, and implications for aerosol retrieval over dark water, J. Atmos. Sci., 62(4), 1032-1052, 2005b.

Kahn, R., Ogren, J. A., Ackerman, T. P., et al.: Aerosol data sources and their roles within PARAGON, Bull. Amer. Meteorol. Soc., 85, 1511-1522, 2004a.

Kahn, R., Anderson, J., Anderson, T. L., et al.: Environmental snapshots from ACE-Asia, J. Geophys. Res., doi:2003JD004339, 2004b.

Kahn, R., Banerjee, P., and McDonald, D.: The sensitivity of multiangle imaging to natural mixtures of aerosols over ocean, J. Geophys. Res., 106, 18 219-18 238, 2001.

Kalashnikova, O. V., Kahn, R., Sokolik, I. N., and Li, W-H.: The ability of multi-angle remote sensing observations to identify and distinguish mineral dust types: Optical models and retrievals of optically thick plumes, J. Geophys. Res., 110, D18S14, doi:10.1029/2004JD004550, 2005a.

Kaufman, Y. J., Setzer, A., Ward, D., Tanré, D., Holben, B. N., Menzel, P., Pereira, M. C., Rasmussen, R.: Biomass Burning 
Airborne and Spaceborne Experiment in the Amazonas (BASEA), J. Geophys. Res., 97, 14 581-14 599, 1992.

Kaufman, Y., and T. Nakajima, Effect of Amazon smoke on cloud microphysics and albedo - Analysis from satellite imagery, J. Appl. Meteorol., 32, 729-744, 1993.

Kaufman, Y. J., Tanré, D., Remer, L. A., Vermote, E. F., Chu, A., and Holben, B. N.: Operational remote sensing of tropospheric aerosol over land from EOS moderate resolution imaging spectroradiometer, J. Geophys. Res., 102, 17 051-17 067, 1997.

Kaufman, Y. J., Hobbs, P. V., Kirchhoff, V., et al.: Smoke, Clouds, and Radiation-Brazil (SCAR-B) Experiment, J. Geophys. Res., 103(D24), 31 783-31 808, 1998.

Kaufman, Y. J., Holben, B. N., Tanré, D., Slutsker, I., Smirnov, A., and Eck, T.F.: Will aerosol measurements from Terra and Aqua polar orbiting satellites represent daily aerosol abundance and properties?, Geophys. Res. Lett., 27, 3861-3864, 2000.

Kaufman, Y. J., Tanré, D., Dubovik, O., Karnieli, A., and Remer, L.A.: Absorption of sunlight by dust as inferred from satellite and ground-based measurements, Geophys. Res., Lett., 28, 1479-1482, 2001.

Kaufman, Y. J., Tanré, D., and Boucher, O.: A satellite view of aerosols in the climate system, Nature, 419, doi:10.1038/nature01091, 2002a.

Kaufman, Y. J., Martins, J.V., Remer, L. A., Schoeberl, M. R., and Yamasoe, M. A.: Satellite retrieval of aerosol absorption over the oceans using sunglint, Geophys. Res. Lett., 29(19), 1928, doi:10.1029/2002GL015403, 2002b.

Kaufman, Y. J., Haywood, J. M., Hobbs, P. V., Hart, W., Kleidman, R., and Schmid, B.: Remote sensing of vertical distributions of smoke aerosol off the coast of Africa, Geophys. Res. Lett., 30(16), 1831, doi:10.1029/2003GL017068, 2003.

Kaufman, Y. J., Boucher, O., Tanré, D., Chin, M., Remer, L. A., and Takemura, T.: Aerosol anthropogenic component estimated from satellite data, Geophys. Res. Lett., 32, L17804, doi:10.1029/2005GL023125, 2005a.

Kaufman, Y. J., Remer, L. A., Tanré, D., Li, R.-R., Kleidman, R., Mattoo, S., Levy, R., Eck, T., Holben, B. N., Ichoku, C., Martins, J., and Koren, I.: A critical examination of the residual cloud contamination and diurnal sampling effects on MODIS estimates of aerosol over ocean, IEEE Trans. on Geoscience \& Remote Sensing, 43(12), 2886-2897, 2005b.

Keil, A. and Haywood, J.: Solar radiative forcing by biomass burning aerosol particles during SAFARI-2000: A case study based on measured aerosol and cloud properties, J. Geophys. Res., 108(D13), 8467, doi:10.1029/2002JD002315, 2003.

Kiehl, J. T. and Briegleb, B. P.: The relative role of sulfate aerosols and greenhouse gases in climate forcing, Science, 260, 311-314, 1993.

Kim, D., Sohn, B. J., Nakajima, T., and Takemura, T.: Aerosol radiative forcing over east Asia determined from ground-based solar radiation measurements, J. Geophys. Res., 110, D10S22, doi:10.1029/2004JD004678, 2005.

King, M. D., Kaufman, Y. J., Tanré, D., and Nakajima, T.: Remote sensing of tropospheric aerosols: Past, present, and future, Bull. Am. Meteorol. Soc., 80, 2229-2259 1999.

King, M. D., Platnick, S., Moeller, C. C., Revercomb, H. E., and Chu, D. A.: Remote sensing of smoke, land, and clouds from the NASA ER-2 during SAFARI 2000, J. Geophys. Res., 108(D13), 8502, doi:10.1029/2002JD003207, 2003a.
King, M. D., Menzel, W. P., Kaufman, Y. J., et al.: Cloud and aerosol properties, precipitable water and profiles of temperature and water vapor from MODIS, IEEE Trans. Geosci. Rem. Sens., 41, 442-458, 2003b.

Kinne, S. and Pueschel, R.: Aerosol radiative forcing for Asian continental outflow, Atmos. Environ., 35, 5019-5028, 2001.

Kinne, S., Lohmann, U., Feichter, J., et al.: Monthly averages of aerosol properties: A global comparison among models, satellite data, and AERONET ground data, J. Geophys. Res., 108(D20), 4634, doi:10.1029/2001JD001253, 2003.

Kinne, S., Schulz, M., Textor, C., et al.: An AeroCom initial assessment - optical properties in aerosol component modules of global models, Atmos. Chem. Phys. Discuss., 5, 8285-8330, 2005.

Kleidman, R. G., O’Neill, N. T., Remer, L. A., Kaufman, Y. J., Eck, T. F., Tanré, D., Dubovik, O., and Holben, B. N.: Comparison of Moderate Resolution Imaging Spectroradiometer (MODIS) and Aerosol Robotic Network (AERONET) remote-sensing retrievals of aerosol fine mode fraction over ocean, J. Geophys. Res., 110, D22205, doi:10.1029/2005JD005760, 2005.

Koch, D. and Hansen, J.: Distant origins of Arctic black carbon: A Goddard Institute for Space Studies ModelE experiment, J. Geophys. Res., 110, D04204, doi:10.1029/2004JD005296, 2005.

Koren, I.Y., Kaufman, Y. J., Remer, L. A., and Martins, J. V.: Measurement of the effect of Amazon smoke on inhibition of cloud formation, Science, 303, 1342-1345, 2004.

Kotchenruther, R. A. and Hobbs, P. V.: Humidification factors of aerosols from biomass burning in Brazil, J. Geophys. Res., 103, 32 081-32 089, 1998.

Lelieveld, J., Berresheim, H., Borrmann, S., et al.: Global air pollution crossroads over the Mediterranean, Science, 298, 794-799, 2002.

Léon, J.-F., Tanré, W., Pelon, J., Kaufman, Y. J., Haywood, J. M., and Chatenet, B.: Profiling of a Saharan dust outbreak based on a synergy between active and passive remote sensing, J. Geophys. Res., 108(D18), 8575, doi:10.1029/2002JD002774, 2003.

Li, F., Vogelmann, A. M., and Ramanathan, V.: Dust aerosol radiative forcing measured from space over the Western Africa, J. Climate, 17(13), 2558-2571, 2004.

Liu, H., Pinker, R., and Holben, B. N.: A global view of aerosols from merged transport models, satellite, and ground observations, J. Geophys. Res., 110, D10S15, doi:10.1029/2004JD004695, 2005.

Li, R.-R., Kaufman, Y. J., Hao, W.-M., Salmon, J. M., and Gao, B.-C.: A technique for detecting burn scars using MODIS data. IEEE Trans. on Geoscience \& Remote Sensing, 42(6), 13001308, 2004.

Liao, H. and Seinfeld, J. H.: Effects of clouds on direct aerosol radiative forcing of climate, J. Geophys. Res., 103, 3781-3788, 1998.

Lindesay, J. A., Andreae, M. O., Goldammer, J. G., Harris, G., Annegarn, H. J., Garstang, M., Scholes, R. J., and van Wilgen, B. W.: International Geosphere Biosphere Programme/International Global Atmospheric Chemistry SAFARI-92 field experiment: Background and overview, J. Geophys. Res., 101, $23521-$ $23530,1996$.

Loeb, N. G. and Kato, S.: Top-of-atmosphere direct radiative effect of aerosols over the tropical oceans from the Clouds and the Earth's Radiant Energy System (CERES) satellite instrument, J. 
Climate, 15, 1474-1484, 2002.

Loeb, N.G., and Manalo-Smith, N.: Top-of-Atmosphere direct radiative effect of aerosols over global oceans from merged CERES and MODIS observations, J. Climate, 18, 3506-3526, 2005.

Lubin, D., Satheesh, S. K., McFarquar, G., and Heymsfield, A. J.: Longwave radiative forcing of Indian Ocean tropospheric aerosol, J. Geophys. Res., 107(D19), 8004, doi:10.1029/2001JD001183, 2002.

Luo, Y. F., Lu, D., Zhou, X., Li, W., and He, Q.: Characteristics of the spatial distribution and yearly variation of aerosol optical depth over China in last 30 years, J. Geophys. Res., 106(D13), 14501, doi:10.1029/2001JD900030, 2001.

Magi, B. I. and Hobbs, P. V.: Effects of humidity on aerosols in southern Africa during the biomass burning season, J. Geophys. Res., 108, 8495, doi:10.1029/2002JD002144, 2003.

Magi, B. I., Hobbs, P. V., Kirchstetter, T. W., Novakov, T., Hegg, D. A., Gao, S., Redemann, J., and Schmid, B.: Aerosol properties and chemical apportionment of aerosol optical depth at locations off the United States East Coast in July and August 2001, J. Atmos. Sci., 62, 919-933, 2005.

Mahesh, A., Gray, M. A., Palm, S. P., Hart, W. D., and Spinhirne, J. D.: Passive and active detection of clouds: Comparisons between MODIS and GLAS observations, Geophy. Res. Lett., 31, L04108, doi:10.1029/2003GL018859, 2004.

Malm, W. C., Sisler, J. F., Huffman, D., Eldred, R. A., and Cahill, T. A.: Spatial and seasonal trends in particle concentration and optical extinction in the United States, J. Geophys. Res., 99, 13471370, 1994.

Malm, W. C. and Kriedenweiss, S. M.: The effects of models of aerosol hygroscopicity on the apportionment of extinction, Atmos. Environ., 31, 1965-1976, 1997.

Malm, W. C., Schichtel, B. A., Pitchford, M. L. Ashbaugh, L. L., and Eldred, R. A.: Spatial and monthly trends in speciated fine particle concentration in the United States, J. Geophys. Res., 109, D03306, doi:10.1029/2003JD003739, 2004.

Markowicz, K. M., Flatau, P. J., Ramana, R. V., Crutzen, P. J., and Ramanathan, V.: Absorbing mediterranean aerosols lead to a large reduction in the solar radiation at the surface, Geophys. Res. Lett., 29, 1968, doi:10.1029/2002GL015767, 2002.

Markowicz, K. M., Flatau, P. J., Vogelmann, A. M., Quinn, P. K., and Welton, E. J.: Clear-sky infrared aerosol radiative forcing at the surface and the top of the atmosphere, Q. J. R. Meteorol. Soc., 129, 2927-2947, 2003.

Marshall, S., Covert, D. S., and Charlson, R. J.: Relationships between asymmetry parameter and hemispheric backscatter ratio: Implications for climate forcing by aerosols, Appl. Opt., 34, 6306-6311, 1995.

Martins, J. V., Artaxo, P., Liousse, C., Reid, J. S., Hobbs, P. V., and Kaufman, Y. J.: Effects of black carbon content, particle size, and mixing on light absorption by aerosols from biomass burning in Brazil, J. Geophys. Res., 103, 32 041-32 050, 1998.

Martins, J. V., Tanré, D., Remer, L. A., Kaufman, Y. J., Mattoo, S., Levy, R.: MODIS cloud screening for remote sensing of aerosol over oceans using spatial variability, Geophys. Res. Lett., 29(12), doi:10.1029/2001GL013252, 2002.

Martonchik, J. V., Diner, D. J., Pinty, B., Verstraete, M. M., Myneni, R. B., Knjazikhin, Y., and Gordon, H. R.: Determination of land and ocean reflective, radiative, and biophysical properties using multiangle imaging, IEEE Trans. Geosci. Rem. Sens., 36, 1266-
1281, 1998b.

Martonchik, J. V., Diner, D. J., Kahn, R., Verstraete, M. M., Pinty, B., Gordon, H. R., and Ackerman, T. P.: Techniques for the Retrieval of aerosol properties over land and ocean using multiangle data, IEEE Trans. Geosci. Rem. Sens., 36, 1212-1227, 1998a.

Martonchik, J. V., Diner, D. J., Crean, K. A., and Bull, M. A.: Regional aerosol retrieval results from MISR, IEEE Trans. Geosci. Rem. Sens., 40, 1520-1531, 2002.

Massie, S. T., Torres, O., and Smith, S. J.: Total ozone mapping spectrometer (TOMS) observations of increases in Asian aerosol in winter from 1979 to 2000, J. Geophys. Res., 109, D18211, doi:10.1029/2004JD004620, 2004.

Matsui, T., Kreidenweis, S., Pielke Sr., R. A., Schichtel, B., Yu, H., Chin, M., Chu, A., and Niyogi, D.: Regional comparison and assimilation of GOCART and MODIS aerosol optical depth across the eastern U.S., Geophys. Res. Lett., 31, L21101, doi:10.1029/2004GL021017, 2004.

Matthis, I., Ansmann, A., Müller, D., Wandinger, U., and Althausen, D.: Multiyear aerosol observations with dualwavelength Raman lidar in the framework of EARLINET, J. Geophys. Res., 109, D13203, doi:10.1029/2004JD004600, 2004.

McCormick, R. A. and Ludwig, J. H.: Climate modification by atmospheric aerosols, Science, 156(3780), 1358-1359, 1967.

McMurry, R. H., Zhang, X., and Lee, C.-T.: Issues in aerosol measurement for optical assessments, J. Geophys. Res., 101, 19189 $19197,1996$.

Mishchenko, M. I., Lacis, A. A., Carlson, B. E., and Travis, L. D.: Nonsphericity of dust-like tropospheric aerosols: implications for aerosol remote sensing and climate modeling, Geophys. Res. Lett., 22, 1077-1080, 1995.

Mishchenko, M. I., Geogdzhayev, I. V., Cairns, B., Rossow, W. B., and Lacis, A. A.: Aerosol retrievals over the ocean by use of channels 1 and 2 AVHRR data: Sensitivity analysis and preliminary results, Appl. Opt., 38, 7325-7341, 1999.

Mishchenko, M. I., Geogdzhayev, I. V., Liu, L., Ogren, J. A., Lacis, A. A., Rossow, W. B., Hovenier, J. W., Volten, H., and Muñoz, O.: Aerosol retrievals from AVHRR radiances: Effects of particle nonsphericity and absorption and an updated longterm global climatology of aerosol properties, J. Quant. Spectro. Rad. Trans., 79-80, doi:10.1016/S0022-4073(02)00331-X, 953972, 2003.

Mishchenko, M. I., Cairns, B., Hansen, J. E., Travis, L. D., Burg, R., Kaufman, Y. J., Martins, J. V., and Shettle, E. P.: Monitoring of aerosol forcing of climate from space: analysis of measurement requirements, J. Quant. Spectro. \& Rad. Trans., 88, 149-161, 2004.

Mitchell Jr., J. M.: The effect of atmospheric aerosols on climate with special reference to temperature near the Earth's surface, J. Appl. Meteorol., 10, 703-714, 1971.

Moody, E. G., King, M. D., Platnick, S., Schaaf, C. B., and Gao, F.: Spatially complete global spectral surface albedos: value-added datasets derived from Terra MODIS land products, IEEE Trans. Geosci. Remote Sens., 43(1), 144-158, 2005.

Murayama, T., Sugimoto, N., Uno, I., et al.: Ground-based network observation of Asian dust events of April 1998 in East Asia, J. Geophys. Res., 106, 18 346-18 359, 2001.

Myhre, G., Grini, A., Haywood, J. M., Stordal, F., Chatenet, B., Tanré, D., Sundet, J. K., and Isaksen, I. S. A.: Modeling the radiative impact of mineral dust during the Saharan Dust Exper- 
iment (SHADE) campaign, J. Geophys. Res., 108(D18), 8579, doi:10.1029/2002JD002566, 2003.

Nakajima, T., Higurashi, A., Takeuchi, N., and Herman, J. R.: Satellite and ground-based study of optical properties of 1997 Indonesian forest fire aerosols, Geophys. Res. Lett., 20(16), 2421-2424, 1999.

National Research Council (NRC): Climate Change Sciences: An analysis of some key questions, 42pp., National Academy Press, Washington D.C., 2001.

Nemesure, S., Wagener, R., and Schwartz, S. E.: Direct shortwave forcing of climate by anthropogenic sulfate aerosol: Sensitivity to particle size, composition, and relative humidity, J. Geophys. Res., 100, 26 105-26 116, 1995.

Penner, J. E., Dickinson, R. E., and O’Neill, C. A.: Effects of aerosol from biomass burning on the global radiation budget, Science, 256, 1432-1434, 1992.

Penner, J. E., Charlson, R. J., Hales, J. M., et al.: Quantifying and minimizing uncertainty of climate forcing by anthropogenic aerosols, Bull. Amer. Meteorol. Soc., 75, 375-400, 1994.

Penner, J. E., Zhang, S. Y., Chin, M., et al.: A comparison of modeland satellite-derived aerosol optical depth and reflectivity, J. Atmos. Sci., 59(3), 441-460, 2002.

Pilinis, C., Pandis, S. N., and Seinfeld, J. H.: Sensitivity of direct climate forcing by atmospheric aerosols to aerosol size and composition, J. Geophys. Res., 100, 18 739-18 754, 1995.

Pinker, R. T., Zhang, B., and Dutton, E. G.: Do satellite detect trends in surface solar radiation?, Science, 308, 850-854, 2005.

Platnick, S. and Valero, F.: A validation of a satellite cloud retrieval during ASTEX, J. Atmos. Sci., 52, 2985-3001, 1995.

Platnick, S., King, M. D., Ackerman, S. A., et al.: The MODIS cloud products: Algorithms and examples from Terra, IEEE Trans. Geosci. Rem. Sens., 41, 459-473, 2003.

Podgorny, I. A., Conant, W. C., Ramanathan, V., and Satheesh, S. K.: Aerosol modulation of atmospheric and solar heating over the tropical Indian Ocean, Tellus, Ser. B, 52, 947-958, 2000.

Podgorny, I. A. and Ramanathan, V.: A modeling study of the direct effect of aerosols over the tropical Indian Ocean, J. Geophys. Res., 106, 24 097-24 105, 2001.

Podgorny, I. A., Li, F., and Ramanathan, V.: Large aerosol radiative forcing due to the 1997 Indonesian forest fire, Geophys. Res. Lett., 30(1), 1028, doi:10.1029/2002GL015979, 2003.

Quinn, P. K., and Coffman, D. J.: Local closure during the First Aerosol Characterization Experiment (ACE 1): Aerosol mass concentration and scattering and backscattering coefficients, J. Geophys. Res., 103, 16575-16 596, 1998.

Quinn, P. K., Bates, T. S., Miller, T. L., Coffman, D. J., Johnson, J. E., Harris, J. M., Ogren, J. A., Forbes, G., Anderson, T. L., Covert, D. S., and Rood, M. J.: Surface submicron aerosol chemical composition: What fraction is not sulfate?, J. Geophys. Res., 105, 6785-6806, 2000.

Quinn, P. K. and Bates, T. S.: North American, Asian, and Indian haze: Similar regional impacts on climate? Geophys. Res. Lett., 30(11), 1555, doi:10.1029/2003GL016934, 2003.

Raes, F., Bates, T., McGovern, F., and van Liedekerke, M.: The 2nd Aerosol Characterization Experiment (ACE-2): General overview and main results, Tellus, 52B, 111-125, 2000.

Rajeev, K. and Ramanathan, V.: Direct observations of clear-sky aerosol radiative forcing from space during the Indoex Ocean Experiment, J. Geophys. Res., 106(D15), 17 221-17 236, 2001.
Ramana, M. V., Ramanathan, V., Podgorny, I. A., Pradhan, B. B., and Shrestha, B.: The direct observations of large aerosol radiative forcing in Himalayan region, Geophys. Res. Lett., 31, L05111, doi:10.1029/2003GL018824, 2004.

Ramanathan, V., Crutzen, P. J., Kiehl, J. L., and Rosenfeld, D.: Aerosols, climate, and the hydrological cycle, Science, 294, 2119-2124, 2001a.

Ramanathan, V., Crutzen, P. J., Lelieveld, J., et al.: Indian Ocean Experiment: An integrated analysis of the climate forcing and effects of the great Indo-Asian haze, J. Geophys. Res., 106, 28 371-28 398, $2001 \mathrm{~b}$.

Ramanathan, V., and Crutzen, P. J.: Atmospheric Brown "Clouds", Atmos. Environ., 37, 4033-4035, 2003.

Reddy, M. S. and O.Boucher: A study of the global cycle of carbonaceous aerosols in the LMDZT general circulation model, J. Geophys. Res., 109(D14), D14202, doi:10.1029/2003JD004048, 2004.

Reddy, M. S., Boucher, O., Bellouin, N., Schulz, M., Balkanski, Y., Dufresne, J.-L., and Pham, M.: Estimates of multicomponent aerosol optical depth and direct radiative perturbation in the LMDZT general circulation model, J. Geophys. Res., 110, D10S16, doi:10.1029/2004JD004757, 2005a.

Reddy, M. S., Boucher, O., Balkanski, Y., and Schulz, M.: Aerosol optical depths and direct radiative perturbations by species and source type, Geophys. Res. Lett., 32, L12803, doi:10.1029/2004GL021743, 2005b.

Redemann, J., Russell, P. B., and Hamill, P.: Dependence of aerosol light absorption and single-scattering albedo on ambient relative humidity for sulfate aerosols with black carbon cores, J. Geophys. Res., 106, 27 485-27 495, 2001.

Reid, J. S., Hobbs, P. V., Rangno, A. L., and Hegg, D. A.: Relationships between cloud droplet effective radius, liquid water content, and droplet concentration for warm clouds in Brazil embedded in biomass smoke, J. Geophys. Res., 104, 6145-6153, 1999.

Reid, J. S., Kinney, J. E., and Wesphal, D. L., et al.: Analysis of measurements of Saharan dust by airborne and groundbased remote sensing methods during the Puerto Rico Dust Experiment (PRIDE), J. Geophys. Res., 108(D19), 8586, doi:10.1029/2002JD002493, 2003.

Reid, J. S., Eck, T. F., Christopher, S. A., Koppmann, R., Dubovik, O., Eleuterio, D. P., Holben, B. N., Reid, E. A., and Zhang, J.: A review of biomass burning emissions part III: intensive optical properties of biomass bunring particles, Atmos. Chem. Phys., 5, 827-849, 2005.

Remer, L. A., Gassó, S., Hegg, D., Kaufman, Y. J., and Holben, B. N.: Urban/industrial aerosol: ground based sun/sky radiometer and airborne in situ measurements, J. Geophys. Res., 102, 16 849-16 859, 1997.

Remer, L. A., Tanré, D., Kaufman, Y. J., Ichoku, C., Mattoo, S., Levy, R., Chu, D. A., Holben, B., Dubovik, O., Smirnov, A., Martins, J. V., Li, R.-R., and Ahman, Z., Validation of MODIS aerosol retrieval over ocean, Geophys. Res. Lett., 29(12), doi:10.1029/2001/GL013204, 2002.

Remer, L. A., Kaufman, Y. J., Tanré, D., Mattoo, S., Chu, D. A., Martins, J. V., Li, R.-R., Ichoku, C., Levy, R. C., Kleidman, R. G., Eck, T. F., Vermote, E., and Holben, B. N.: The MODIS aerosol algorithm, products and validation, J. Atmos. Sci., 62(4), 947-973, 2005. 
Remer, L. A. and Kaufman, Y. J.: Aerosol direct radiative effect at the top of the atmosphere over cloud free ocean derived from five years of MODIS data, Atmos. Chem. Phys., 6, 237-253, 2006.

Rosenfeld, D. and Lensky, I. M.: Satellite-based insights into precipitation formation processes in continental and maritime convective clouds, Bull. Amer. Meteorol. Soc., 79, 2457-2476, 1998.

Ross, J. L., Hobbs, P. V., and Holben, B. N.: Radiative characteristics of regional hazes dominated by smoke from biomass burning in Brazil: Closure tests and direct radiative forcing, J. Geophys. Res., 103(D24), 31 925-31 941, 1998.

Rossow, W. B. and Schiffer R. A.: ISCCP cloud data products, Bull. Amer. Meteorol. Soc., 72, 2-20, 1991.

Rossow, W. B. and Schiffer R. A.: Advances in understanding clouds from ISCCP, Bull. Amer. Meteorol. Soc., 80, 2261-2287, 1999.

Russell, P. B., Kinne, S. A., and Bergstrom, R. W.: Aerosol climate effects: local radiative forcing and column closure experiments, J. Geophys. Res., 102(D8), 9397-9407, 1997.

Russell, P. B., Livingston, J. M., Hignett, P., Kinne, S., Wong, J., Chien, A., Bergstrom, R., Durkee, P., and Hobbs, P. V.: Aerosolinduced radiative flux changes off the United States mid-Atlantic coast: comparison of values calculated from sun photometer and in situ data with those measured by airborne pyranometer, J. Geophys. Res., 104, 2289-2307, 1999.

Satheesh, S. K. and Ramanathan, V.: Large differences in tropical aerosol forcing at the top of atmosphere and Earth's surface, Nature, 405, 60-63, 2000.

Satheesh, S. K.: Radiative forcing by aerosols over Bay of Bengal region, Geophys. Res. Lett., 29, 2083, doi:10.1029/2002GL015334, 2002.

Satheesh, S. K. and Srinivasan, J.: Enhanced aerosol loading over Arabian Sea during pre-monsoon season: Natural or Anthropogenic?, Geophys. Res. Lett., 29(18), 1874, doi:10.1029/2002GL015687, 2002.

Satheesh, S. K., Ramanathan, V., Holben, B. N., Moorthy, K., Loeb, N. G., Maring, H., Prospero, J. M., and Savoie, D.: Chemical, microphysical, and radiative effects of Indian Ocean aerosols, J. Geophys. Res., 107, 4725, doi:10.1029/2002JD002463, 2002.

Satheesh, S. K. and Lubin, D.: Short wave versus long wave radiative forcing by Indian Ocean aerosols: Role of sea-surface winds, Geophys. Res. Lett., 30(13), 1695, doi:10.1029/2003GL017499, 2003.

Sato, M., Hansen, J., Koch, D., Lacis, A., Ruedy, R., Dubovik, O., Holben, B., Chin, M., and Novakov, T.: Global atmospheric black carbon inferred from AERONET, Proc. Nat. Aca. Sci., 100, 6319-6324, 2003.

Schaaf, C. B., Gao, F., Strahler, A. H., et al.: First operational BRDF, albedo and nadir reflectance products from MODIS, Rem. Sens. Environ., 83, 135-148, 2002.

Schiffer, R. A. and Rossow, W. B.: The International Satellite Cloud Climatology Project (ISCCP): The first project of the World Climate Research Programme, Bull. Amer. Meteorol. Soc., 64, 779784, 1983.

Schutz, B. E.: Spaceborne laser altimetry: 2001 and beyond, in: Book of Extended Abstracts, edited by: Plag, H. P., WEGENER98, Norwegian Mapping Authority, Honefoss, Norway, 1998.

Seinfeld, J. H., Carmichael, G. R., Arimoto, R., et al.: ACE-Asia: Regional climatic and atmospheric chemical effects of Asian dust and pollution, Bull. Amer. Meteorol. Soc., 85(3), 367-380, 2004. Seinfeld, J. H., Kahn, R. A., Anderson, T. L., Charlson, R. J., Davies, R., Diner, D. J., Schwartz, S. E., and Wielicki, B.: Scientific objectives, measurement needs, and challenges motivating the PARAGON aerosol initiative, Bull. Amer. Meteorol. Soc., 85(10), 1503-1509, 2004.

Sellers, P. J., Los, S. O., Tucker, C. J., Justice, C. O., Dazlich, D. A., Collatz, C. J., and Randall, D. A.: A revised land surface parameterization (SiB2) for atmospheric GCMs, Part II, The generation of global fields of terrestrial biospheric parameters from satellite data, J. Climate, 9, 706-737, 1996.

Sheridan, P. J. and Ogren, J. A.: Observations of the vertical and regional variability of aerosol optical properties over central and eastern North America, J. Geophys. Res., 104, 16793-16 805, 1999.

Smirnov, A., Holben, B. N., Eck, T. F., Dubovik, O., and Slutsker, I.: Cloud screening and quality control algorithms for the AERONET database, Rem. Sens. Environ., 73, 337-349, 2000.

Smith Jr., W. L., Charlock, T. P., Kahn, R., Martins, J. V., Remer, L. A., Hobbs, P. V., Redemann, J., and Rutledge, C. K.: EOS Terra aerosol and radiative flux validation: An overview of the Chesapeake Lighthouse and aircraft measurements for satellites (CLAMS) experiment, J. Atmos. Sci., 62(4), 903-918, 2005.

Sokolik, I. N., Winker, D., Bergametti, G., et al.: Introduction to special section: outstanding problems in quantifying the radiative impacts of mineral dust, J. Geophys. Res., 106, $18015-$ $18027,2001$.

Spinhirne, J. D., Palm, S. P., Hart, W. D., Hlavka, D. L., and Welton, E. J.: Cloud and Aerosol Measurements from the GLAS Space Borne Lidar: initial results, Geophs. Res. Let., 32, L22S03, doi:10.1029/2005GL023507, 2005.

Stanhill, G. and Cohen, S.: Global dimming: a review of the evidence for a widespread and significant reduction in global radiation with discussion of its probable causes and possible agricultural consequences, Agricultural and Forest Meteorology, 107, 255-278, 2001.

Stephens, G. L., Engelen, R. J., Vaughan, M., and Anderson, T. L.: Toward retrieving properties of the tenuous atmosphere using space-based lidar measurements, J. Geophys. Res., 106, $28143-$ $28157,2001$.

Stephens, G. L., Vane, D. G., Boain, R. J., Mace, G. G., Sassen, K., Wang, Z., Illingworth, A. J., O'Conner, E. J., Rossow, W. G., Durden, S. L., Miller, S. D., Austin, R. T., Benedetti, A., and Mitrescu, C.: The CloudSat mission and the A-Train, Bull. Amer. Meteorol. Soc., 83, 1771-1790, 2002.

Sumanth, E., Mallikarjuna, K., Stephen, J., et al.: Measurements of aerosol optical depths and black carbon over Bay of Bengal during post-monsoon season, Geophys. Res. Lett., 31, L16115, doi:10.1029/2004GL020681, 2004.

Tahnk, W. R. and Coakley, J. A.: Aerosol optical depth and direct radiative forcing for INDOEX derived from AVHRR: Observations, Januray-March 1996-2000, J. Geophys. Res., 107, 8010, doi:10.1029/2000JD000183, 2002.

Takemura, T., Okamoto, H., Maruyama, Y., Numaguti, A., Higurashi, A., and Nakajima, T.: Global three-dimensional simulation of aerosol optical thickness distribution of various origins, J. Geophys. Res., 105, 17 853-17 873, 2000.

Takemura, T., Nakajima, T., Dubovik, O., Holben, B. N., and Kinne, S.: Single-scattering albedo and radiative forcing of var- 
ious aerosol species with a global three-dimensional model, J. Climate, 15, 333-352, 2002.

Takemura, T., Nozawa, T., Emori, S., Nakajima, T. Y., and Nakajima, T.: Simulation of climate response to aerosol direct and indirect effects with aerosol transport-radiation model, J. Geophys. Res., 110, D02202, doi:10.1029/2004JD005029, 2005.

Tanré, D., Kaufman, Y. J., Herman, M., and Mattoo, S.: Remote sensing of aerosol properties over oceans using the MODIS/EOS spectral radiances, J. Geophys. Res., 102, 16971-16988, 1997.

Tanré, D., Haywood, J., Pelon, J., Léon, J. F., Chatenet, B., Formenti, P., Francis, P., Goloub, P., Highwood, E. J., and Myhre, G.: Measurement and modeling of the Saharan dust radiative impact: Overview of the Saharan Dust Experiment (SHADE), J. Geophys. Res., 108(D18), 8574, doi:10.1029/2002JD003273, 2003.

Tegen, I. and Fung, I.: Contribution to the atmospheric mineral aerosol load from land surface modification, J. Geophys. Res., 100(D9), 18 707-17 726, 1995.

Tegen, I., Werner, M., Harrison, S. P., and Kohfeld, K. E.: Relative importance of climate and land use in determining present and future global soil dust emission, Geophy. Res. Lett., 31, L05105, doi:10.1029/2003GL019216, 2004.

Textor, C., Schulz, M., Guibert, S., et al.: Analysis and quantification of the diversities of aerosol life cycles within AEROCOM, Atmos. Chem. Phys. Discuss., 5, 8331-8420, 2005.

Torres, O., Bhartia P. K., Herman J. R., Ahmad Z., and Gleason J.: Derivation of aerosol properties from satellite measurements of backscattered ultraviolet radiation: Theoretical bases. J. Geophys. Res., 103, 17 009-17 110, 1998.

Torres, O., Bhartia, P. K., Herman, J. R., Sinyuk, A., Ginoux, P., and Holben, B. N.: A long-term record of aerosol optical depth from TOMS observations and comparison to AERONET measurements, J. Atmos. Sci., 59(3), 398-413, 2002.

Torres, O., Bhartia, P. K., Sinyuk, A., Welton, E. J., and Holben, B. N.: Total Ozone Mapping Spectrometer measurements of aerosol absorption from space: Comparison to SAFARI 2000 ground-based observations, J. Geophys. Res., D10S18, doi:10.1029/2004JD004611, 2005.

Tsvetsinskaya, E. A., Schaaf, C. B., Gao, F., et al.: Relating MODIS-derived surface albedo to soils and rock types over Northern Africa and the Arabian Peninsula, Geophys. Res. Lett., 29(9), 1353, doi:10.1029/2001GL014096, 2002.

Turner, D. D., Ferrare, R. A., Brasseur, L. A.: Average aerosol extinction and water vapor profiles over the southern Great Plains, Geophys. Res. Lett., 28(23), 4441-4444, doi:10.1029/2001GL013691, 2001.

Turner, D. D., Ferrare, R. A., Brasseur, L. A., Feltz, W. F., and Tooman, T. P.: Automated retrievals of water vapor and aerosol profiles from an operational Raman lidar, J. Atmos. Ocean Tech., 19, 37-50, 2002.

Twomey, S.: The influence of pollution on the shortwave albedo of clouds, J. Atmos. Sci., 34, 1149-1152, 1977.

van de Hulst, H. C.: Light scattering by small particles, John Wiley (1957), reprinted by Dover, New York, 1981.

Vogelmann, A. M., Flatau, P. J., Szczodrak, M., Markowicz, K. M., and Minnett, P. J.: Observations of large aerosol infrared forcing at the surface, Geophys. Res. Lett., 30(12), 1655, doi:10.1029/2002GL016829, 2003.

von Hoyningen-Huene, W., Schmidt, T., Schienbein, S., Kee, C.
A., and Tick, L. J.: Climate-relevant aerosol parameters for South-East-Asia forest fire haze, Atmos. Environ., 33, 31833190, 1999.

Wang, J., Christopher, S. A., Brechtel, F., Kim, J., Schmid, B., Redemann, J., Russell, P. B.: Patricia Quinn and B. N. Holben, Geostationary satellite retrievals of aerosol optical thickness during ACE-Asia, J. Geophys. Res., 108(D23), 8657, 10.1029/2003JD003580, 2003a.

Wang, J, Christopher, S. A., Reid, J. S., Maring, H., Savoie, D., Holben, B. N., Livingston, J. M., Russell, P. B., Yang, S-K.: GOES 8 retrieval of dust aerosol optical thickness over the Atlantic Ocean during PRIDE, J. Geophys. Res., 108(D19), 8595, 10.1029/2002JD002494, 2003b.

Welton, E. J., Voss, K. J., Quinn, P. K., Flatau, P. J., Markowicz, K., Campbell, J. R., Spinhirne, J. D., Gordon, H. R., and Johnson, J. E.: Measurements of aerosol vertical profiles and optical properties during INDOEX 1999 using micro-pulse lidars, J. Geophys. Res., 107, 8019, doi:10.1029/2000JD000038, 2002.

Welton, E. J., Campbell, J. R., Spinhirne, J. D., and Scott, V. S.: Global monitoring of clouds and aerosols using a network of micro-pulse lidar systems, in: Lidar Remote Sensing for Industry and Environmental Monitoring, edited by: Singh, U. N., Itabe, T., Sugimoto, N., Proc. SPIE, 4153, 151-158, 2001.

Wendisch, M., Heintzenberg, J., and Bussemer, M.: Measurementbased aerosol forcing calculations: the influence of model complexity, Meteorologische Zeitschrift, 10(1), 45-60, 2001.

Wielicki, B. A., Barkstrom, B. R., Harrison, E. F., Lee, R. B. I., Smith, G. L., and Cooper, J. E.: Clouds and the Earth's radiant energy system (CERES): An Earth observing system experiment, Bull. Amer. Meteorol. Soc., 77, 853-868, 1996.

Wild, M., Gilgen, H., Roesch, A., et al., From dimming to brightening: Decadal changes in solar radiation at Earth's surface, Science, 308, 847-850, 2005.

Winker, D. M., Pelon, J. R., and McCormick, M. P.: The CALIPSO mission: spaceborne lidar for observation of aerosols and clouds, Proc. SPIE, 4893, 1-11, 2003.

Xu, J., Bergin, M. H., Greenwald, R., and Russell, P. B.: Direct aerosol radiative forcing in the Yangtze delta region of China: Observation and model estimation, J. Geophys. Res., 108(D2), 4060, doi:10.1029/2002JD002550, 2003.

Yu, H., Liu, S. C., and Dickinson, R. E.: Radiative effects of aerosols on the evolution of the atmospheric boundary layer, J. Geophys. Res., 107(D12), 4142, doi:10.1029/2001JD000754, 2002.

Yu, H., Dickinson, R. E., Chin, M., Kaufman, Y. J., Holben, B. N., Geogdzhayev, I. V., and Mishchenko, M. I.: Annual cycle of global distributions of aerosol optical depth from integration of MODIS retrievals and GOCART model simulations, J. Geophys. Res., 108, (D3), 4128, doi:10.1029/2002JD002717.

Yu, H., Dickinson, R. E., Chin, M., Kaufman, Y. J., Zhou, M., Zhou, L., Tian, Y., Dubovik, O., and Holben, B. N.: The direct radiative effect of aerosols as determined from a combination of MODIS retrievals and GOCART simulations, J. Geophys. Res., 109, D03206, doi:10.1029/2003JD003914, 2004.

Zhang, J. and Christopher, S. A.: Longwave radiative forcing of Saharan dust aerosols estimated from MODIS, MISR, and CERES observations on Terra, Geophys. Res., Lett., 30(23), 2188, doi:10.1029/2003GL018479, 2003.

Zhang, J., Christopher, S. A., Remer, L. A., and Kaufman, Y. J.: 
Shortwave aerosol radiative forcing over cloud-free oceans from Terra. I: Angular models for aerosols, J. Geophys. Res., 110, D10S23, doi:10.1029/2004JD005008, 2005a.

Zhang, J., Christopher, S. A., Remer, L. A., and Kaufman, Y. J.: Shortwave aerosol radiative forcing over cloud-free oceans from Terra. II: Seasonal and global distributions, J. Geophys. Res., 110, D10S24, doi:10.1029/2004JD005009, 2005b.

Zhao, T., Laszlo, I., Dubovik, O., Holben, B., Sapper, J., Tanré, D., and Pietras, C.: A study of the effect of non-spherical dust particles on the AVHRR aerosol optical thickness retrievals. Geophys. Res. Lett., 30, 1317, doi:10.1029/2002GL016379, 2003.
Zhou, M., Yu, H., Dickinson, R. E., Dubovik, O., and Holben, B. N.: A normalized description of the direct effect of key aerosol types on solar radiation as estimated from AERONET aerosols and MODIS albedos, J. Geophys. Res., 110, D19202, doi:10.1029/2005JD005909, 2005.

Zwally, H. J., Schutz, B., Abdalati, W., Abshire, J., Bentley, C., Brenner, A., Bufton, J., Dezio, J., Hancock, D., Harding, D., Herring, T., Minster, B., Quinn, K., Palm, S., Spinhirne, J., and Thomas, R.: ICESat's laser measurements of polar ice, atmosphere, ocean, and land, J. Geodyn., 34, 405-445, 2002. 